$S B$

608

F8G75

Sectional Volume No. 2.

Entomol.nistry of Agriculture and Fisheries.

UC-NRLF

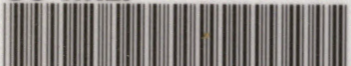

.

B 3844513

\title{
COLLECTED LEAFLETS
}

\author{
ON \\ INSECT PESTS
}

OF

FRUIT TREES.

LONDON:

PRINTED FOR HIS MAJESTY'S STATIONERY OFFICE.

To be abtained at the Office of the

MINISTRY OF AGRIOULTURE AND FISHERIES,

10, Whitehall Place, London, S.W.1.

Agents for Aduertisements : C. VERNON \& SONS, Ltd., 38, Holborn Viaduct, London, E. C.1.

1921.

Price 10d. net, Post Free. 


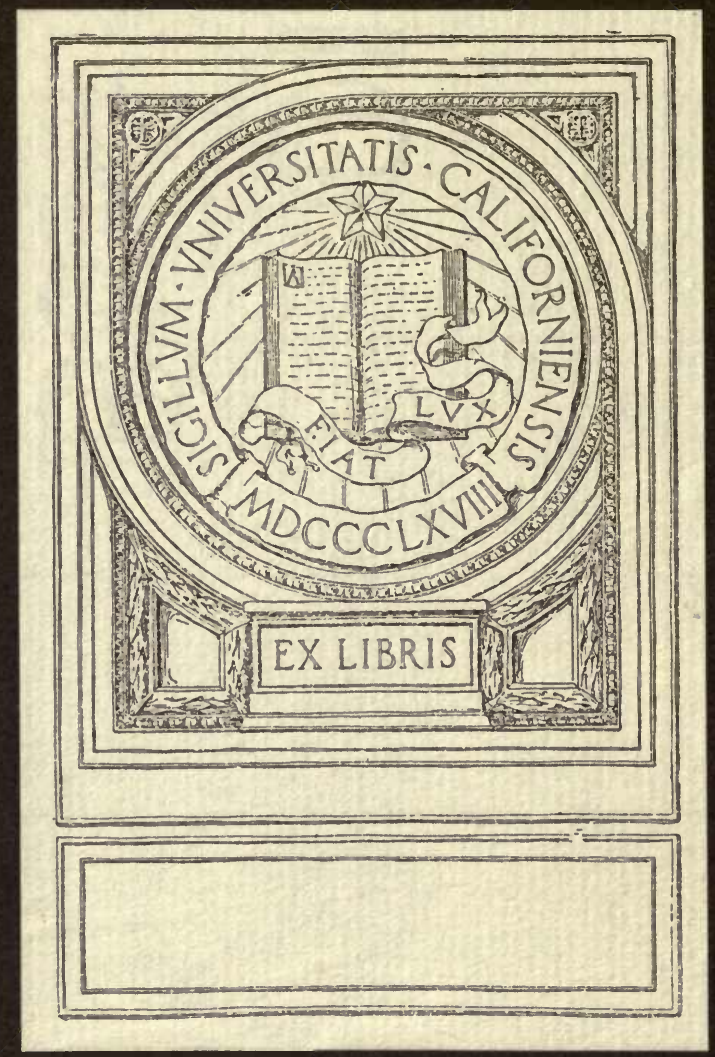


Sectionar Volixine 2

\title{
Ministry of Agriculture and Fisheries.
}

\section{COLLECTED LEAFLETS}

\author{
ON \\ INSECT PESTS \\ OF \\ FRUIT' TREES.
}

LONDON :

PRINTED FOR HIS MAJESTY'S STATIONERY OFFICE.

To be obtained at the Office of the MINISTRY OF AGRICULTURE AND FISHERIE-

10, Whitehall Place, London, S.W.1.

Agents for Advertisements : C. VERNON \& SONS, Ltd., 33, Holborn Viaduct, London. E.C.1.

1921.

Price 10d. net, Post Free. 
敬

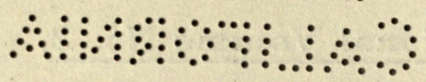

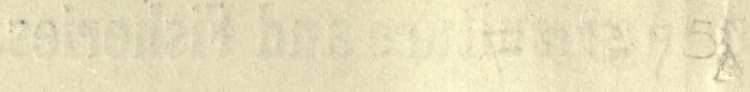

$1 / 9 / 23$ 


\section{LIST OF CONTENTS.}

\section{Introduction}

LEAFLET No.

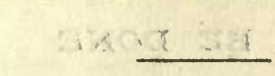

PAGE.

15. The Applo Blossom Weevil (Anthonomus

E

Librar

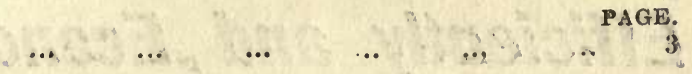

\section{Title.}

16. The Apple Sucker (Psylla mali, Schmidb. $^{2} \quad \cdots \quad 14$

319. Apple Capsids (Plesiocoris rugicollis, Fall.) ‥ 20

330. Apple Aphides (Aphis malifolice, Fitch., \&e.) 23

34. The Woolly Aphis (Schizoneura lanigera, Hausmann) ... ... ... .. $\quad \ldots . \quad \ldots \quad 27$

107. The Mussel Scale (Mytilaspis pomorum, $\begin{array}{lllllll}\text { Bouché) } & \ldots & \ldots & \ldots & \ldots & \ldots & 31\end{array}$

69. The Lackey Moth (Clisiocampa neustria, Linn.) $\mathbf{3 4}$

4. Winter Moths (Cheimatobia brumata, L., \&c.) 37

30. The Codling Moth (Cydia pomonella, L.) ... 43

65. The Small Ermine Moths (Genus Hyponomeuta) 47

205. The Apple Sawfly (Hoplocampa testudinea: $\begin{array}{llllllll}\text { Klug.) } & \ldots & \ldots & \ldots & \ldots & \ldots & \ldots & 50\end{array}$

49. Bark Beetles (Scolytus rugulosus, Ratz.) and Shot Borers (Xyleborus dispar, Fab., and X. saxeseni, Ratz.) ‥ $\quad$.. $\quad \ldots \quad$... 52

308. Plum Aphides (A phis pruni, Réaumur, \&c.) $\ldots .58$

210. The Oyster-shell Scale (Aspidiotus ostreceformis, $\begin{array}{llllllll}\text { Curtis) } & \ldots & \ldots & \ldots & \ldots & \ldots & \ldots\end{array}$

239. The Pear Leaf Blister Mite (Eriophyes pyri,

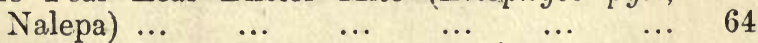

53. The Pear Midge (Diplosis (Contarinia) pyrivora. Riley) $\ldots \begin{array}{lllllll}\ldots & \ldots & \ldots & \ldots & \ldots & \ldots & 66\end{array}$

62. The Pear and Cherry Sawfly (Eriocampa lima-

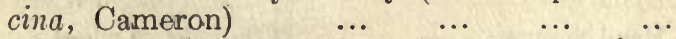

1. The Black Currant Mite (Eriophyes ribis,

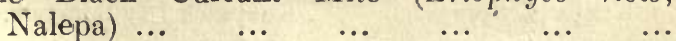

41. Red Spiders (Bryobia and Tetranychus) $\quad \ldots \quad 74$

68. Currant and Gooseberry Aphides (Genus Ribes) 77

223. The Brown Scale (Lecanium persicae, Geoffroy) 79

20. The Magpie Moth (Abraxas grossulariata, Linn.) 82

12. The Gooseberry Sawfly (Nematus ribesii, Curtis) 85

14. The Raspberry Moth (Lampronia rubieila

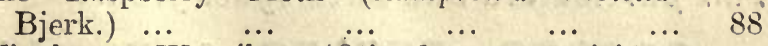

2. Wingless Weevils (Otiorrhyncus picipes, Fab., \&c.) $\quad$... $\quad \ldots \quad$... $\quad \ldots \quad \ldots$

161. The Vapourer Moth (Orgyia antiqua, Linn.) ...

60. The Goat Moth (Cossus ligniperda, Fab.) and the Wood Leopard Moth (Zeuzera asculi, Zini..) 
$\therefore \quad \because \vdots$

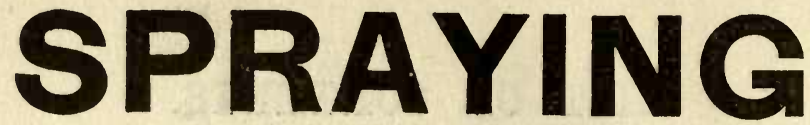

CAN BE DONE

Efficiently and Economically

BY

\section{VERMOREL "ECLAIR" IMACHINES.}

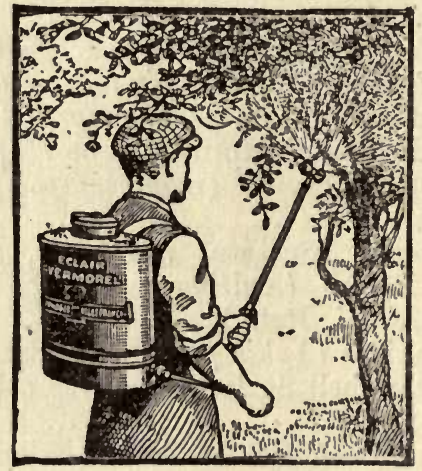

\section{AII Types of SPRAYERS are MADE and STOCKED}

Garden Syringes.

$3 \frac{1}{2}$ pint Hand Sprayer,

$3 \frac{1}{4}$ Gallon Knapsack Sprayer,

$3 \frac{1}{2}$ Gallon Bucket Sprayer,

Extension Lances for tall trees,

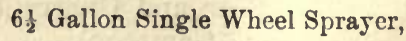

22 Gallon two wheel Sprayer,

Knapsack Dry Sprayers,

66 Gallon Horse drawn Potato and Charlock Sprayer.

"Ready for use" Spraying Mixture.

Full particulars and Catalogues from:-

\section{COOPER, PEGLER \& Co., Ltd.,} 24b, Christopher Street,

London, E.C.2. 


\section{INTRODUCTION.}

Contents of the Book.-The number of insect pests attacking fruit trees is large-so large that only a comparatively small proportion of them can be dealt with individually in this collection of leaflets. On the other hand the control measures which it is possible to take are few, and as the majority are illustrated by one or other leaflet, hints may be obtained not only as to how to deal with the particular pests described in this volume but with many others which do similar damage.

Contents of the Leaflets.-Most leaflets are divided into certain sub-sections:- " Plants Attacked and Nature of Damage," "Description and Life-History," and "Measures of Control." It is sometimes complained that these subsections contain too much " technical matter" and that all that is required is " how to recognise the pest" " and " how to control it." Now recognition and control are exactly the objects at which each leaflet aims, but the necessary information cannot be given without the introduction of some so-called "technical matter," particularly in relation to the habits and life of the pest. The following consideration will make this clear. Insects, though very small, are creatures with their own habits and ways, living in a perfectly wild state just like birds, fish, or any wild animal. In order to fish successfully, whether for minnows or sharks, the first essential is to understand the habits of the fish. This applies also to shooting, no matter whether the game is a tiger or a rabbit. A man, for instance, who realised that his crops were being eaten by rabbits but knew nothing whatever about them-even whether they ran or burrowed underground-would not make much of a bag, or protect his crops successfully!

The same considerations apply to insect pests-to hunt or control them successfully it is essential to know as much as possible of their habits, and in dealing with insects it is as unreasonable to object to the use of certain special-socalled "technical "-terms as it would be to object to the use of such terms as warren in the case of rabbits, leveret in the case of a young hare, or brush in the case of a fox's tail!

A useful leaflet, therefore, must contain some technical matter, but it is hoped that in spite of this the whole will be read. for only material is put in which may have a definite bearing on the control of pests, while the technical terms are reduced to a very few which may easily be learnt.

(39204) P.1149/R.206. 3,000 11/21. M. \& S. Gp. 95. 
$\therefore \because \cdots \because \cdots \vdots \vdots \cdots$

The sections in a leaflet follow on naturally. The first thing which attracts attention to a pest is the damage. Under "Plants Attacked and Nature of Damage" is given a list of the crops likely to be attacked and the characteristic signs of injury. Under the next section, "Description and Life-History," are described, the appearance of the pest in its various forms, and its life-history or habits, showing where it lives at each season of the year and which are its vulnerable stages. With this information it is then possible to follow the suggestions given under " Measures of Control," carrving out each operation with discretion and not by rule of thumb-a most important point, for success is often dependent on adapting a measure to meet special local conditions.

Notes on Insects in General. - As it is impossible to deal separately with many insects in the leaflets themselves, a few general notes may be found useful.

Description. - Insects belong to a group of creatures characterised (1) by the possession of a jointed body which is supported not by bones inside but by a hard horny skin, and (2) by the possession on one or more segments of the body of jointed "appendages" which may be modified to act as legs, jaws, antennae (feelers), \&c. Strictly speaking, the term Insects should be confined to the creatures in the group with only three pairs of legs (in addition to other characteristics), such, for instance, as moths, beetles or bugs, but for practical purposes the name usually includes the groups containing mites (red spiders) and spiders with four pairs of legs, and the millipedes and centipedes with many pairs of legs. From the practical point of view no detailed knowledge of the various organs of the body is necessary but it is helpful to know a little of the features which characterise an insect as a living creature.

The body consists of three parts-the head, the thorax and the abdomen.

(a) The head bears the antennae (or " feelers "). which are not only organs of touch but are probably connected with other senses, possibly in some forms with smell. (Little; however, is known about the senses of insects except that by some means they smell and probably hear also.) There are also on the head the eyes which when well developed enable them to see the shape of things, or in other cases may be only sufficient to detect light or darkness. The mouth, on the underside of the head, is surrounded by " appendages " which vary in the different groups, in some taking the form of biting jaws and fingerlike organs to push food between them, while in others the same organs may be modified so as to form a "trunk" enabling the insect to bore holes and suck up juices. From 
the practical aspect it is very important to recognise the difference in feeding habits which must correspond with the difference in the mouth parts, since species with jaws can eat solid matter, while those with trunks merely suck up juices through a minute hole.

(b) The second section of the body, the thorax, is essentially the part connected with movement. It usually carries three pairs of legs and it may also be provided with one or two pairs. of wings.

(c) The third section of the body, the abdomen (often called the " tail "), corresponds more or less with the lower part of the body in man, and contains the organs of reproduction and the gut, in passing through which food is digested. Extending down the whole length of the insect, just under the upper surface, is a long tube which pumps the blood, beating like the heart, to which it may be compared.

It will be noticed that no reference has yet been made as to how insects breathe. This is because they have entirely different " machinery" from that in man. In the latter case the air is taken into the lungs and the oxygen is absorbed by the blood and carried to wherever it is needed. In insects the same result is obtained but by a " short cut " since they have a series of holes (spiracles) along the sides of the body (usually thorax and abdomen) which lead into tubes passing to every part, so enabling air to flow freely in and out. Every organ has therefore a direct air supply and there is no need for lungs. In controlling insect pests the special method of breathing is an important point to remember.

Finally, as regards the structure, the statement may be recalled that insects have no bones, but depend for their support on their " skin," which in consequence may bo regarded as their skeleton, being either hard or tough and in many cases forming almost an armour plate. This armoured character of the skin makes many insects difficult to kill.

Life History. - In addition to a knowledge of the structure of insects, it is helpful, or even necessary, to have some idea of their life history - their methods of breeding and development. The usual method of starting life is from an egg laid by the mother, but the young which are hatched from these eggs often at first have little likeness to their parents. In course of time they grow to resemble the latter, but in so doing pass through stages so unlike in shape or form that it seems hardly credible they can be the same creature. This great change of form is perhaps explained by the fact that insects at the different stages of their lives concentrate strictly on " the business in hand," definite periods of their existence being devoted very largely to one object. This is clearly shown in the case of the White Butterfly, the egg of which gives rise to a caterpillar 
with one main object and that is to eat. The caterpillar having eaten all it requires at that period of its life, turns to a chrysalis, a stage in which the insect neither feeds nor travels but undergoes great changes internally. From the chrysalis comes the butterfly which, though it may sip a little nectar, concentrates on breeding and spreading the species. In each stage the form of the insect is such as to adapt it to one object at a time-the caterpillar with its jaws and absence of wings is fitted to do little else but feed, the chrysalis must remain outwardly immovable, and the butterfly with wings, with a trunk which does not allow of its taking solid food, and with breeding organs well developed, is clearly adapted to propagating the species.

The bearing of all this on insect control is that it is very necessary to be on the lookout for the different stages, which though not in all cases as strongly marked as in the butterfly, nevertheless always occur to a greater or less extent. Obviously the stage when damage is likely to be done is that adapted to feeding, but it serves equally well if the pests are destroyed in one of the other stages. The great thing therefore is to look for the condition in which the insect is most vulnerable and to tackle it then, even though at the time it may be doing no actual damage. Finally, in connection with breeding, it may be pointed out that some groups of insects such as Aphides (Green Fly) have found it possible to do without males for many generations, the females producing young without pairing, while in a few cases (certain sawflies) males appear to have been nearly lost altogether. This power of dispensing with males naturally causes such insects to prove dangerous enemies, for instead of about half the total population being able to produce young, all can. Indeed throughout the insect world it is possible to see how every development has been regulated by the supreme necessity for rapid reproduction, and it is this perpetual increase which so threatens the fruitgrower.

Nature's Control of Pests.-The conditions under which fruit trees are grown render them peculiarly liable to the attacks of insect pests, for in the first place the fruit tree is an artificial product which through cultivation has lost many of the good constitutional features of wild trees, and secondly the planting of large districts with the same kinds of fruit enables a pest to penetrate throughout the area without ever being at a loss for food. The reasons why, under conditions so favourable to pests, fruit trees are not completely overwhelmed is that the insects are to a considerable extent kept in check by natural agencies. Thus, while for a year or several years the destruction wrought by a pest may rise in a wave which seems to threaten the very existence of a certain 
crop, natural agencies sooner or later step in and again reduce the numbers of the pest-and in consequence the damage done by it - to more reasonable proportions. Thus over a term of years a balance is more or less preserved. In times gone by this natural control was perhaps sufficient to meet commercial needs, but now with keen competition and the call for high quality and high yield, the average damage due to pests is more than the industry can bear. It is therefore necessary to add artificial measures to the natural agencies already at work. Any consideration of such measures would, however, be incomplete without some further reference to the chief agencies of natural control-i.e., weather conditions, the attacks of other insects, and of birds.

Of these agencies, the weather admits of no interference on behalf of fruit-growing, but there is some hope that in years to come a greater knowledge of the effects of weather on insects may make it possible to predict the appearance or absence of serious epidemic pests, and so enable measures against them to be taken in time. Work to this end is going forward.

As regards birds, the pros and cons of protection, legal and voluntary, are gradually being placed upon more sure and sensible foundations, and there is no doubt that insectivorous species are among the very best friends of the fruit-grower and therefore to be encouraged whenever possible. At the same time the conditions of modern fruit-growing and agricul: ture, with the necessity for destroying weeds and clearing up overgrown hedgerows, limit to some extent the chief means of encouraging the more useful birds (by the provision of suitable breeding places). It seems clear therefore that useful as birds are as allies, it will never be possible to rely upon them alone for winning the fight against insect pests.

The remaining great natural factor in regulating the number of pests is found in beneficial insects-that is to say, those insects which prey upon others. Such insects are always of great value and are sometimes of overwhelming importance in saving fruit trees from their enemies, and of all natural means of control they perhaps offer the most scope for human interference. It is, however, not yet possible to increase beneficial insects sufficiently to render the use of purely artificial methods of control unnecessary, and in the case of practically every pest some such measure as spraying is required. In this connection it cannot be too strongly emphasised that artificial control not seldom results in the destruction of both friend and foe together, and that, therefore, having once taken over a responsibility from Nature, the work must in future be thorough or epidemics may be even more frequent than they were in former times, when matters were left to take an entirely natural course. 
Methods of Controlling. Insect Pests.-Measures for keeping insect pests in check may be divided roughly into Indirect, which tend to make conditions unfavourable to pests in general, and Direct, which are designed to destroy a certain definite pest.

Indirect Measures.-From what has been said above it is clear that insects in their various stages are adapted to certain special conditions - the caterpillar to living and feeding on a leaf, the butterfly to breeding, and so on. 'The object of all indirect measures is to make the conditions unsuitable to pests in one or more of their stages and so cut the cycle. An instance or two will show what is meant. Certain beetles (Scolytus rugulosus, $S$. pruni, \&c.) which burrow into the twigs and branches of plum and other fruit trees, find a difficulty in beginning an attack on a tree of which all the branches are in vigorous health, probably because the sap flow blocks up the tunnels and hinders the beetles from working. A branch dying, however, or recently dead, suits them exactly and enables them to begin their attack. If an orchard is well pruned so that all dead and weakly branches are removed, and if the soil is kept reasonably fertile, the trees will never be in the condition to suit boring beetles and a serious infestation is rendered most unlikely.

Again, certain pests spend the winter in one of the active stages and so are compelled to find protection of some sortas, for instance, in heaps of rubbish, in moss and lichen on tree trunks, or in rough growth in ditches. If trees are kept clear of moss and lichiens, heaps of rubbish are burnt, and hedgerows and ditches are cleaned out, the winter shelter is at once much reduced with the result that, however favourable to pests the orchard may be at other seasons, they will always be kept in check by the lack of suitable winter quarters.

These instances show the possibility of influencing the numbers of insect pests by making conditions unfavourable during a period of their life-history.

Finally, reference may be made to the temptation to defer too long the removal of worn-out pest attacked trees or bushes. It is true that they can often be cleaned up to some extent and their productive life in this way prolonged, but from the commercial point of view it is better policy to grub or burn them-substituting young stock in their place. In this way possible centres of infestation are got rid of and the productive capacity of the whole plantation will be kept at a high level.

Direct Measures.-Chief among direct measures for the control of fruit pests is spraying - which is very efficient when done thoroughly and with understanding. Haphazard work carried out with no clear idea as to what is required is usually waste of money. Sprays may be divided into $(a)$ Cleansing 
Washes, (b) Cover Washes, (c) Internal Poison Insecticides, (d) Contact Insecticides.

(a) Cleansing Washes, such as a solution of caustic soda, might equally have been dealt with under Indirect Measures as they are used primarily with the idea of killing moss, lichen, \&c., which serve as winter quarters for pests. They are only applied in winter as they would burn foliage, and except in badly neglected orchards can generally be replaced by cover washes which also help to destroy moss, lichen, \&c.

(b) Cover Washes, of which plain lime-wash is a typical example, are applied in spring early or late according to the season and kind of fruit tree. They act by covering or sealing up the eggs of pests just at the time they should be hatching, and also by smothering any young insects which may already have hatched. This being the case it is obvious that the more complete the coat of wash applied, the more pests will be killed, and since insect eggs oceur more abundantly on the twigs than on the larger branches, the sprayers should specially endeavour to cover the twigs properly. Further, in the case of lime, as the wash should dry on and resist rain for some weeks, as thick a fluid as can be forced through the spraying machine should be used.

(c) Internal Poison Insecticides are insecticides which when eaten cause death but otherwise may be quite harmless, having no effect on the skin or external parts of an insect. In using internal poisons therefore the object is to spray not the pest but the leaves of the tree, which under favourable conditions remain poisonous to pests for a considerable period.

As it is necessary to cover every leaf and bud with a uniform coating of poison, a nozzle giving the finest spray should be used, and further, the nozzle must be moved from one direction to another fairly rapidly for if leaves receive too much spray, the minute drops run together and collect at the tip of the leaf, with the result that there is too much poison at the tip and too little elsewhere. A further point is that the liquid should stick to the leaves and not merely collect in globules. Just as plain water will not thoroughly wet a greasy plate, some leaves are so formed that they are not easily wetted. In such cases it is necessary to add to the insecticide some substance such as saponin which enables the liquid to wet the leaf-just as the addition of soap to water allows it to wet the greasy plate.

Finally, in connection with internal poisons, attention should be drawn to the necessity for spraying soon enough. It should be noted (1) that young insects are more easily poisoned than old, and (2) that insects such as caterpillars cause damage very rapidly -an orchard green and seemingly not much injured may be completely stripped of leaves a 
week or ten days later. The great thing is to know the habits of the pest and to apply the spray just at the right time so as to catch the young insects as soon as possible after they have hatched.

(d) Contact Insecticides destroy insects by actual contact with them. It has been shown that while some insects have jaws and eat solid matter, others have "trunks" with which they suck the sap or juice of plants through a minute hole. 'I'hese sucking insects cannot be forced to eat a poison spread on the surface of the leaves, since they bore through the poisoned layer and only feed when they have reached the inside of the leaf. In spraying against such pests, a poison which kills by contact-on touching the insect-must be used. Insects having hard or tough skins are fairly well protected against poisons applied to them, but their defences have a weak spot-the breathing hole or spiracle through which poisons can reach the interior. As the spiracles are very small and few in number it is evident that to poison an insect through them the body must be thoroughly wetted, while further, the fluid must be of such a nature that it will run well into minute holes. These two needs give the clue to all contact insecticide spraying. The necessity for the fluid to touch the insect involves a spray applied with force through a coarse nozzle-passed uf and down each bough in order to reach both sides of every leaf and every hole and corner between buds and in flower trusses, where the pests may be hiding.

The need for a fluid which runs well involves the use of some substanse such as soap which enables the liquid to penetrate the breathing holes (spiracles) of the insect, carrying with it the poison (e.g., nicotine) which may be used. If these two needs are met, good results may confidently be expected. This also applies to certain contact insecticides which do not act by poisoning the insect but by smothering it with some sticky substance. Thus red - spiders (mites) can be killed by a thin paste made of flour and water which is not poisonous but sticks the pests to the leaves.

Finally, as in the case of internal poisons, it is most important to time the application of contact insecticides properly, especially not to spray too late. Many insects such as Aphides (Green Fly) cause the leaves they feed upon to curl round and inside these curled leaves the pests are naturally protected against any contact insecticide. To avoid the difficulty it is necessary to spray soon after the pests have appeared and before they have had time to induce the leaves to curl. In judging the period during which useful spraying is possible, some knowledge of the lifehistory of the pest is clearly invaluable, and such knowledge is equally necessary to ensure that those spraying are placing 
the insecticide where it will do good. "Rule of thumb" spraying is likely to be wasteful and inefficient.

In concluding these notes on spraying, reference should be made to dusting, in which the insecticide is applied as a dust instead of as a fluid, and also to the application of insecticides by hand. As regards dusting, this treatment has made some progress in the United States of America, but it has not clearly shown its superiority over liquid spraying. In certain cases (e.g., Black Currant Mite and Pear Slug Worm) good results have been claimed in Britain, and where a grower has a dusting machine for use in connection with fungus pests, the possibility of attacking insects with the same methods should be kept in mind.

Hand application of insecticides (except in greenhouses and very small gardens) is practically limited to the destruction of Woolly Aphis on apples (Leaflet No. 34), where the insecticide is painted on to the colonies of the pest, but it may also be useful where " bendable" twigs attacked at the growing point can be bent over and dipped in a vessel of insecticide. Gooseberries attacked by Aphides are sometimes treated in this way.

Other Direct Measures.-In addition to spraying there are certain other direct measures for pest control. (a) In small gardens, and sometimes even in commercial orchards, " hand picking " may be of great use if the owner is sharp enough to detect the pest when it is just beginning to obtain a foothold. Hand-picking may consist in the removal by hand of the insects or their egg -as for instance the nests of the Lackey Moth caterpillars - or more usually it takes the form of collecting attacked leaves and fruit in or on which the pest is still living. Instances of these are Apple Sawfly in the fruits, Pear Leaf Blister Mite in the leaves, or Apple Blossom Weevil in the closed " capped " blossom. In the case of single trees attacked by a pest not controllable by spraying handpicking is always worth a trial as it may save the whole orchard.

(b) Next to hand-picking may be mentioned the running of poultry in orchards (chiefly of course those containing standard or half-standard trees). Fowls are extraordinarily efficient insect hunters, and if not too few in number can be relied upon to destroy any pest which passes a part of its life in the soil.

(c) Where a pest has to crawl up or down a tree trunk, banding may be employed. This consists in placing round the trunk a band of sticky material to catch any insects which try to pass over it (Leaflet No. 4, Winter Moths), while another form of banding consists in placing round the trunks bands of hay or sacking, \&c., in which the pests find suitable quarters to spend the winter or the chrysalis stage (Leaflet No. 30, Codling Moth). 
(d) Where pests are attacking roots, the use of soil fumigants or insecticides-e.g., the injection of carbon bi-sulphide -is sometimes advised, but the results obtainable are uncertain, sometimes hopeful but more often unsatisfactory and it is advised that at present all soil insecticides should be treated as experimentai only.

Against insects other than those in the soil, fumigation his a few special applications-e.g., in cleaning stock from pests prior to planting. This, however, requires certain facilities and is better left to the nurseryman. The grower can, however, use fumigants in the case of certain large insects (Leopard Moth) which burrow into fruit trees, and it is then no difficult matter to insert the necessary chemical in the burrow and block up the hole. Further particulars are given in Leaflet No. 60.

Conclusion.-The preceding notes relate solely to insect pests but readers should be warned that the different aspects of fruit-growing cannot be shut off into water-tight compartments. To show the bearing of this, brief reference may be made to three points.

(1) Just as separate varieties of a crop differ in regard to flavour of fruit, character of growth, \&c., so they also differ in their susceptibility to damage by pests. This point has not perhaps been sufficiently realised in the past, but plant breeders are now fully alive to the importance of immunity, and have already achieved some notable successes. Unfortunately new varieties of fruit take so long to raise and have to combine such a number of qualities, that progress in producing resistant varieties must necessarily be slow. Nevertheless this aspect of pest control should always be remembered and even if new resistant varieties are not forthcoming, much may yet be done by observing the difference in suscertibility already shown by well-known commercial fruits so that kinds may be selected which show themselves more resistant to the pests prevalent in the district.

(2) Insects are not the only organisms which attack fruit trees. Fungus pests are often quite as important, and it is thus necessary to control both simultaneously. Fortunately, it is often possible to mix insecticides and fungicides and apply them together, though unless such mixing has been definitely advised it is better to get expert advice before trying experiments, since some mixtures would prove most injurious. Indirect measures for pest control, notably pruning out weak and dead wood, are usually equally valuable in the case of insects and fungi.

(3) Good cultivation generally has a considerable bearing on pest control. Just as a man when in good health is less likely to contract an illness, so a flourishing plant is much better able to resist the attacks of its enemies, and an addi- 
tional freedom from losses so caused may well be credited to the expense of proper cultivation under modern conditions. Even in the best cultivated orehard, however, the " doctor" is sometimes required and it may again be emphasised that if he cannot visit the orchiard, a good large piece of his patient (the affected tree) should be sent him, as his trouble is enormously increased if he has to base his opinion on the examination of a few scraps.

J. C. F. Fryer.

London, S.W.1.

October, 1921. 


\section{THE APPLE BLOSSOM WEEVIL.}

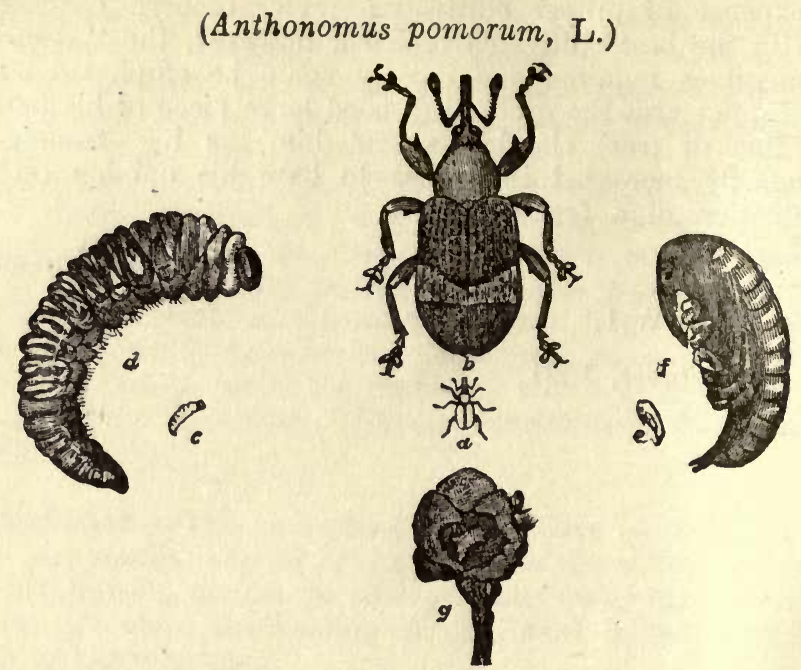

$a$, Weevil, nat. size; $b$, magnificd. $c$, Larva, nat. size; $d$, magnified. $e$, Pupa, nat. size; $f$, magnified. $g$, Larva in blossom bud.

The Apple Blossom Weevil occurs in most counties in England and Wales, and is recorded from Scotland and Ireland. It is specially prevalent from the midlands southward, being a serious pest in the Evesham district, in Cambridgeshire, Kent, and in the southern and south-western counties. Abroad the insect is well known in most European countries, in some of which-as, for instance, France-it has proved even more destructive than in the British Isles, and indeed has caused such damage that growers have been forced to take co-operative action for its destruction.

The Apple Blossom Weevil is notoriously difficult to control owing to the fact that it is little amenable to treatment by spraying, but there are certain general measures which serve to check its numbers to some extent.

Nature of Injury.- If an apple orchard be examined at the close of the blooming period it will often be noticed that certain of the blossoms have failed to expand, the petals having died and become brown in colour without falling off. Such blossoms are usually known as " capped blossom," and a further examination will show that underneath the brown petals is a small yellowish grub (or later a pupa), which has eaten away the base of the flower and so prevented all further growth. Blossoms so attacked ultimately die and fall off. In bad cases a high proportion of the flowers in an orchard may 
be damaged in this manner, with the result that the crop is almost entirely lost. Pear blossoms are also ocsasionally attacked by the weevil, but the losses are seldom serious.

Description and Life-History. - The adult beetle is a small insect about $\frac{1}{4}$ in. in length with a long rostrum or " trunk." In colour it is black or brownish, dotted with fine grey hair, and across the wing-cases (elytra), which appear to form the "back" of the insect, is a light-coloured, greyish or yellowish mark. This mark is more or less in the form of a V, and is very characteristic of the insect (Fig. b). The adult weevils appear in spring and crawl or fly to the apple trees, on which they may often be found in numbers during the period preceding the opening of the blossom. Eggs are laid as follows:-The female weevil bores a hole into the unopened bud, lays an egg in the hole and then pushes it down with her trunk, afterwards sealing up the hole with saliva. Only one egg is laid in each blossom, and a single female can probably lay 50 eggs or more. If the weather happens to be such that the apple blossom expands very rapidly, the Howers may open before or about the time when the egg hatches, in which case the insect dies. As a rule, however, the grub appears first and prevents the petals from expanding. The larva grows rapidly, and in a fortnight is full grown. It is then a pale yellowish grub with a brown head (Fig. $d$ ) and lies in the cavity of the capped blossom in the curved position usual to weevil larvæ. The bloom by then is practically dead and the larva turns to a pupa (Fig. f). About a week or ten days afterwards the pupa casts its skin and becomes an adult weevil, the insect remaining a short time within the blossom and then eating its way out through a hole in the side. These weevils may be found upon the apple trees for 3 or 4 weeks after their emergence, but they gradually disappear and long before the autumn they have all found their way to winter quarters-as, for instance, under rough bark on the trees, beneath stones or rubbish on the ground, or in dead leaves, hedge cuttings, \&c. They remain there during the winter, and in the following spring come out again and return to the apple trees, when a fresh generation is produced.

Natural Enemies.-The Apple Blossom Weevil is eaten by birds such as tits, and is also destroyed by insect parasites. The larva of the ichneumon Pimpla pomorum feeds on the larva and pupa of the weevil in the capped blossom, and in this way very many are destroyed. Dr. Imms, of the Rothamsted Experimental Station, has shown that in an orchard in Cambridgeshire over 25 per cent. of the weevils were killed by this ichneumon. 
Methods of Control.-From the above account of the lifehistory it will be clear that the Apple Blossom Weevil is at no time really susceptible to those measures usually employed against orchard pests. The insect when young is protected within the "capped blossom "; when adult it appears to feed little-or at all events, not in such a manner as to make a lead arsenate spray of much use. It spends the winter in various places, always well concealed, and winter treatment cannot be wholly effective.

(1) Nevertheless, in most orchards something, and in many, much, can be done in winter. In the first place, if the trees are mossy and the trunks encrusted with loose bark many weevils will hibernate on the trees and a winter wash, or later a lime wash, will destroy many of them; recent reports tend to show that late lime-washing is fairly successful against the weevil. The burning of all rubbish and the cleaning of hedge bottoms and ditches will also be helpful, as will the cultivation of the ground underneath the trees.

(2) In France it has been found practicable to reduce the numbers of the beetles by shaking them off the trees just before they lay their eggs. A large sheet is spread under the tree which is shaken or tapped with a stick, and the beetles which fall down are tipped into a pail containing a little paraffin.

(3) In small orchards or where the trees are young it is worth collecting the capped blossom by hand before the beetles emerge.

(4) In connection with this hand picking, the possibility of increasing the number of ichneumon parasites is worth consideration. If the collected " capped blossom " be placed in the orchard in a box with a muslin cover of a certain mesh (about $1 / 32$ inch) the weevils will be imprisoned while the ichneumons will be able to escape: It has already been pointed out that the ichneumon is an efficient enemy of the weevil, destroying 25 per cent. and if capped blossoms could be collected over a wide area and the ichneumons released, this percentage might be considerably increased. In France results obtained by this method are said to have been distinctiy hopeful.

(5) The weevils seek winter quarters fairly early in the summer and they may then be trapped by means of bands of sacking tied round the trunks of the trees-as for Codling Moths. The band should be in a position by the beginning of June and should be removed and be burned in the aucumn. This method of control may prove of more value than has hitherto been supposed.

(6) Apart from winter washing, no spray has yet been proved to be of much use and spraying should only be tried experimentally. 


\section{THE APPLE SUCKER.}

\section{(Psylla mali, Schmidb́)}

The Apple Sucker is a widespread and abundant insect and is usually regarded as one of the most harmful pests of the apple, both in the British Isles and on the continent of Europe. It has not, however, been recorded from America, Australia, New Zealand, or South Africa.

Nature of Injury.-Apple Suckers belong to the same Order of insects as Aphides and Capsid bugs, which obtain their food by sucking up the sap of plants through minute holes, or punctures, so causing the injury or death of the parts attacked-especially when the latter are in a young growing state.

In the case of the Apple Sucker, the most serious damage is done to the flower buds and flowers. The insects when quite young attack the flower buds and later the stems of the blossoms, draining away the sap, with the result that the buds may die unopened, or if they expand, fail to set fruit. In the latter case the trusses of bloom often remain on the tree, dead and brown as if damaged by frost. This is the most. characteristic sign of attack. Damage is also done to the developing leaf buds and leaves, the latter being sometimes deformed, stunted, and rendered light in colour. After the blooming peribd and when the leaves have reached their full development, further injury is not obvious; but, nevertheless, it seems likely that the trees may be weakened by the attacks of the sucker to the prejudice of the succeeding crop. Certain varieties of apple, such as Bramley's Seedling, appear to suffer less than others, and, in fact, in most varieties there is considerable variation in the precise amount of injury, trusses of bloom noted as being infested sometimes developing a full crop.

Description and Life-History.-The eggs (Fig. 1) of the Apple Sucker are minute, oval, and creamy white in colour, with a small projection at one end and a longer proiection at the other, the latter passing into the bark and holding the egg in position. They are laid mainly on the fruit spurs (Fig. 2), and to a less extent at the base of the leaf buds and on the twigs generally. The eggs hatch from the end of March to the end of April, varying with the season and also with the variety of apple on which they are laid, those on early leafing varieties hatching first. The newly-hatched suckers, small rather flat, yellow insects, crawl in between the leaf folds and later into the trusses, puncturing them and feeding on the sap. The young suckers grow rapidly, and before long excrete from the hind end of their bodies a small whitish globule or drop, and later long waxy threads which are usually 

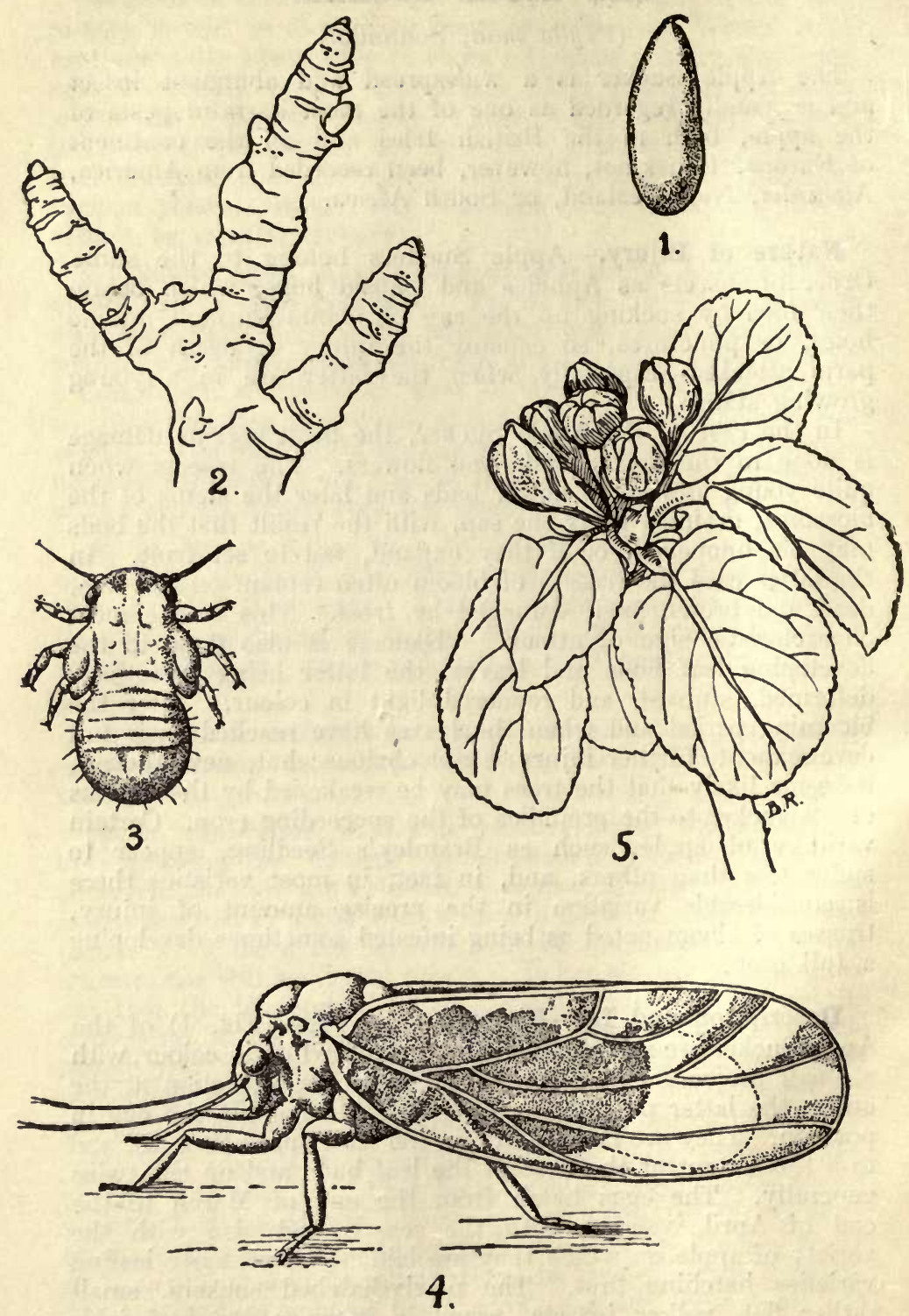

The Apple Sucker.

1. Egg. 2. Position of eggs on fruit spur (represented by dots) 3. Sucker (larval form). 4. Adult Sucker. 5. Condition of Apple buds for spraying. 
very conspicuous, being sometimes white, sometimes blue, and iridescent. By this time the suckers have become bright green in colour, and rudiments of wings can be seen (Fig. 3). In the succeeding moults the wing rudiments become more conspicuous, and finally, four to six weeks from the date of hatching, the adult winged suckers appear (Fig. 4).

The adult suckers live on the apple trees throughout the summer, but do not lay eggs until the autumn. In September, egg-laying begins, and may continue until November, when the adults die. The eggs then remain until the following spring, when they give rise to a further generation.

Methods of Control.-There are three methods of dealing with the Apple Sucker, the first two being those usually employed.

(1) The trees are sprayed with lime-wash about the time when the buds begin to swell; if necessary the spraying may be continued until within about a week of the bursting of the blossom. It is sometimes thought that late lime-washing may injure the young leaves and blossom buds, but the injury, if it occurs, is unimportant, and the results as regards insects are more satisfactory than when the work is done too early. The lime-wash forms a coating over the twigs, which tends to seal up the eggs just when they are about to hatch, and also to kill any young suckers which may already have appeared. The work must therefore be done thoroughly, so that the twigs and branches are well coated with lime. The following is a formula for making lime-wash:-

$$
\begin{aligned}
& \text { Best Quick Lime (in lumps) _.. 10-15 lb. }
\end{aligned}
$$

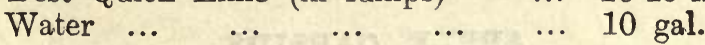

Only the best stone quick lime should be used, ordinary builder's lime is often impure and partially air slacked. In making the wash a small quantity of water should first be poured into the lime to slake it; the remainder of the water should then be added, and atter a thorough stirring, the wash should be carefully strained into the machine.

(2) The trees are sprayed with a contact insecticide shortly before the blossoms open (Fig. 5), a nozzle with a rather coarse jet being used for the purpose, so as to get a driving spray. Occasionally, the newly-hatched suckers may be found somewhat earlier in large numbers on the unexpanded leaf buds, and in this case they are specially amenable to treatment by spraying. The best contact insecticide is nicotine and 
soap, which also deals with Aphides, Capsid bugs and young caterpillars. The following formula has proved satisfactory :-

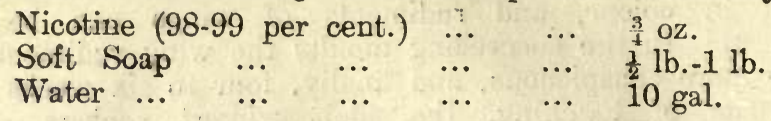

The soft soap is first dissolved in a little hot water, and the solution is added to the remainder of the water. Finally, the nicotine* is poured in, and after stirring the wash is ready for use. Sufficient soap is needed to make the mixture lather well. With soft water $\frac{1}{2} \mathrm{lb}$. will be, sufficient. An emulsion containing creosote oil has been recommended as an efficient insecticide for the control of sucker. In practice, however, it has at times caused such severe injury to the foliage that its use cannot be advised without further investigation.

(3) It has been pointed out that the suckers do not lay eggs until the autumn. It may therefore be possible, in the case of early varieties of Apple, to kill the great majority after the apples have been picked, and before eggs have been laid. At this date injury to the leaves is not of great importance and any contact insecticide, as for instance a paraffin or creosote emulsion, will answer the purpose.

\section{References.}

Theobald.- “Insect Pests of Fruit," p. 153.

Petherbridge.-Journal of the Board of Agriculture, 1915, Vol. XXI, p. 915, “ Spraying for Apple Sucker and Plum Aphis."

Awati-A -Anals of Applied Biology, 1915, Vol. I., p. 247. Petherbridge. - A nnals of Applied Biology, 1916, Vol. II, p. 230, "Spraying for Apple Sucker."

Lees.-Annals of A pplied Biology, 1916, Vol. II, p. 251, "Some Observations on the Egg of Psylla Mali."

\section{APPLE CAPSIDS.}

(Plesiocoris rugicollis, Fall.)

Capsid bugs have only recently attracted much attention among fruit growers, but they must now be reckoned among the most dangerous insect pests of the apple, while their attacks on currants, though less serious, must also be regarded with some alarm. $f$

The most harmful species (possibly the only harmful species), is the Green Apple Capsid, Plesiocoris rugicollis, an

* Nicotine, especially when undiluted is very poisonous, and must. therefore, be used with care.

+ Articles giving further information as to Capsid Bugs appeared in the Ministry's Journal, Vol. XXII, No. 10, Vol. XXIV, Nos. 1 and 12, and Vol. XXT, No. 1 . 
insect which is almost always to be found on willows and sallows, and is widely distributed throughout the country, though its occurrence in apple orchards is still somewhat irregular. Abroad the insect is known to attack apples in Norway, while allied species cause a similar form of injury to apples in Canada and the United States.

Capsid bugs feed on the sap of plants, sucking it up through a trunk (or proboscis), and in order to reach the sap, they drill small holes or punctures, which in the case of the apple form the centres of more or less extensive injuries. The first signs of attack are shown by the appearance, early in the season, of small brown spots on the young growing leaves, each spot marking the position of a puncture. As the leaves become larger, the parts round each puncture either die and fall out or fail to develop properly, with the resuit that attacked leaves are deformed, ragged and under-sized. The bugs also attack the shoots which are checked or even killed, thus encouraging the formation of an excessive number of side shoots, and in consequence a badly-shaped, stunted tree.

Of all injuries, however, the most obvious is that to the fruit. Attacked apples are usually deformed; the skin shows rough russetted patches with scattered pits and pimples indicating the position of the original punctures. Really bad specimens are shapeless, often with cracks extending deeply into the interior, and the whole surface so discoloured, rough and corky, that the fruit has little resemblance to an apple. The crop of course is much reduced, since many fruits fall off before they reach maturity, while a large percentage of the remainder are always so scarred as to be of little value for the market. There appears to be some variation in the extent of the injury to different varieties of apple, certain varieties as, for instance, Bramley's Seedling, sometimes suffering less than others, but nothing definite can yet be stated with regard to this point. In addition to apple, black and red currants are also attacked, the leaves showing the characteristic spotting. It seems likely that the bugs have only recently transferred their attentions to apple and currant.

Description and Life-History.-The eggs of the Green Apple Capsid are oval, white in colour, and are laid under the bark of the apple twigs, being therefore practically invisible unless the twig is peeled. Towards the end of April -earlier or later, according to the season-the eggs produce small green insects which if it were not for their great activity might possibly be confused with aphides (green fly). The young Capsids, as soon as hatched, creep in between the developing leaves and flower buds, puncturing them and sucking up the sap. Feeding on the leaves, shoots and fruitlets, the young bugs grow rapidly, and from the end of May 
to the middle of June become full grown. They are then winged, are bright green in colour, and have the general form shown in Fig. 4. The full-grown bugs-as in the previous stages-are very active, running or falling off the branch when disturbed, and using their wings to get back to a tree. They do not appear to fly long distances or to migrate from one orchard to another. From the middle of "June to the middle of July, sometimes later, the bugs lay their eggs in the apple twigs, and by the middle of August are no longer to be found in the orchards. The eggs remain through the autumn and winter, and give rise to bugs in the following spring.

Methods of Control.-Apple Capsids are difficult insects to control, but the damage can be greatly reduced by careful spraying. 'l'he work, however, must be well done, for it is necessary to wet each bug with the spray fluid-not an easy matter when they are sheltering between the Hower buds in the trusses or among the developing leaves. Further, a very few bugs are capable of doing great injury, and therefore the majority of the insects must be killed if real benefit is to be gained. A fairly coarse nozzle should be used so as to get a driving spray, which should be directed first downwards into the trusses and leaves of a branch passing from the tip to the trunk, and then back again to the tip after turning the nozzle upwards so as to catch bugs sheltering underneath the leaves.

The best time to spray varies with the season, but it is generally during the week or ten days immediately preceding the bursting of the blossom. A watch should be kept for the first signs of spotting of the leaves-then after an interval of ten days to allow the majority of the bugs to hatch, the spray should be applied. Much good can be done by one spraying, but in a badly affected orchard, especially if a good crop is anticipated, it is better to spray again immediately after the petals have fallen.

The best insecticide to use is nicotine, which should always be combined with soap or paraffin emulsion to assist it to run freely in the trusses and between the young leaves. The following formula has proved satisfactory:-

$$
\begin{array}{lccccc}
\text { Nicotine } & (98-99 & \text { per } & \text { cent. }) & \ldots & 3 \mathrm{oz} . \\
\text { Soft soap } & \ldots & \ldots & \ldots & \ldots & 4 \mathrm{lb} \\
\text { Water } & \ldots & \ldots & \ldots & \ldots & 40 \text { gal. }
\end{array}
$$

This wash is, of course, expensive, but it is waste of labour and time to spray against Capsids with a wash which is not highly efficient. Further, nicotine and soap will kill aphides, apple suckers, and a good proportion of any winter moth caterpillars which may be present, and it is therefore a good "general purpose" spray. 


\section{APPLE APHIDES.*}

The so-called "Aphis" or "Blue Bug " Blight, which attacks apples, and to a minor extent pears, is in some years one of the worst pests fruit growers and gardeners have to contend with in this country. The terms Aphis, Dolphin or Blue Bug " Blight" are common names in all fruit-growing districts. They apply to damage done by several species of plant lice or aphides.

Of the eight sfecies of aphides recorded as attacking the apple in Great Britain only four are of general importance. These are: (i) the Blue Bug or Rosy Apple Aphis (Aphis malifolia, Fitch); (ii) the Green Apple Aphis (Aphis pomi, De Geer); (iii) the Oat Apple Aphis (Siphocoryne avena Fabr.), and the Woolly Aphis or American Blight (Schizoneura lanigera, Hausmann).

This leaflet deals only with the first three, which are leaf, blossom, shoot or fruit feeders. In this resfect they are unlike the Woolly Aphis, which usually feeds on the wood and roots, although in very bad attacks it may spread to the leaves and fruit. This latter insect is dealt with in Leaflet No. 34. By far the greatest amount of harm is done by the Rosy Apple Aphis (Aphis malifolice). but in some years and in certain localities the Green Apple Aphis (Aphis pomi) and the Oat Apple Aphis (Siphocoryne avence) are of considerable importance.

Nature of Damage.-The damage by the three species of apple pests mentioned above is mainly to the foliage and young wood, but also to some extent to the fruit, which is stunted and deformed. The Oat Apple Aphis (Siphocoryne avena) may damage the blossom as well as the leaves, and in some seasons similar damage is done by the Blue Bug or Rosy Apple Aphis (A. malifolia). The Green Apple Aphis (A. pomi) mainly attacks the young shoots, and so densely do the insects cluster on them that they check the growth. They do not, however, produce such distortion as is caused by $A$. malifolia.

The Blue Bug or Rosy Apple Aphis (A. malifalia) causes the leaves to curl up, and beneath this shelter the lice reproduce, in certain seasons, at a great rate. The foliage becomes smothered and poisoned by their honey-dew and other secretions and turns brown. In some cases they produce, earlier in the year, yellow or rosy-red, galled masses on the leaves. Later they may swarm on the leaf-stalks, shoots and fruitlets, and by their punctures deform them. The leaves may fall and only a few stunted and galled apples remain.

* An abridged edition of an article, by Mr. F. V. Theobald, published in the Journal of the Board of Agriculture, for April, 1919, pp. 63-71. 
The crop is now and then completely ruined by this pest, and the trees have a serious set-back for the next season and probably for a longer time.

The Green Apple Aphis (A. pomi) may on occasions produce a certain amount of leaf-curl, but never to the same disastrous extent as A. malifolice. Moreover, it never occurs in such vast numbers. It mainly feeds upon the young top growths, and although producing but little deformed growth, it nevertheless checks the health of the tree, especially when on young stock.

The Oat Apple Aphis ( $S$. avena) does little harm as a rule, except where it invades the blossom trusses, in which case appreciable damage may be done. It produces little or no leaf curling, appears earlier, matures and flies away much sooner than the other two kinds.

Description.-The general appearance of the aphides found on apple is familiar to most people, while the blue-black or reddish colour of the Rasy Aphis usually enables this species to be distinguished from either of the other two. Accurate distinctions, however, cannot be given without entering into greater detail than the average reader desires. The following descriptions, therefore, are printed in small type and may be passed over except by those who require some guide as to the identification of the species.

(1) Apterous or Wingless Viviparous Females:-

1. A. malifolia.-Blue-black, slatey-grey or pink. Cornicles long, black; fat, rounded and more or less mealy.

2. A. pomi.-Green, not mealy. Cornicles long and black.

3. S. avena.-Green, not mealy. Cornicles rather short, constricted at base and apex, brown and green.

(2) Alate or Winged Viviparous Females:-

1. A. malifolia.-Cornicles black, rather long. Abdomen red and black.

2. A. pomi.-Cornicles black, rather long. Abdomen green, with black lateral spots.

3. S. avena.-Cornicles pale brown to green, rather short, constricted at base and apex. Abdomen green, with black lateral spots.

Life-Histories.-All three species pass the winter in the egg stage on apples and pears. The small oval eggs are pale at first, but soon become black and shining. They are placed on the shoots and buds, those of the Rosy Aphis and the Oat Aphis mostly singly, but those of the Green Aphis in masses all over the wood. These eggs hatch during April into wingless females, usually known as "Mother Queens," which are viviparous (capable of giving rise to living wingless females in every respect resembling themselves), their progeny quickly reaching enormous numbers. These wingless females act somewhat differently in the different species; those of the Rosy Aphis cause the leaves 
to curl up and afford them protection to a much greater extent than those of the Green Aphis, while those of the Oat Aphis cause no curling whatever. By June or July a change in the life-history of all three species takes place, and winged forms are produced, which nevertheless are all females and all viviparous. These winged forms in the case of the Rosy and Green Apple Aphides now fly off to other food plants for the rest of the summer. In the case of the Rosy Aphis the alternate food-plant is said, in America and Canada, to be different kinds of plantain (Plantago spp.), but this does not appear to be the case in Britain. Where they really fly to has not yet been traced; but they have been found on the guelder rose (Viburnum opulus). The Green Aphis is not normally a migrant. It can and does alternate between the apple and the thistle (Carduus), but such a migration is unusual, and it normally continues its activities upon the apple. The third species, the Oat Aphis, migrates regularly during the first half of June to such plants as cultivated and wild oats, barley, wheat, and different grasses. Late in September and during October the migrants return to the apple and pear and produce a generation of oviparous or egg-laying wingless females, and in the case of the Green Aphis wingless males. In the Rosy and Oat Aphides winged males are normally produced before the return migration takes place, and fly back to the apple later than the migrating females. The generation of wingless females produced on the return of the migrants to the apple are fertilised by the males, and before the winter arrives lay their eggs, thus completing the cycle.

Natural Enemies.-Aphides have several natural enemies. None appear, however, to check them much until most of the damage has been done. These natural enemies are (1) parasitic insects, (2) predaceous insects, and (3) fungoid enemies. The parasitic enemies are small Hymenopterous insects, called Chalcid Flies; the predaceous are Lady Bird Beetles and their larvæ or Coccinellida; the Aphis Lions or larvæ of the Lace Wing Flies (Chrysopida); the Slug or Leech-like larvæ of the Hover Flies (Syrphida); and the maggots of certain Gall Midges (Cecidomyiida). The latter seem to be most abundant in North Britain. None of these, however, appear to be of any practical helf on a large scale, and no reliance can be placed on them as a means of checking "Aphis Blights."

The fungoid enemies, of which there appear to be many, also appear too late to stop any eridemic, and when they attack late colonies, that is, after all the damage has been done, a few Plant Lice escape, enough to produce under favourable circumstances a blight in the following seasons. 
Methods of Control.-Apple Aphides can be controlled by spraying, but too frequently this treatment proves ineffective owing to the fact that it has been carried out too late. The most injurious species-the Rosy. Aphis-causes such curling of the leaves that the pests are quite protected, and spraying under these conditions is to all intents and purposes a waste of insecticide. Effective spraying can, however, be carried out:-

(1) By using lime-wash early in the season when the eggs are about to hatch. The normal time to apply this wash is when the leaf-buds are swelling and about to burst, but many growers continue the treatment with good results to within a week or so of the opening of the blossom. The effect of the wash is to prevent some of the eggs from hatching and to kill newly hatched aphides or so hamper their movements that they are unable to establish themselves. In lime-washing, the whole tree must be covered, and specially the twigs and smaller branches.

(2) By using a contact insecticide (such as nicotine and soap or pyridene and soap) during the period between the opening of the leaf-buds and the bursting of the bloom. Where there is no curling of the leaves, this spray may also be applied soon after the petals have fallen from the blossom. In using all contact insecticides, the application must be very thorough, so that the insecticide penetrates into the halfexpanded buids and reaches every insect. The nozzle used should give a rather coarse and powerful spray.

(3.) By using a contact insecticide such as paraffin emulsion from the middle to the end of October when the leaves are falling. The aphides are then laying the winter eggs and can be killed by a thorough application of the cheapest aphis wash available. At that period there is no danger to be anticipated from "burning" the foliage, and a strong paraffin emulsion is probably as good as anything.

Apart from spraying, the only precaution to be taken is the reduction of ants in the orchard, since it appears that these insects are most active in spreading the Rosy Aphis. When nests are found powdered naphthalene may be dug into them.

Formula.-

I. Lime Wash.

$$
\begin{array}{lllll|l}
\text { Best Quicklime } & \ldots & \ldots & \ldots & 10-15 \mathrm{lb} . \\
\text { Water } & \ldots & \ldots & \ldots & \ldots & 10 \text { gallons. }
\end{array}
$$

Obtain only the best stone quicklime and store carefully to prevent it from air-slaking. Builders' lime, which is often partially air-slaked, should not be used.

Slake the lime with a little water and then add the remainder of the water, stirring vigorously the whole time. Strain carefully before filling the spraying machine. Keep well agitated throughout the application. 


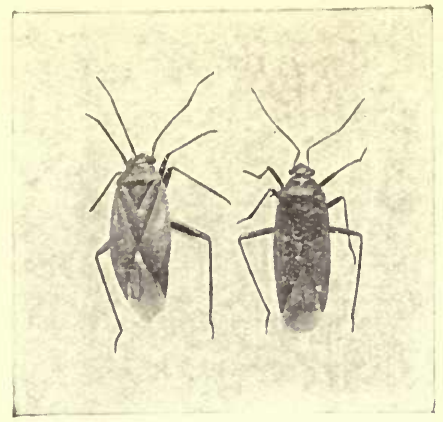

Fig. 1.-Apple CAPSids (Plesiocoris rugicollis).

(Three times natural size.)

Reproduced from the Annals of Applied Biology, Vol. 1, by kind permission of the Cambridge University Press.
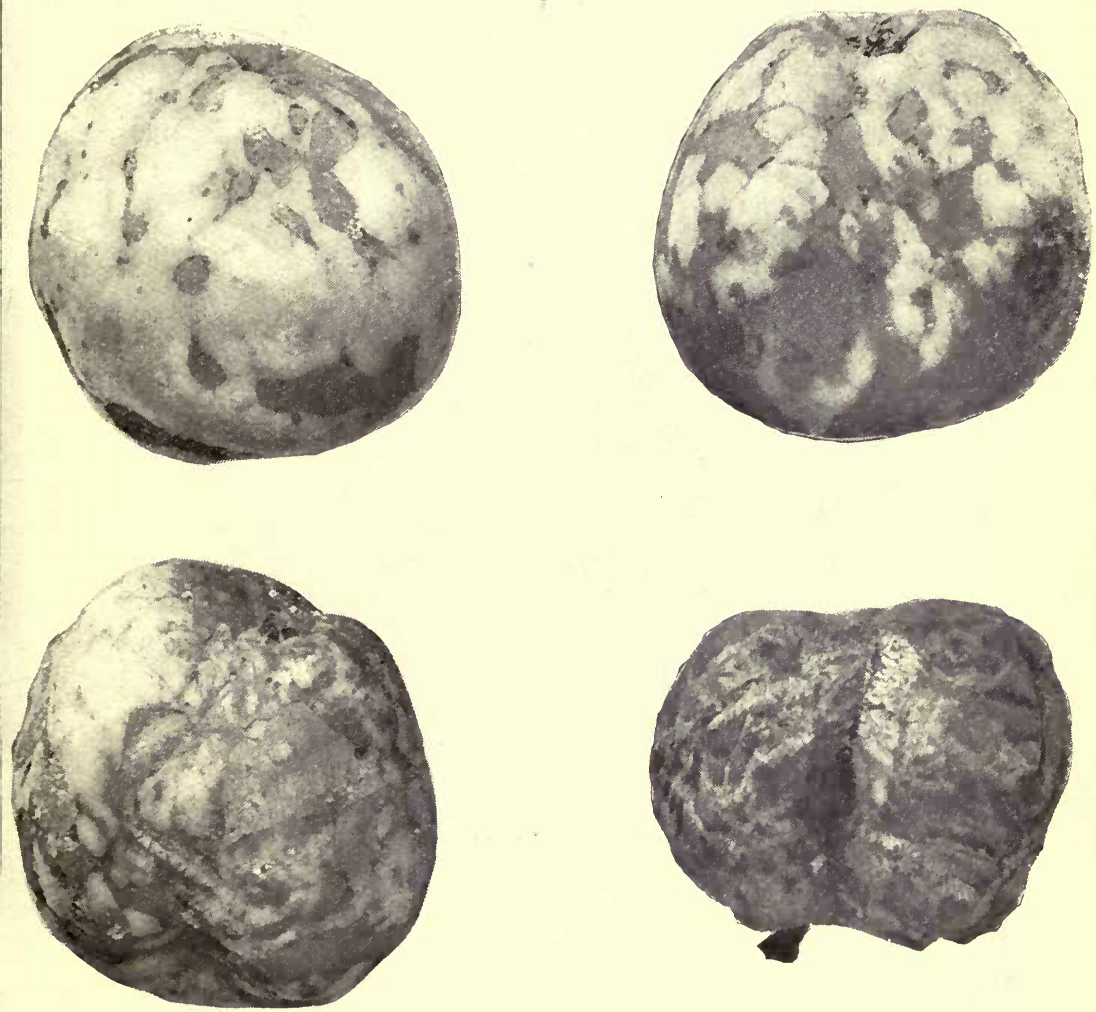

Fig. 2.-Apples attacked by Capsid Bugs. 


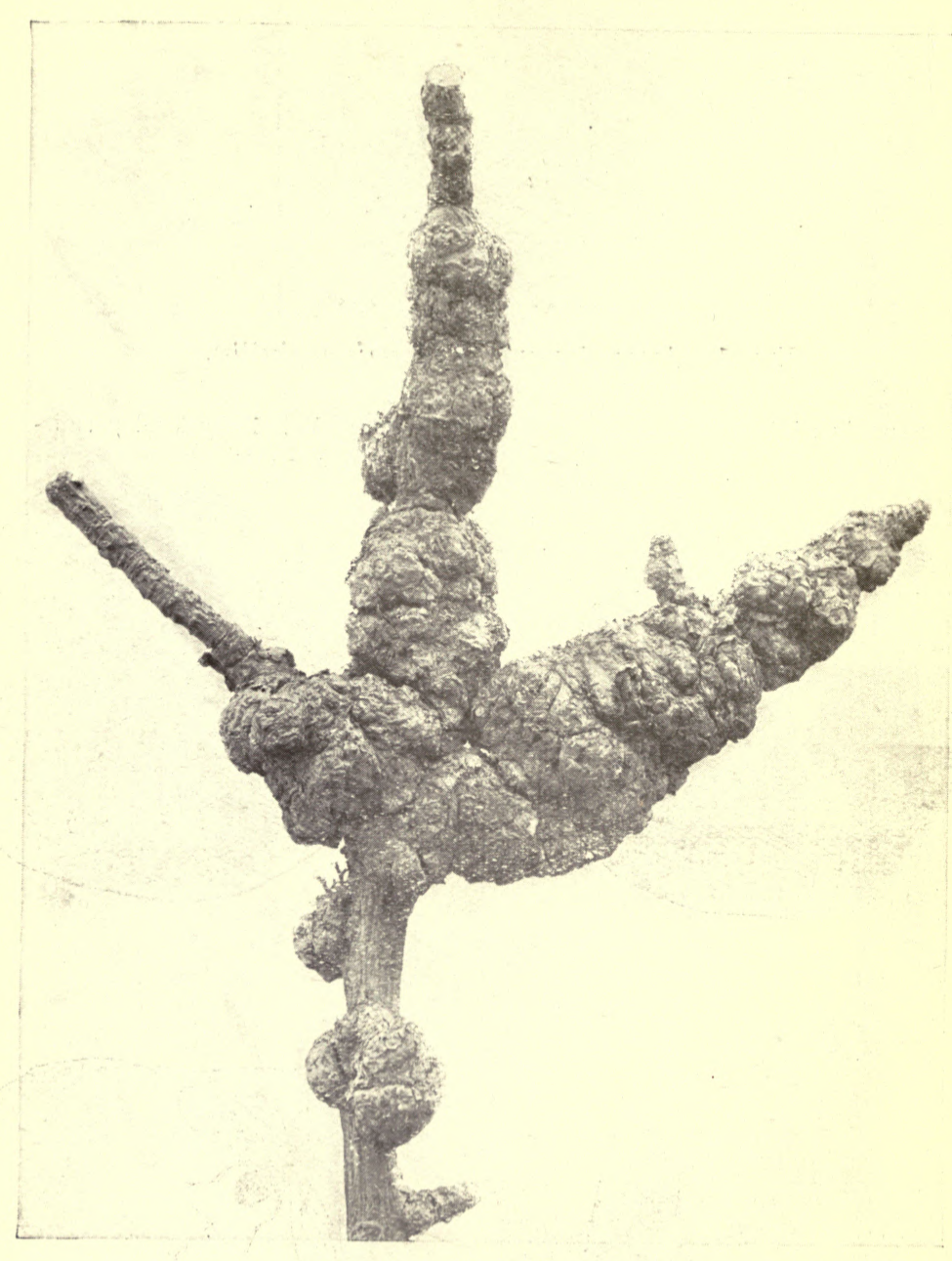

WoOLly ApHis.

FIG, 4-- -ppie twig showirg canker-ilke galls produced by Woolly Aphis ttacks (slightly less than natural size). 
Theobald strongly advises the addition of $\frac{1}{2} \mathrm{lb}$. of common salt to each 10 gallons of the above wash.

II. Nicotine and Soap Wash.

Nicotine (95-99 per cent.) ... …

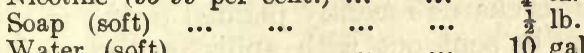

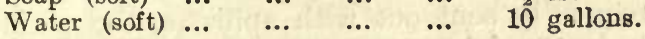

If the water is hard, $1 \mathrm{lb}$. of soap should be used. Dissolve the soap in hot water, dilute to the required strength, add the nicotine and stir well. If soft soap is unobtainable, hard soap should be used instead. This is the best contact insecticide. It will also kill Apple Sucker, Capsid Bugs and young caterpillars.

III. Pyridene and Soap Wash.

$$
\begin{array}{llllll}
\text { Pyridene } & \ldots & \ldots & \ldots & \ldots & 4 \mathrm{oz} . \\
\text { Soap (soft) } & \ldots & \ldots & \ldots & \ldots & \frac{1}{2} \mathrm{lb} . \\
\text { Water (soft) } & \ldots & \ldots & \ldots & \ldots & 10 \\
\text { gallons. }
\end{array}
$$

Pyridene may be used as a substitute for nicotine to reduce the cost of the wash. It is slightly less effective against Carsids and is of little use against caterpillars.

\section{THE WOOLLY APHIS.}

(Schizoneura lanigera, Hausmann.)

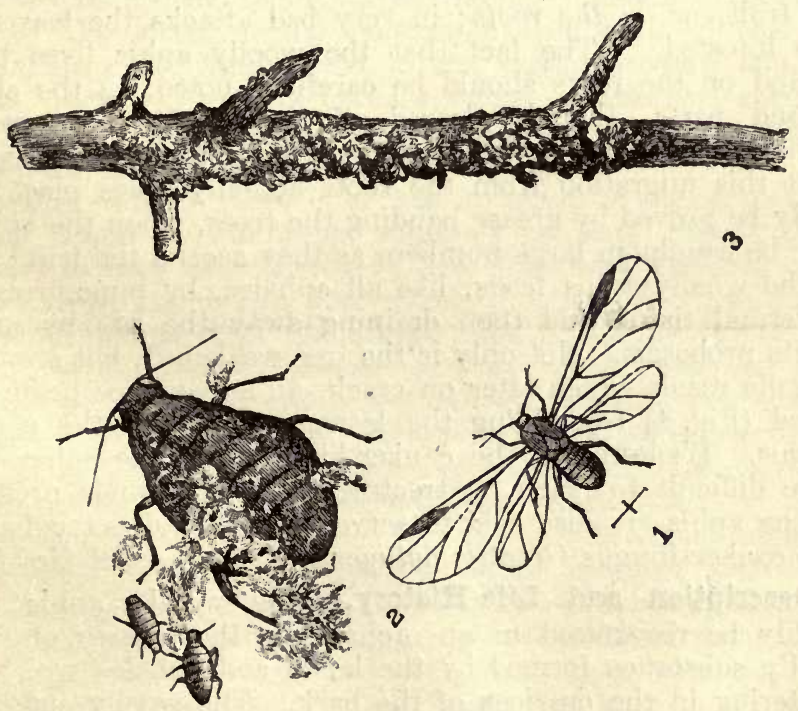

1. Winged female, magnified; and line showing natural size. 2. Wingless viviparous female, magnified.* 3 . Apple twig, covered by woolly aphides.

* Figure 2 is reproduced, with permission, from Mr. G. B. Buckton': "British Aphides." 
Distribution.-This insect is always more or less abundant in old and neglected orchards and apple plantations where no attention is given to pruning or to keeping the trees free from moss, lichens, \&c. Unfortunately it is also sometimes seen in orchards recently planted owing to nursery stock being frequently sent out with aphis on the plants. Indeed, although dispersal by the agency of wind is not unimportant, by far the most common way for the pest to be distributed is on infested nursery stock. Not only has the woolly aphis been carried from orchard to orchard in Britain in this way, but also from country to country, until it is now found in every part of the world where apples are grown. It has been stated that this aphis, although termed the American Blight, was originally a European insect, but it is doubtful whether its country of origin has yet been conclusively settled.

Injury Caused.-All varieties of apple in this country are subject to the ravages of woolly aphis, but perhaps the old Ribston Pippin suffers most of all. The Blenheim Orange, Cox's Orange Pippin, and Lord Suffield also suffer severely. Varieties having a soft bark are most affected. Certain experiments conducted in Victoria and elsewhere show that in the case of apples grafted on Majetin and Northern Spy stocks the roots are free from attack.

Infestation may be on the main trunk, on the branches, on the fruit, or on the roots; in very bad attacks the leaves are also infested. The fact that the woolly aphis lives below ground on the roots should be carefully noted, as the aboveground parts, though cleared of the insect, may receive a new infection as a result of migration from below. That this migration from the roots actually takes place may easily be proved by grease banding the trees, when the aphides may be caught in large numbers as they ascend the truniss.

The woolly aphis feeds, like all aphides, by puncturing the epidermal tissue and then draining away the sap by means of its proboscis. Not only is the tree weakened, but swellings or galls result which later on crack, an appearance being produced (Fig. 4) resembling the lesions caused by the cankerfungus. Sheltered in the canker-like cracks, the aphides are more difficult to reach by treatment. The wounds produced by the aphis are also said to serve as points of entry for the true canker fungus (Nectria galligena.) (See Leaflet No. 56.*)

Description and Life-History.-The woolly aphis may readily be recognised in an orchard by the masses of white woolly substance formed by the larvæ and females which are sheltering in the crevices of the bark. The woolly substance arises as an excretion from glands in the backs of both the young and mature females. It may often be seen hanging

* To be obtained from the Ministry, also included in Sectional Volume No. 1, price $8 \mathrm{~d}$. 
in festoons from the trees. Parts of this "wool "get biown off and are carried by the wind, often for some little distance, and in this material young Schizoneurce may be carried.

Various forms of the woolly aphis are found in the course of the year's cycle:- - wingless females that produce live young; winged females that are also viviparous; and males without wings, which pair with wingless egg-laying females.

The wingless viviparous females are oval in shape and purplish-brown in colour. Numerous white threads pașs from their backs. Their antennæ and legs are very short, and in colour are dark reddish-brown to black. Such wingless viviparous females may be found all the year round. They give rise to great numbers of young (so-called lice) which are at. first of a dull yellowish colour but later become purple brown. It is the woolly material secreted by these that gives rise to the festoons mentioned above. These lice on becoming adult produce live young in turn, and a number of such generations can be produced in the summer.

The wingless viviparous females may, however, give rise, between June and late October, to winged viviparous females, the exact function of which has not yet been discovered. Patch* appears to have shown conclusively that in America these winged females, which there occur commonly, migrate to elm trees, where they give rise to wingless males and wingless egg-laying females. The eggs laid by the latter in the crevices of the bark of the elm remain over the winter, and in the spring produce wingless forms from which arise aphides which attack and curl the elm leaves. Subsequently the elm leaf form produces winged individuals which migrate back to the apple.

In this country there is as yet no direct evidence that the woolly aphis of the apple migrates to elm, but it is of interest to note that Theobald $t$ has discovered a woolly aphis which curls elm leaves and which produces a winged form indistinguishable from the winged form found on apple. No males or egg-laying females of this aphid have yet been discovered in this country and its relation-if any-to the apple woolly aphis is still unknown. It is, of course, quite distinct from the usual species of Schizoneura (S. ulmi or fodiens) which attacks elm and currant in Britain.

On the apple in this country the woolly aphis produces winged forms only occasionally, while wingless males and females, which lay winter eggs, are known on apple trees, but are exceedingly rare. The usual method of passing the

* Bull. 203. Agric. Exp. Station, Maine, U.S.A.

$t$ An account of this observation has not yet boen published, but Mr. Theobald kindly allows a refererce to be made to it. He finds the EIm form common all over Britain-the top of the young shoots being extensively curled. Winged forms appear in June and July and fly away from the EIms 
winter is as a wingless viviparous form which hides in cracks in the bark, in the canker-like wounds, or in the galls on roots. There appears to be a migration of individuals from the portions of the tree above ground to the roots at the approach of winter and a return migration from below to the branches in the spring.

Natural Enemies.-There are not many natural enemies that do much good in checking the increase of this pest. Possibly the woolly excretions and oily globules that surround the insect protect it from the various foes which attack unprotected plant lice.

The larvæ of Lady Birds (Coccinellida) devour them, as -also do the adult Lady Birds. Larvæ of several species of Hover Flies (Syrphida) also feed upon them, but not to the same extent as upon other plant lice. Lace Wing Flies and Ichneumon Flies are seldom found attacking them. Small dipterous larvæ of the genus Pipiza feed on the subterranean form. Perhaps the Tits (Parid.a) (See Leaflet No. 43*) do most good in keeping down this pest. These little birds, especially the Blue Tit, do inestimable good by devouring woolly aphis and other pests all the year round, and should bo protected in every orchard.

Methods of Prevention and Remedies.-(1) Woolly aphis is especially prevalent in neglected orchards where the trees are close together and where their trunks are covered with lichens and moss. To clean the trees and destroy the hibernating females a winter wash should be used. This may be the simple alkaline wash composed of caustic soda, 2-2 $\frac{1}{2} \mathrm{lb}$., and water, 10 gallons, or it may be one of the more efficient Woburn washes (See Leaflet No. 70*). Lime or lime sulphur winter washes have also been found useful, but they are naturally less effective than the more caustic fluids.

(2) Any portion of a tree which has been wounded, as for instance, by pruning, is specially liable to an attack by woolly aphis. If large branches have been removed the cut surface should always be dressed, Stockholm tar being an excellent dressing for this purpose.

(3) Methylated spirit brushed well into the affected portions of trunk or branches is the most successful treatment for young trees or when an attack first manifests itself in an orchard. Owing to the rapidity with which methylated spirit evaporates and its consequent expense, paraffin or petrol is sometimes substituted for the spirit, but where the trees are young and the bark thin, this may lead to injury. A wide range of compounds containing linseed oil, Stockholm tar, shellac and other substances have. also been invented for brushing on to the affected portions

* Obtainable from the Ministry. 
of the trees. In all cases, however, success depends on the thoroughness with which the treatment is carried out.

(4) For a summer spray nicotine and soft soap, dilute paraffin emulsion, or quassia and soft soap have all been recommended. If used they must be applied with force and the affected parts thoroughly drenched owing to the necessity of penetrating the woolly material before the insects themselves are reached.

(5) To prevent the introduction of the aphis, great care should be taken to see that all young stock is clean before planting. If any traces of either the root or the aerial forms are seen, the trees should be returned to the nurseryman to be disinfected before being planted. All nursery stock can be fumigated with hydrocyanic-acid gas (see Leaflet No. 188*), and thus thoroughly cleared of woolly aphis before planting.

\section{THE MUSSEL SCALE.}

\section{(Mytilaspis pomorum, Bouché.) •}

The Mussel Scale is one of the most abundant scale insects in the British Isles; it also occurs on the Continent of Europe, in North America, South Africa, Australia and New Zealand, having been introduced into the three last countries on infested nursery stock. As a pest the insect is most conspicuous in neglected apple orchards, but it is always present on apple and certain other trees in all the fruit-growing districts in the kingdom, and wherever it is allowed to increase unchecked is likely to cause serious damage. In America it is regarded as an insect of considerable importance to apple growers and is there known as the Oyster-Shell Scale from its resemblance in shape to American oysters.

Description and Life-History.-The Mussel Scale lives on the stem and branches, and occasionally on the leaves and fruit of the plants, such as the apple, which it attacks. If a branch infested by this insect be examined, it will be found that the surface of the bark is more or less covered by small brown objects (Fig. 1) about $\frac{1}{3}$ inch in length, which are shaped somewhat like a mussel shell. Each mussel-like scale forms a roof or covering over the living insect during the summer, and over its eggs in winter.

The winter is spent in the egg stage, the eggs-exceedingly minute and like a whitish dust-lying underneath the scales. At the end of May or early in June very small wingless, louselike insects (larvæ) are hatched from the eggs and crawl from 
under the scale on to the bark of the tree, where they wander about for three or four days, and may during this period be

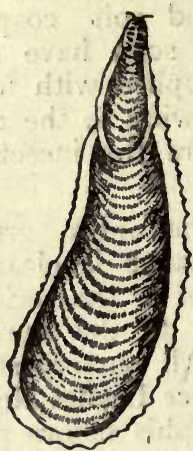

a

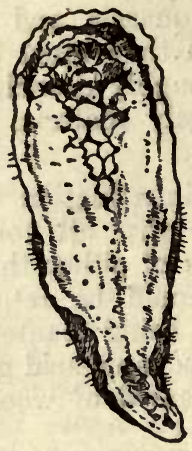

b.

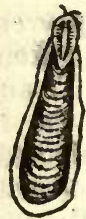

c.

Fia. 2.

a. Female Mussel Scale, dorsal view; $b$. The same, ventral view;

c. Male scale.

carried to other trees by means of the wind or by clinging to birds and insects. When one of these "lice" (larvæ) reaches a suitable spot, it drives its "trunk" (or proboscis) into the bark and begins to feed by sucking up the sap-just like a Green Fly or a Capsid Bug. Unlike either of the latter pests, however, it soon loses all power of movement and remains fixed to the bark in which its trunk is buried. As it grows it forms the scale under which it lives, building up the scale in such a way that the insect itself is always completely covered (Fig. 2).

In the case of the Mussel Scale, the insects are practically all females, and when they become adult towards the end of summer they lay eggs (as a rule without the intervention of a male) under the scale, continuing until there may be as many as 80 eggs under one scale. The female then dies and the eggs remain in safety under the scale during the winter. Mussel Scale insects of the male sex do occur, but they are very rare on fruit trees. When young, the males, like the females, live under scales, but the male scales are somewhat different, being straighter and not so large (Fig. 2c). Under the scale the young male passes through a pupal (chrysalis) stage, and on becoming adult emerges as a minute fly-like insect with two wings. The males pair with the females and soon die, having no mouth parts for feeding.

Plants attacked and Nature of Injury.-Mussel Scales are injurious to apples, and less frequently to pears and currants. (both black and red). The insects also attack sallow, hawthorn, broom and other plants.. Trees growing against walls 
suffer more than others, as the pests flourish most in warm, sheltered situations.

The injury to the tree is caused by the loss of sap which is sucked up and devoured by the pests. In a bad case, where the branches are completely encrusted with scales, the tree suffers so severely that it may die in part if not altogether. Old trees are more often infested than young trees, but at the same time they are able to withstand the attack better, and when by bad management, a young plantation is allowed to become badly infested, the damage sustained may be irreparable. Since Mussel Scales are to be found in small numbers in practically every apple orchard, a careful watch should always be kept so that if any increase in the numbers of the pest is noted, control measures may be taken before serious harm has resulted.

Natural Enemies.-Mussel Scales are devoured by Tits and probably also by the Tree Creeper and Wryneck. They are attacked by certain minute parasitic insects (Chalcids) which, however, are not a sufficient check on the pest to render artificial measures of control unnecessary.

Control Measures.-(1) In the case of a bad attack, the trees or bushes should be sprayed when dormant (November to February) either with an oil emulsion or with Woburn wash (see Leaflet No. 70). There are now on the market several makes of oil which mix (or form an emulsion) with water, and if used they should be diluted in the proportions recommended by the makers for a winter wash. A home-made emulsion for winter use may be mixed as follows:-

$$
\begin{array}{llllll}
\text { Paraffin oil } & \ldots & \ldots & \ldots & \ldots & 1 \text { gall. } \\
\text { Soft soap } & \ldots & \ldots & \ldots & \ldots & 1 \frac{1}{2}-2 \mathrm{lb} . \\
\text { Water } & \ldots & \ldots & \ldots & \ldots & 10 \text { gall. }
\end{array}
$$

The soap is first dissolved in about a gallon of boiling water. The soap solution is then removed from the fire, and the paraffin is at once added, the whole being emulsified by squirting the liquid back into itself with a hand syringe. The strong emulsion may be kept until required for use, when the remaining nine gallons of water should be added and the whole thoroughly stirred-or better, emulsified again with the hand'syringe,

Oil emulsions, whether bought or home-made, must be applied carefully so as to wet every portion of the tree, not forgetting the undersides of the large branches. The eggs under the scales will be killed only where the scales themselves are thoroughly wetted, and if a few escape the trees will be re-infested.

(2) In America good results have been obtained by the use of lime-sulphur washes, and although in England limesulphur has proved rather disappointing in the case of bad 
infestations, it will probably be found satisfactory in keeping moderate or slight attacks in check. Lime-sulphur should be bought ready made, and be diluted when required for use (not before) with water in the proportions recommended by the makers to form a winter wash (usually 3 quarts of limesulphur to 10 gallons of water). The wash should be applied in late winter or early spring up to the period when the buds begin to open.

(3) If the pest has not been dealt with in winter-the best time-it may be greatly reduced by spraying when the eggs are hatching, about the end of May or early June. At this period a weak paraffin emulsion has proved satisfactory, and probably any other contact insecticide, such as nicotine and soap, would do as well. A suitable paraffin emulsion may be made as recommended in paragraph (1) abore, but using the ingredients in the following proportions:-

$$
\begin{array}{llllll}
\text { Paraffin } & \ldots & \ldots & \ldots & \ldots & 2 \text { pints. } \\
\text { Soft soap } & \ldots & \ldots & \ldots & \ldots & 1 \text { lb. } \\
\text { Water } & \ldots & \ldots & \ldots & \ldots & 10 \text { gall. }
\end{array}
$$

(4) Growers, when buying fruit trees, especially apple, should examine them for Mussel Scale (and also such pests as Woolly Aphis) before making a purchase.

(5) It is better to prevent attacks by occasional winter washing than to wait until it has become necessary to deal with a serious infestation, and in this connection it is worth noting that trees which are regularly sprayed and kept free from moss, lichen, \&c., seldom suffer from Mussel Scale, even though the washes used have not been srecially directed against Scale.

\section{THE LACKEY MOTH.}

(Clisiocampa neustria, Linn.)

The Lackey Moth is an insect which is always present in orchards throughout the southern half of the country but which is rare and seldom harmful north of the Midlands. The chief characteristic of the Lackey from the fruit-grower's point of view, is that it will remain for years in a district without to all appearance increasing in numbers or causing much harm. Then, suddenly, with little warning, the insects become so abundant that the caterpillars are a veritable plague, stripping troes of their foliage and almost defying efforts to exterminate them. After a season, or perhaps two, the Lackey population resumes its normal proportions and again several years nay elapse before another epidemic breaks out. 


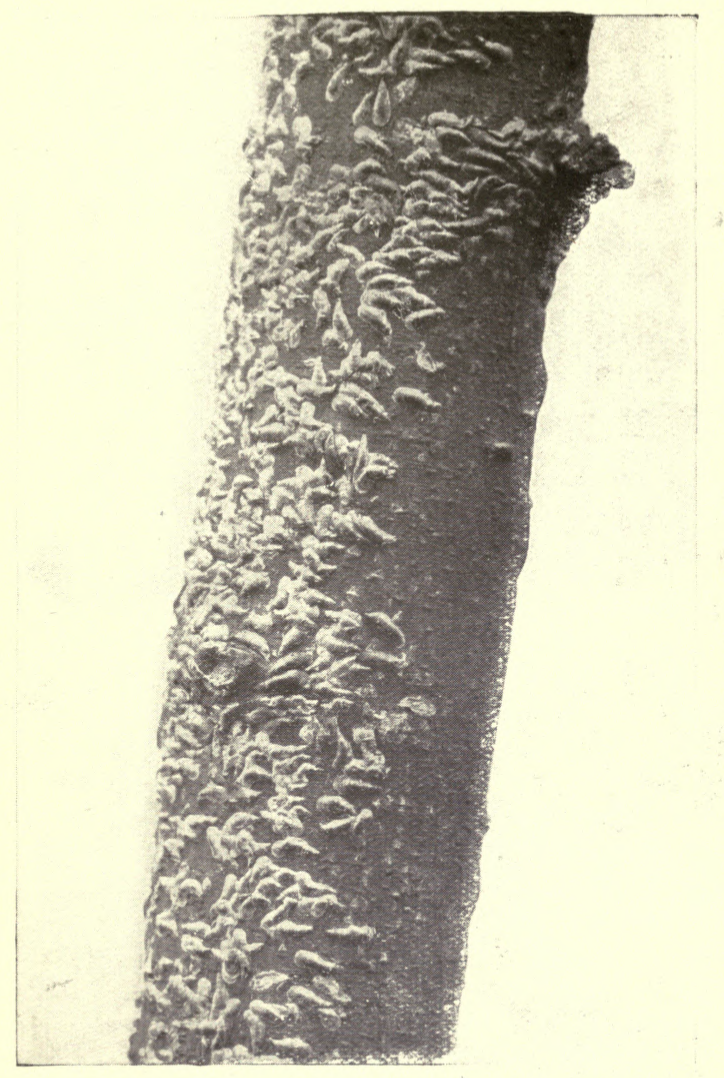

Photo.] [R. A. Malby. Mussel Scale.

FIG. 1.-Piece of infected Branch. (Twice natual size.) 


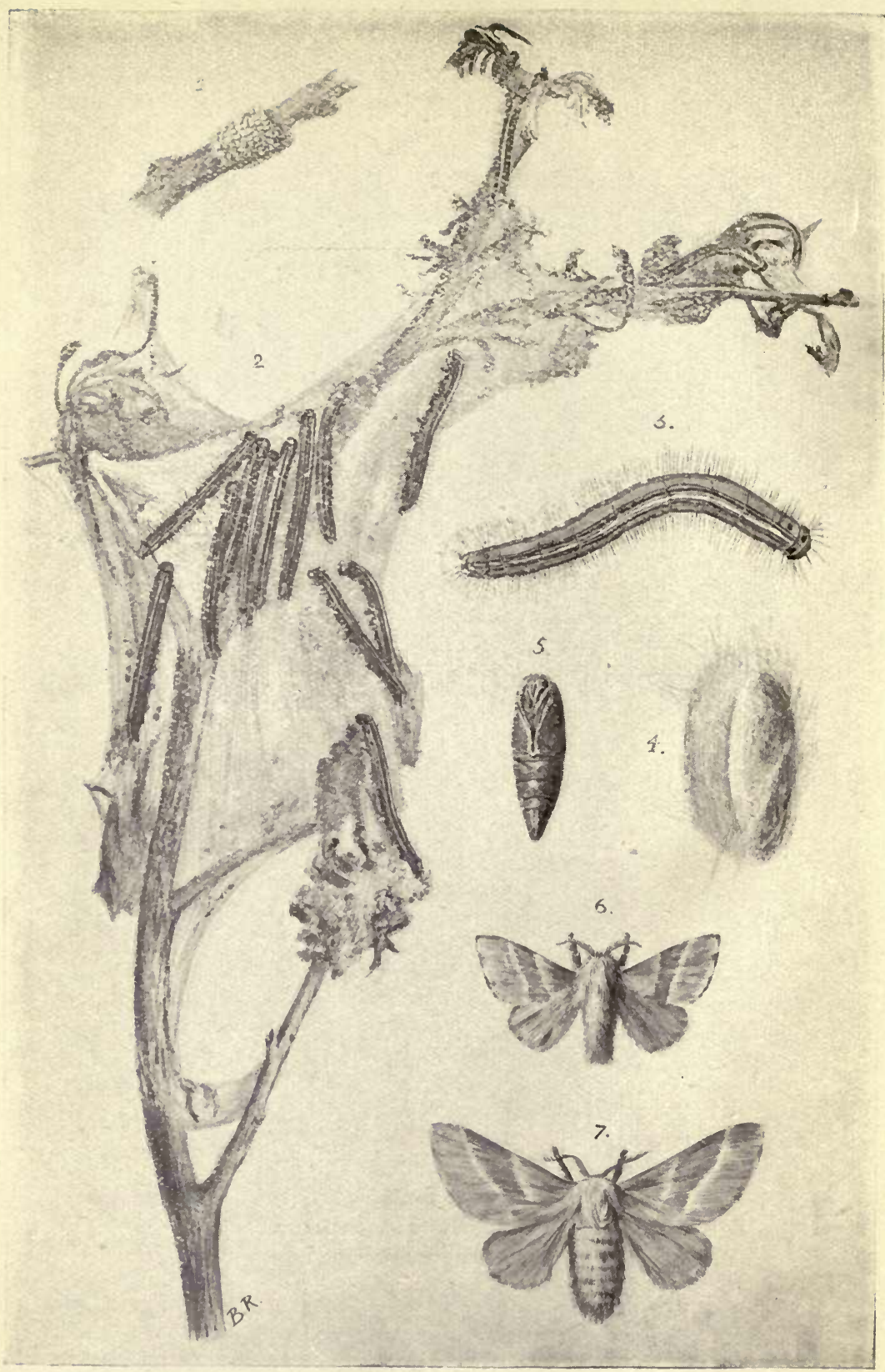

THR LACKey Moth.

Fig. 1.-Eggs on twig. Fig. 2.-Web on apple branch, showing caterpillars and cast skins. FIG. 3.-Full grown caterpillar. FIG. 4.Cocoon. FIG. 5.-Chrysalis. Fra. 6.-Male Lackey Moth. Fig. 7.Female Lackey Moth. 
Plants Attacked and Nature of Damage.-Lackey Moth caterpillars feed on the foliage of many kinds of trees and shrubs including apple, cherry, plum, and pear among truits, and oak, hawthorn, willow, alder, elm and rose among forest trees and shrubs. As the caterpillars live and feed together for the greater part of their lives their work of destruction is very thorough and every leaf on the branches attacked is often completely devoured. Naturally. if there are several colonies on one tree the foliage is wiped out, the fruit in consequence cannot mature, and in addition to the loss of the current year's crop the health oi the tree is so prejudiced that a crop the following season is also unlikely.

Description and Life-History.-Lackey Moths come out of their chrysalides at the end of July and may be found from August to September. They are brown moths one-and-aquarter to one-and-a-half inches in spread of wings, and of the general shape shown in Figs. 6 and 7. The exact shade of brown varies greatly, some moths being quite light-almost yellow-brown-and others a rusty red-brown, with all inter. mediate shades. On each of the front pair of wings are two light bars and the space between them is usually darker than the general ground colour. As regards habits, the moths fly only at night and the males (Fig. 6) are strongly attrsicted by light, sometimes coming in numbers to lighted rourns or to street lamps. The females (Fig. 7) are more sluggish. After pairing, they lay their eggs on the twigs of the various trees on which the caterpillars feed. The eggs (Fig. 1) are laid together in a ring, a quarter to half an inch wide, which completely encircles the twig, the whole comprising a hundred to two hundred eggs. These eggs are grey-brown in colour and the mass is sufficiently large to be seen easily. The moths die in September or earlier and the eggs remain throughout the winter and hatch about the end of April.

The little caterpillars when first hatched are tiny, darkcoloured, hairy creatures, but they soon develop a coloration which becomes more brilliant as they grow. Their general appearance is shown in Figs. 2 and 3, and their coloration is roughly as follows:-The ground colour is blue-grey: down the middle of the back is a white line, on each side of which are two broad orange-red stripes divided by a black line. Then, lower down the sides is a blue stripe, followed again by a third orange-red stripe (or a series of orange-red spots), while the whole insect. except the head, is clothed in reddish brown hairs. All markings are narrowly outlined in black.

In habits Lackey caterpillars are gregarious and live in company for the greater part of their lives. When newly hatched they spin between two or three leaves a small silken weh and as they grow they build larger nests by spinning together twigs and branches in a thick web of silk (Fig. 2). A 
numerous colony may require a nest $1 \mathrm{ft}$. long and 6 inches wide, a conspicuous object on the tree, especially when most of its foliage has been devoured. The caterpillars shelter inside these nests but they may often be found sunning themselves on the outside, where they also cast their skins (as they must from time to time when growing). Their fondness for sunning themselves is also shown by their habit of lying, many together, along any exposed branch.

Throughout their existence the rests feed voraciously, devouring leaf by leaf,so that in some cases the tree is stripped bare of foliage and almost smothered in web. When full-fed in the latter half of June or early July each caterpillar spins a silk cocoon (Fig. 4), yellow or white in colour, between leaves on the tree, on the trunk, on a neighbouring fence, or among grass and other herbage. Inside the cocoon the caterpillar turns to a blackish-brown chrysalis (Fig. 5) from which the moth emerges some three weeks later.

Natural Enemies.-Lackeys, in the egg or caterpillar stages, are attacked by numerous enemies which consist chiefly of such other insects as Ichneumonid, Braconid or Tachinid flies. Sixteen or more kinds of Ichneumon fly have been found to destroy them and at least two kinds of Braconids related to those which parasitise White Butterflies (making the small yellow cocoons so often found beside the dead or dying butterfly caterpillars). Lackey caterpillars do not seem to be readily eaten by birds, but of course are subject to disease. It is not yet known whether the sudden epidemics are due to a temporary lack of natural enemies or to favourable weather conditions, but it is clear at present the pest is not always kept in check by these means.

Control Measures.-1. Spraying is effective if carried out early enough, and also at any time if there are not many caterpillars on the tree. When, however, the whole tree is enveloped in webbing it is impossible to get enough poison on to the leaves to do any good. The best time to spray is within three weeks after the dropping of the petals from the flowers. Lead arsenate ( $1 \mathrm{lb}$. paste to 20 gallons water) is the best insecticide to use and the wash should be applied through a fine nozzle, giving a light dressing to every leaf on the tree.

2. Nest Destruction.- In gardens with only a few trees affected, the nests can be destroyed by hand, taking care that caterpillars which fall do not escape. Nest destruction is also necessary in orchard epidemics where spraying could not be carried out sufficiently early. Sometimes the trees are first banded with sticky material to prevent fallen larvæ from crawling up again, and in cases where the trees are very high shot-guns have been used to destroy the nests. Naturally nest destruction is ruinously expensive in commercial orchards but it has on several occasions been necessary to resort to it. 
3. Egg Collection,-As the egg-bands are not difficult to see in winter they can be collected and destroyed. This has been done systematically in times of epidemics but it is not a measure which can be given much attention in normal years, though workers should be instructed to look out for and destroy every egg-band they detect when pruning trees. In small gardens and on small trees it is quite possible to deal with the Lackey wholly by this means.

\section{WINTER MOTHS.}
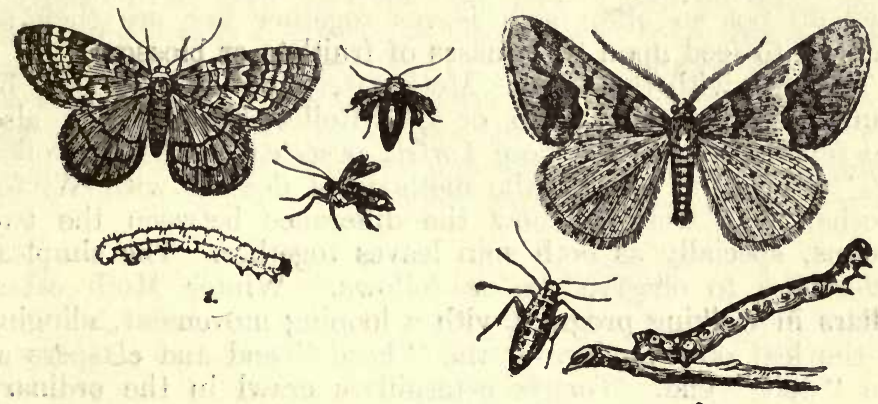

2.

Fig. 1.-Winter Moth (Cheimatobia brumata). Fig. 2.-Mottled Umber Moth and Caterpillar (Hybernia defoliaria). Male Moth, winged;

Female Moth, wingless. All naturai size.

The caterpillars of three species of moth do greai damige to fruit trees in the spring and are among the most serious pests with which the fruit grower has to contend. These moths are the Winter Moth (Cheimatobia brumata, L.), the Mottled Umber (Hybernia defoliaria, Cl.) and the March Moth (Anisopteryx ascularia, Schiff). All three are sometimes known collectively as Winter Moths.

Plants attacked and Nature of Damage.-Practically every form of standard and bursh fruit is attacked by these pests as well as most forest trees and bushes. indeed it would be easier to mention the kinds of plant not sttacked, (e.g., Conifers) than to list every tree or bush upon which one or other of the caterpillars can live. The nature of the injury is also rather extensive. The caterpillars appear early in spring and feed during the entire period in which fruit trees are making their foliage, producing blossom or setting fruit, and all may be injured or in a severe attack be practically destroyed. The characteristic method of feeding of the Winter Moth and the March Moth is to spin together very loosely two leavesor a leaf to the side of a blossom truss-and then to eat holes in the leaf, attacking more pr less indiscriminately the edges 
and the centre of the leaf. In the case of the blossom truss they may eat out the buds before these have opened and later bite holes in the young fruitlet. If the leaves are not ont when the eggs hatch the young caterpillars burrow into the unopened leaf and fruit buds and do much harm in this way. In bad attacks practically everything green on the tree has been devoured by the end of May and the orchards are as leafless as they were in winter. Fresh leaves are produced later but the orchard is crippled for the year and possibly as regards crop poduction for the year after as well.

The caterpillars of the Mottled Umber feed on the foliage in much the same way as the above-mentioned species but they do not so often spin leaves together nor are they so inclined to feed upon the trusses of fruitlets or blossom.

Together with the Winter Moth caterpillars may usually be found those of the Tortrix or Leaf-Roller Moths which also are very harmful. As these Tortrix pests cannot be controlled by " banding" (one of the methods of dealing with Winter Moths) it is well to know the difference between the two groups, specially as both spin leaves together. The simplest differences to observe are as follows. Winter Moth caterpillars in walking progress with a looping movement, clinging to the leaf only by legs at the " head" end and claspers at the " tail" end. Tortrix caterpillars crawl in the ordinary way, lying flat on the leaf, while in addition they have the very characteristic habit of wriggling rapidly backward if touched in front.

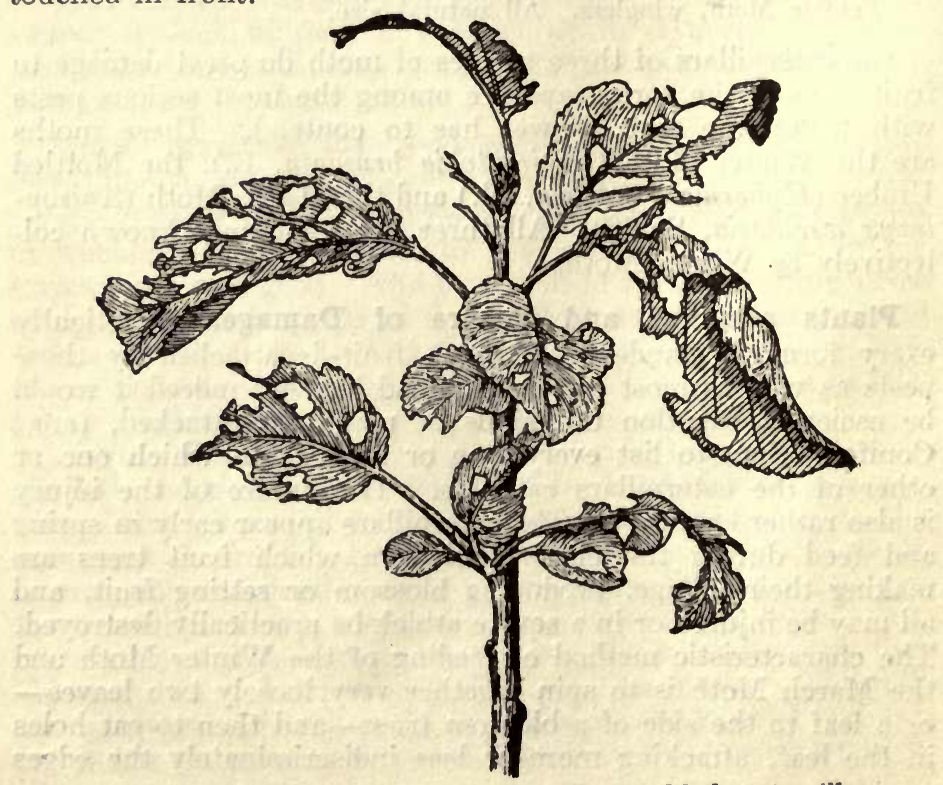

Fia. 3.-Apple Shoot being eaten by Winter Moth caterpillars. 


\section{Description and Life-History of Winter Moths.}

Winter Motr (Cheimatobia brumata).-The Moths.-The male of the Winter Moth measures 1-1 $\frac{1}{2}$ inches in spread of forewings, which in colour are grey-brown with numerous darker wavy lines, the hindwings being grey without markings. From the middle of Octaber to the end of December it emerges from its chrysalis in the soil and may frequently be seen flitting about orchards and hedges at dusk, later in the evening coming to street lamps and other artificial lights. The female Winter Moth is very different in appearance from the male, having tiny shrivelled-up looking wings, so small that flight is not possible. The body is large, the legs appearing long, thus giving the insect a superficial resemblance to a spider, quite unlike the popular conception of a moth. From the second week in October onwards to December these female Winter Maths emerge from chrysalides buried in the ground at the base of a tree (the result of infestation the previous spring), crawl up the trunk to the small terminal shonts, and deposit eggs upon them.

The Egg.-The eggs are small, cylindrieal, at first light green in colour, but later becoming reddish, and are placed singly or in small groups at the base of buds and on pruned surfaces. From 100 to 200 are laid by one female.

The Caterpillar.-From the eggs laid by the moth in winter the devastating caterpillars hatch in early spring, usually about the middle of March just before the bursting of the buds. When first hatched they are grey with black heads and are extremely small. As they grow and change their skins they become green with white stripes and greenish heads. As already mentioned they progress by " looping," having, like all members of the group to which they belong, six true legs in front and but two pairs of claspers behind, instead of the five pairs possessed by caterpillars of most other groups of moths and butterflies.

They eat bud, leaf, blossom and young fruit, spinning leaves and blossom heads together and living under the protective covering thus formed. In May and June they become fully fed, let themselves down to the ground by silken threads and form chrysalides in the soil. Moths emerge from these chrysalides in the following autumn and winter to hegin the cycle again.

The March Motu and the Mottlen Umber.-For all practical purposes the life histories of these species resemble sufficiently that of the Winter Moth to render separate treatment unnecessary.

The March Moth appears in the month bearing its name or sometimes earlier. The male measures about $1 \frac{1}{2}$ inches in spread of the rather narrowish forewings, which are grey-brown 
with transverse bands, the hindwings being pale greyish white with a darker zig-zag line running across them. The female is quite wingless and brown in colour with a peneil or tuft of hairs at the hind end of the body. The eggs are laid round the twigs in bands or rows and embedded in the down or liairs from the hind tuft of the female. The egg bands somewhat resemble those of the Lackey, but are, of course, visibly smaller.

The caterpillar is yellowish green with a darker green line down the back, edged with yellow, and there are pale yellowish lines at the sides. It is more slender than the caterpillar of the Winter Moth, but is difficult to distinguish from it. The pupal or chrysalis stage is spent in the ground in a similar way to that of the Winter Moth.

The Mottled Umber Moth is about twice the size of the Winter Moth. The male has the forewings pale brown or brownish yellow banded and mottled with dark brown as is shown in Fig. 2, the hindwings being paler with a brown spot near their middle. The female is wingless, the yellow brown hody having two dark spots on every segment.

The moths normaliy appear from the first week in October to the middle of Decemher, but occasionally are seen in January or even February. The eggs are rather larger than those of the two foregoing species, somewhat longer in shape and rusty coloured. As many as 400 are deposited by one female.

The caterpillar when full grown is much larger than those of the Winter and March Moths and quite distinct in colour:ation, being chestnut brown (sometimes yellow brown) above and yellow on the sides and inderneath, with a wavy dark stripe on each side of the brown. When full grown it descends to the ground in a similar way to the other two species to form a chrysalis. It is the caterpillar of the Mottled Umber which contributes largely to the serious defoliation of oaks and other forest trees which in some years is so noticeable.

Natural Enemies.-The insects just described are subject to the attacks of numerous insect parasites, and birds also devour them in large numbers. It is possible that the fluctuations in numbers, which are so characteristic of Winter Moths may in part be due to the presence or absence of their natural enemies, but in any case it is clear that the fruitgrower. cannot depend on their aid for keeping the pests sufficiently in check.

Methods of Control.-Winter Moths may be controlled either by banding the trees in autumn to catch the wingless females as they ascend the trunks or by spraying the foliage in spring to kill the larvo. The former method is most in use and will be found effective in the case of standard 
trees where the bands can be placed from 3 to 5 feet above the ground. When the bands are placed low down, which is inevitable in the case of bush trees, a number of the moths usually find their way over the bands. How they do so is not altogether clear, but there seems no doubt that the male moths are able to carry the females for a short distance when pairing. Moreover in the case of bush trees the process of banding is somewhat troublesome and spraying is usually the better method to employ.

Where trees are often attacked by larvæ of the " Bud Moth" (Hedya ocellana) or of other moths with winged females, banding is not essential since it is then necessary to apply an arsenical spray in spring which controls moth caterpillars of all kinds including those of the Winter Moth.

(1) Banding. - The bands should be placed on the trees at the beginning of October and should be kept in a "tacky" condition until April. Winter Moths appear between October and January, but the majority are caught in November and early December. March Moths emerge in February and March, while during the latter month and in April the eggs of the Winter Moth hatch. Since some of the latter are likely to have been laid on the trunk of the tree below the band, the young larvæ must be prevented from ascending.

Various compositions for use in banding are on the market and growers will learn by experience which are best suited to their requirements. In general they fall into two classes, (1) those of an oily nature, (2) these which are sticky, like bird lime. The former are usually cheaper to buy but must be renewed about three times during the season, while the latter are more expensive, but one application should be sufficient. Greasy compositions must never be applied directly to the bark of the tree $\mathrm{Cr}$ serious injury may be caused. This warning also applies to many of the "sticky" compounds, though it is said that some of the latter are harmless. Unless the grower has definite information as regards the particular compound he is about to use, it is wise to protect the bark by means of a paper band. Exceptions to this rule are old trees with a very uneren surface, since in these cases the paper band would not fit sufficiently closely to prevent the mothis from craivling undernenth.

A stout, grease-proof paper is usually used for banding purposes and it should be noted that good paper, though more expensive than bad paper, is the more economical in the end, since it will retain the grease in good condition much longer.

The paper band should be from 7 to 9 in. wide and should be firmly tied round the tree 3 to $5 \mathrm{ft}$. from the ground, by two pieces of string, each string being an inch or two from the edge of the paper. The best methods of applying the camposition to the band naturally vary with the class of substance used, but, in general, it should cover from 3 to 6 
in. of the band and should be so applied as to form hori-zontal ridges rather than a uniform smooth surface, since itwill then remain sticky for a longer period. Compounds which are thin and liable to run should be applied mainly to the upper part of the band so as to prevent the drops from running off on to the bark.

It is not always easy to make a neat job of applying the adhesive to the paper bands. If the selected substance be of a birdlime-like consistency the operator's hand is quite the best implement. The method is to " slap " the substance on to the band and draw the hand round the circle. If using the hands in this way be objected to, shaped pieces of wood may be obtained for the purpose.

A good material will retain its sticky qualities for many months, though it may be necessary to scrape the bands occasionally to expose a fresh surface to the air. The bands should be examined periodically to find whether they are still sufficiently " tacky " to fulfil their object, and a fresh coating of composition must be put on if necessary.

(2) Spraying.-Lead arsenate has been found most satisfactory for this purpose. It is usually obtained in the paste form, 4-5 lb. of paste being added to 100 gallons of water. The spray should be applied as soon as the leaves begin to appear (before the blossom opens) and, if necessary, a second application may be made after the petals have fallen, but in $n o$ case should lead arsenate be used on open blossom, owing to the danger of poisoning bees.

A nozzle giving a fine, misty spray is most suitable, and the foliage should not be drenched so that the liquid drops off the tips of the leaves. Lead arsenate may be used in conjunction with either Bordeaux mixture or lime sulphur if it is necessary to deal also with fungus diseases-as for instance Apple Scab. (see Leaflet No. 131) or Brown Rot (see Leaflet No. 86). *

(3) Forest trees such as oaks should never be allowed to overhang the margins of fruit plantations for Winter Moth caterpillars will fall off the oaks and crawl up into the fruit trees. As these caterpillars also feed on hawthorn and nut bushes in hedges, the hedges should be kept well trimmed. and it is a good plan to instruct workers when spraying with lead arsenic to give also a light dressing to the hedges whenever they reach the end of a row.

* Obtainable from the Ministry and also included in Sectional Tolume No. 1 , price $8 \mathrm{~d}$. 


\section{THE CODLNNG MOTH.}

\section{(Cydia pomonella, L.)}

(1)
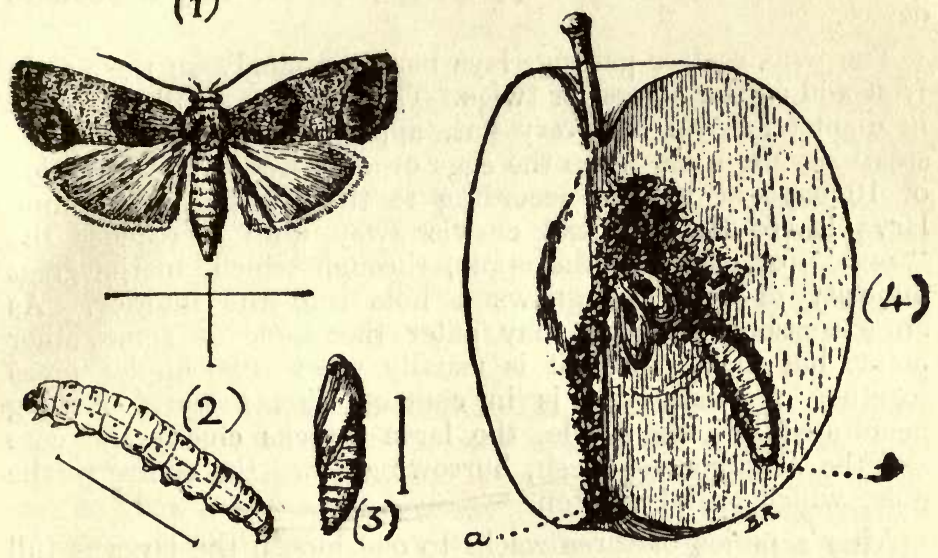

Fra. 1.-Codling Moth, enlarged. Lines showing natural size.

, 2.-Larva of ditto , " , , , " ,

,"3.-Pupa of ditto ", ", ,", , , ", ", ,

, 4.-Section of apple showing work of larva, which has entered at the eye, passed up the core by the burrow $a$, and is leaving the fruit at side at the point shown by letter $b$.

The Codling Moth is probably the most notorious of all apple pests and is to be found in almost every country in which apples are grown. The damage is caused by the larva which burrows into the fruit and so produces the worm-eaten or maggoty apple which must be familiar to everybody.

It must be noted, however, that there is a further pest, the Apple Sawfly (Hoplocampa testudinea), the larvæ of which damage the apples in much the same way as those of the Codling Moth, and it is very necessary to distinguish between the two, since the methods of control in the case of the Codling Moth are quite useless when employed against the Sawfly. An account of the Sawfly will be found in Leaflet No. 205, but the chief distinguishing features are also given below in the sections "Description and Life History of Insect" and "Nature of Damage."

Description and Life History of Insect.-The Codling Moth measures from $\frac{1}{2}-\frac{3}{4}$ inch in spread of wings and $\frac{1}{3}$ inch from head to tail (tip of abdomen). The fore-wings are dark grey with numerous waved brown lines giving the appearance of watered silk. Near the end (outer margin) of the wings is a brown patch which in certain lights has a coppery metallic lustre, the most characteristic feature of the moth. The hind wings are greyish brown often with a coppery tinge. 
Codling Moths emerge from the pupæ towards the end of May and may be found for a period of about three weeks. They fly at dusk and spend the day at rest on the trunk, branches or leaves of the apple trees, but are very difficult to detect.

The female after pairing, lays her eggs singly on the young fruit and on the leaves, or twigs. The eggs are small- $\frac{1}{25}$ jnch in diameter-oval and very flat, aprearing in fact more like small shining scales then the eggs of an insect. After a period of 10 days or longer, according to the weather, the young larva leaves the egg and crawls away until it reaches the " eye" (or calyx) of the apple, through which, in the great majority of cases, it gnaws a hole into the interior. As an exception the larra may enter the apple at some other point, but in this case it is usually where two apples press together or where one is in contact with a leaf. Having penetrated into the apple, the larva attacks chiefly the core and the neighbouring flesh, burrowing down the centre to the pips, which are also eaten.

After a period of three weeks to one month the larva is full fed. It then measures from $\frac{1}{2}-\frac{3}{4}$ inch in length and is pinkish or creamy white in colour with a brown head. It has three pairs of true legs and five pairs of "sucker" legs including the clasper-like pair at the " tail." There are therefore S pairs in all, and this feature will serve to distinguish it from the Apple Sawfly larva, which has ten pairs altogether. In general appearance the two larvæ are different, Sawfly larvæ being often dead white and rather plump, while the Codling larvæ are to some extent coloured and more slender, but these features are not constant and cannot be relied on.

On becoming full fed the Codling larva burrows its way out through the side of the apple, which may still be hanging on the tree or may have dropped to the ground. In either case the larva crawls away in search of some shelter in which to spend the winter, and for this purpose it often chooses a crack or crevice in the bark of the apple tree, though it may conceal itself in a dead leaf or in any other mbbish near by. Having chosen its position it spins a silk cocoon in which it remains as a larra until the following spring, when it changes into a yellowish brown pupa. Very occasionally the larra pupates in the summer and emerges as a moth in August, but this second brood is rare in Britain, though it becomes normal in the warmer climates of America. Then moths of a second brood are produced they give rise to larve which attack the apples in the same way as the first brood. though they often enter the fruit through the side instend of through the ere. As in the case of the first hrood they spin cocoons in which to pass the winter, pupating the following spring and producing moths in due course. 
Plants attacked and Nature of Injury.-The attacks of the Codling Moth are not confined to the apple. Pears at times suffer rather severely and the fruits of the quince, walnut, and of various wild species of Pyrus may also be damaged, though as regards these plants the pest is of little importance.

In the case of the apple, Codling Moth injury may usually be distinguished from that due to Apple Sawfly by the fact that the larva has entered through the eye and has confined itself mainly to the neighbourhood of the core, finally passing out by a burrow to the side. The Sawfly larva, on the other hand, usually both enters and leaves the apples by holes at the side (as opposed to the eye), while instead of attacking mainly the core region, it eats out a large irregular cavity in the flesh. In the case of Sawfly attack the decay produced is more rapid and the apple seldom attains any size, usually falling in June or July.

Distribution and Economic Importance.-The Codling Moth is an insect which has been able to adapt itself to practically every climate in which its chief host plant, the apple, can be grown, and since it is easily carried in infected fruit, it has now spread throughout the apple-growing regions of the world. It appears to have been known to the ancient Romans, and has certainly been long resident in Europe.

In Great Britain the insect is abundant in England and Wales, and occurs in Scotland and Ireland. Descriptions of its life history were made in the 18th century, and it is probably an old inhabitant of these islands, though its numbers have perhaps been reinforced by the introduction of larvæ in infested consignments of apples from abroad.

In Europe-that is to say, in countries in which it has long been resident-it is always a troublesome pest, but its attacks seldom attain the proportions which have marked its spread through America and Australia.

In the latter country, the moth has been made the subject of special legislation. with apparently good results. It is impossible to give any estimate of damage done in Britain by the Codling Moth, since confusion so frequently occurs between the Moth and the Sawfly. Further, the Codling Moth is most numerous in old orchards and gardens attached to houses, where little attention is paid to its ravages. In large commercial orchards it does not seem to be such a serious pest as is sometimes supposed, and this is explained by the facts, (1) that trees in modern orchards are kept very clean, (2) that spraying is carried out if necessary, (3) that there is usually anly one brood in the year. In America, where the annual loss from the Codling Moth has been estimated at no less than $£ 4,000,000$, it is the occurrence of more than one brood in the season which makes it such a dangerous enemy.

There are several insect parasites of the Godling Moth, and birds also devour great numbers of the hibernating larre, but 
it does not appear that these natural enemies are alone capable of keeping the pest in check and recourse must therefore be had to artificial measures of control.

\section{Methods of Control.}

A.-In Orchards where Spraying can be practised-(1) If the trees are covered with moss and loose bark they should be cleaned by means of an alkaline winter wash (see Lreaflet No. 70,* The Renovation of Neglected Orchards). This will the number of eracks and crevices in which they can spin their cocoons.

(2) The trees should be sprayed with lead ar'senate just after the petals have fallen. It will be found that there is a period of from 7.14 days during which the calyx cup, subsequently the eye of the apple, is open, while later it closes. The object in spraying is to force the arsenate into the calyx cup, where it is retained after the calyx closes, with the result that any Codling larva which attempts to "burrow through the " eye " of the apple is poisoned. It is useless therefore to spray too late, when the calyx cup is closed, for then the poison cannot reach the point at which ic will be needed, but it is also necessary to wait until the blosson has completely fallen to avoid poisoning the bees. A nozzle giving a fine spray is usually used and the spray should be directed as much as possible on to the young fruitlets. $1 \mathrm{lb}$. of lead arsenate paste should be allowed to every 20-25 gallons of water, or the water may be replaced by a similar quantity of Bordeaux Mixture if it is desired to control fungus diseases as well. The lead arsenate spr'ay in addition to checking the Codling Moth will also destroy any leaf-eating caterpillars, such as those of Winter Moths, which may be present.

B.-In Orchards where Spraying is impossible.-(1) The trees may be banded in Junet with old frayed sacking, folded paper or ropes of hay. If possible, two bands 4-6 inches wide should be used on each tree, one just below the junction of the branches with the trunk and the other a few inches from the surface of the ground. The upper band will catch those larvæ which crawl down the branches, while the lower will arrest those which fall from the tree and crawl back to the trunk. A single band is fairly effectire and may be placed at any convenient height on the trunk, which must be cleaned as far as possible (see Section 3 below). The bands must not be made "sticky." The larvæ on leaving the fruit are likely to make their cocoons in the folds of the sacking or in the hay, and the bands must therefore be burnt in the autumn after the apples have been gathereal.

* Obtainable from the Ministry.

t If bands are applied at the end of May or rery early in June, they will also trap Blossom Weevil. 



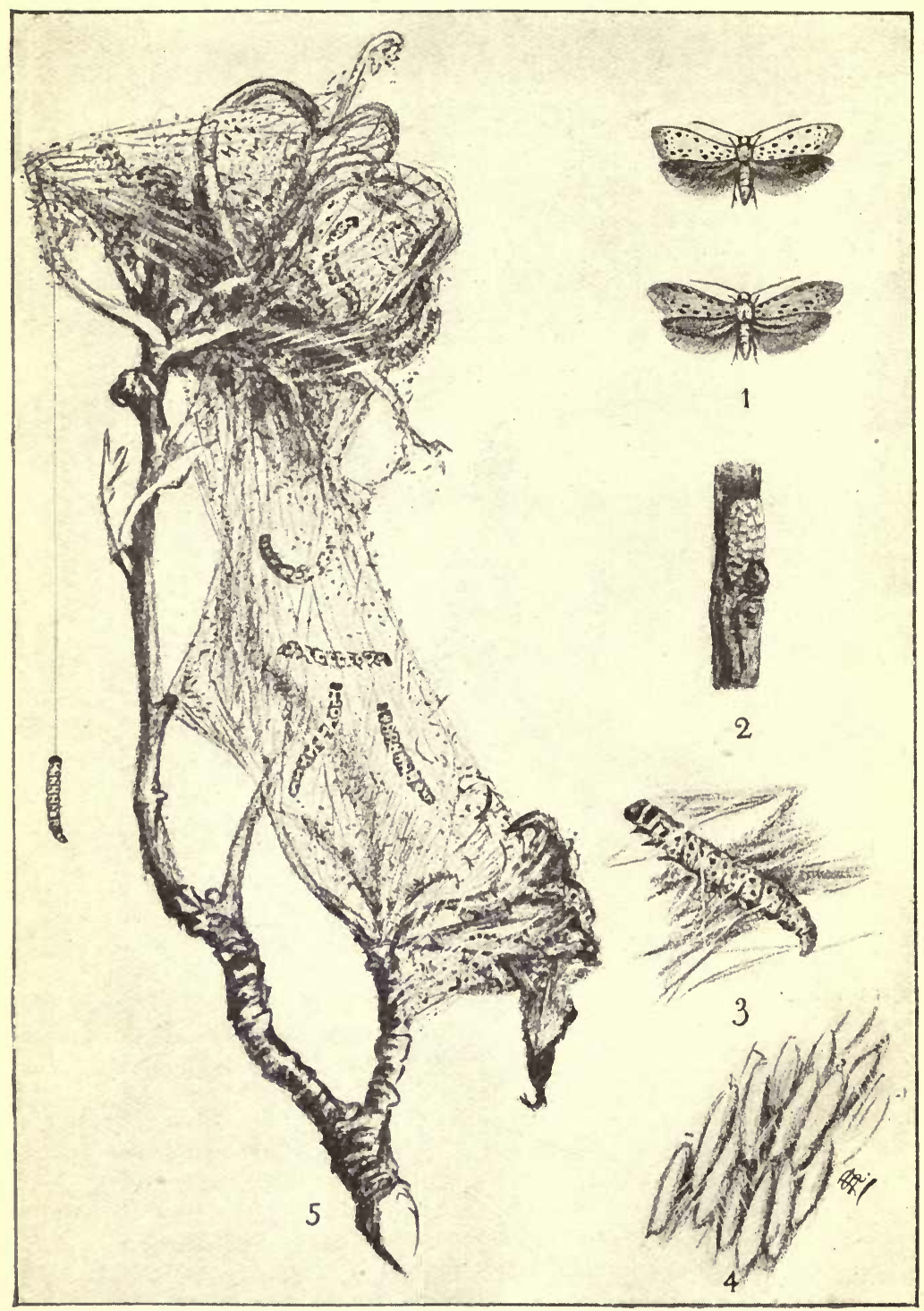

1. Smali, Ermine Mo'th (Hyponomeuta padellus). 2. Egg mass. 3. Caterpillar. 4. Cocoons. 5. Apple shoot with web. 
(2) All fallen fruit should be picked up and disposed of in such a way as to kill any larvæ inside. Attacked apples should be separated from the others when they are picked and if unfit for cooking should be given to the pigs or otherwise dealt with so as to destroy any larvæ which they may contain.

(3) All rubbish near the trees should be cleared away and burnt. Without spraying it is often possible to clean the trees somewhat by pruning out all dead wood and scraping off loose bark and moss.

\section{THE SMALL ERMINE MOTHS.}

(Genus Hyponomeuta.)

The name "Small Ermine Moths" is given to a group of little moths which are often of considerable importance to the fruit grower. They are present in almost every orchard or garden throughout the country, and where no stens are taken to keep their numbers in check they are capable of doing very serious damage. Outside the British Isles Sinall Ermines are known as pests in practically every European country and also in Japan. Recently one of the more harmful species has been introduced into the United States of America, where efforts are being made to stamp it out.

Technical Note.-There are several species of Small Ermine Moth in the British Isles, but this leaflet is chiefly concemed with one or more, which for the present may be dealt with under the name Hyponomeuta padella $\mathrm{L}$. and will include forms often referred to in literature as $H$. malinella $\mathrm{Z}$. and $H$. variabilis $Z$. It is doubtful whether the true $H$. malinella has proved injurious in this country, though it is said to occur on crab apple. A further species, $H$. evonymella (cognatellat Hb.), may also receive brief mention as it is sometimes most injurious to spindle (Euonymus) hedges.

Plants attacked and Nature of Injury.-The Small Ermine (H. padella) is most harmful to apple trees and bawthorn hedges, but it also attacks pear, plum, cherry, mountain ash and other allied plants. The injury consists in the destruction of the leaves by the Ermine caterpillars, which in a bad attack completely defoliate the tree, leaving only bare twigs and a few shrivellel brown leaves spun together by a dense web of silk. As a result, apples usually fall from the. trees when still young, and, although new leaves are produced before the end of the season, the trees are seriously weakenerl and the chances of obtaining a crop the following year are much reduced. The injury to hawthorn hedges (and alsa to Euonymus hedges by $H$. evonymella) is similar, and while there is no loss of fruit, the leafless hedges in summer are rery unsightly; if the attack occurs for two or more years 
in succession portions of the hedge are likely to die out. In the case of both apple and hawthorn the injury is at its worst in "uly.

Description and Life-History.-Small Ermine Moths are about one-third of an inch in length and about three-quarters of an inch in spread of wings. In colour the fore wings are white or grey with a number of black dots; and the hind wings are of a uniform grey. The moths appear at the end of July and in August and lay their eggs on the twigs or small branches of the apple or hawthorn. The eggs are flat and are laid many together in small scalè-like masses, each egg being firmly cemented to the next. These egg-masses are so slightly raised above the surface of the twig and are so nearly of the same colour that they are not easily detected. In September minute caterpillars are hatched from the eggs, but during the winter remain under the egg shells which form a protection over them. In the early spring they crawl out and bore into the buds and later mine into the growing leares. As the foliage develops they feed on the surface of the leaves, spinning two or three together to form a nest.

Towards the end of May and in June the work of the caterpillars becomes more evident, and colonies may be found living in large webs spun between the leaves and twigs, the leaves being eaten and fresh leaves drawn in to serve as food. Gradually the whole branch or even the whole tree may become envelored in a dirty ragged web, and practically every leaf may be devoured. Each web appears to be full of little black caterpillars which wriggle rapidly backwards and forwards, and if disturbed often fall down suspended by a silken thread.

When nearly full grown the caterpillars measure about half an inch in length and are dusky grey in colour with black spots.

In July the caterpillars are full grown and spin cocoons, often many together, in which they turn into chrysalides. The moths appear some three week's after, and the life-cycle begins again.

The above account of the life-history refers in the main to the Eirmines on apple, hawthorn, plum, \&c., but there are one oritwo curious points which are worthy of mention. In the first place the cocoons of the apple-fed caterpillars are formed of dense white silk, and are often spun together in definite rows: On the other hand the chrysalides of the hawthormfeeders are suspended almost at random in the webs and are enclosed in very slight and flimsy cocoons which hardly serve to hide the chrysalides. Secondly, the apple-feeders produce higll proportion of moths with white fore wings, while those irom hawthorn are either white or grey-more often, perhaps, the latter: colour. 
The facts are somewhat suggestive of the presence of two distinct forms, and it is important from the practical point of view that the matter should be decided. If there is only a single species, then the grower who wishes to clear his orchard should treat any surrounding hawthorn hedges as well as his apples. If, on the other hand, there are two species, a severe infestation on the hedges need not necessarily be regarded as a danger to the apples.

The Euonymus-feeder in its life-history does not differ widely from that just described, but the insect is quite distinct, and indeed never feeds on either apple or hawthorn. The moths always have pure white fore wings with very conspicuous black spots, and are somewhat larger than those of the applefeeding species.

Natural Enemies.-Ermine Moths are attacked by a number of species of Ichneumon Fly, such as Angitia majalis Grav., and Herpestomus brunneicornis Grav., the larvæ of which feed inside the Ermine caterpillars. They are also devoured by starlings and probably by other birds.

Methods of Control.-1. The most satisfactory treatment is to spray the affected trees or hedges with lead arsenate $(1 \mathrm{lb}$. lead arsenate paste in 20 gallons of water) soon after the blossom is over. The object is to cover the leaves with a fine spray of lead arsenate which will sooner or later be eaten by the caterpillars, and will poison them. It is useless to wait until serious damage is apparent, for then not only has considerable loss of fruit and foliage already occurred, but also the dense web prevents the spray from reaching those leaves which are left. Provided the webs are small, however, and there is much clean foliage, it is still worth applying the spray, in order to prevent further injury. It is not certain how early the spraying can be done, but it is probable that, many of the caterpillars will be destroyed even if the lead arsenate is put on just before the blossom opens. In no circumstances should the spray be applied to open blossoms.

Lead arsenate is poisonous to man, and must therefore be used with care.

2. It is possible though it does not appear to have been proved - that a winter wash would destroy the young larvæ under the egg scales. In addition to the caustic washes given in the Ministry's. Leaflet No. 70 (The Renovation of Neglected Orchards), paraffin emulsions and miscible oils are worth a trial. Miscible oils must be bought from a manufacturer, and be diluted in accordance with his instructions.

A paraffin emulsion for winter use may be made as follows :-

$\begin{array}{llllll}\text { Paraffin } & \ldots & \ldots & \ldots & \ldots & 1 \text { gallon. } \\ \text { Soft soap } & & \ldots & \ldots & \ldots & 1 \frac{1}{2}-2 \text { lb. } \\ \text { Water } & \ldots & \ldots & \ldots & \ldots & 10 \text { gallons. }\end{array}$


Dissolve the soap in boiling water, using up to $2 \mathrm{lb}$. if the :water is at all hard. Remove from the fire, and, while still very hot, add the paraffin and mix thoroughly by syringing the liquid back into itself with a hand syringe. Thorough mixing is important if a good emulsion is to be obtained.

Any of the above winter washes should be sprayed on to the trees so as to wet thoroughly the twigs and branches.

\section{THE APPLE SAWFLY.}

(Hoplocampa testudinea, Klug.)
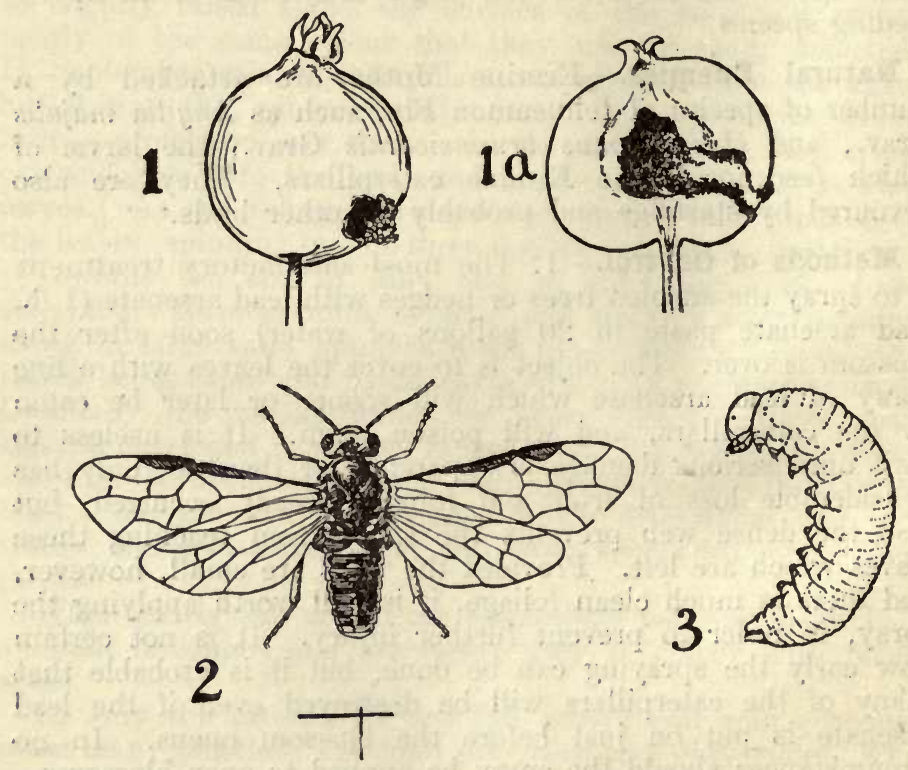

The Apple Sawfly, though a serious pest in many parts of the country, frequently passes unrecognised since the injury it causes resembles in many ways that of the better known Codling Moth (Cydia pomonella). (See Leaflet 30.) It is necessary, however, to distinguish between the two insects since some of the measures of service in the control of the Codling Moth are useless in the case of an attack by the Apple Sawfly. The essential differences are given under the headings "Description " and "Nature of Damage."

The Apple Sawfly is widely distributed in England and it has been reported as injurious in parts of Scotland and Ireland. In Continental Europe it has been recorded from Sweden, Germany, Holland and France. 
Description.-Adult Sawfly.-The general shape and appearance of the adult may be seen from Fig 2. In colour it is reddish yellow, with the top of the head, the thorax between the wings and the upper side of the abdornen, black. It measures about $\frac{1}{4}$ inch in length and about $\frac{5}{8}$ inch in spread of wings.

Larva. - The form of the larva is shown in Fig. 3. In colour it is usually white or cream, but, according to Theobald, pink specimens sometimes occur. When first hatched the head is black and there is also a black plate over the anal (or " tail ") segment, but later the head becomes light brown and the tail plate greyish. There are ten pairs of legs and this character may be used to distinguish the Sawfly larva from that of the Codling Moth. In Sawfly larvæ it will be found that there are three pairs of true legs directly behind the head, which are followed by seven pairs of " sucker" legs including the clasper-like pair at the tail. The Codling Moth larva also possesses the three pairs of true legs but there are only five pairs of sucker legs. The general appearance also of the Sawfly larva differs from that of the Codling Moth and when the two larvæ have once been definitely identified by the character given above they will afterwards be known at a glance.

Cocoon.-The larva pupates in the ground in a yellowish silken cocoon to which grains of earth are attached.

Life-History.-The adult Sawflies leave the cocoons at the end of April and in May, appearing during the period in which the apple is in flower. They may then be found on bright days sitting on the blossoms. The eggs are laid on the flower below the calyx, one egg only being placed on each blossom. After a period varying from a week to a fortnight the egg hatches and the young larva burrows into the developing fruitlet and eats out a large cavity in the interior (Fig. 1a). This cavity communicates with the exterior by means of a small hole through which wet frass exudes, thus indicating the attacked fruitlets (Fig. 1). The larva may require more than one fruit for its support and it may, therefore, leave the original fruit on which the egg was laid and crawl away to attack others. After from four to six weeks the larva is full fed and it then leaves the tree and spins a cocoon in the soil at a depth varying from 1 to 4 inches. The attacked fruits seldom grow to any size, and the majority usually fall off in July. Some of the larvæ remain in the fruits until they fall, but most have become full fed and have left before then. The pupæ normally remain until the following spring before the adults emerge, though occasionally there is said to be a small second brood in July.

Nature of Damage. - The actual loss in fruit is too obvious to need further remark, but a note may be given as to 
the distinguishing features between the injuries caused by Sawfly and those due to Codling Moth. The Sawfly larva enters through the side of the apple and eats out a large irregular cavity. The Codling Moth larva enters through the "eye" and tunnels down through the core, feeding mainly on that portion of the apple; it then mines a hole to the exterior through the side of the fruit. The large irregular cavity is, therefore, characteristic of the Sawfly, while the tunnel down the core is usually the work of the Codling Moth. A further form of injury attributed to the Sawfly consists in curious ribbon-like scars sometimes found on the skin of the apple. These scars are said to be made by the Sawfly larvæ in their efforts to bite a way in through the skin.

Methods of Control.-No practical measures for the control of this insect have yet been discavered. Spraying with lead arsenate or Paris green have been tried without success, the failure being probably due to the fact that the larva enters through the side of the fruitlet and not through the "eye." In the case of the Codling Moth sufficient poison is retained in the eye to poison the young larva. Deterrent sprays against the adult Sawfly have not proved of much use. The measures which have been found of service are as follows, but they are suited to small gardens rather than to fruit-growing on a commercial scale:

(1) All attacked fruits should be picked off the tree and destroyed before the larvæ have left them.

(2) Poultry allowed to run under the trees during June will destroy the larvæ as they go to the soil to pupate.

(3) By thoroughly working the soil under attacked trees some of the pupæ may be exposed to the attacks of birds while others may be injured in the process or prevented from emerging.

\section{BARK BEETLES AND SHOT BORERS.}

Fruit trees such as apples and plums frequently suffer from the attacks of beetles which bore into their trunks, branches and twigs, causing in the case of serious infestations the death of part of or even the whole of the tree. The most common species is the Bark Beetle (S'colytus rugulosus), but the Shot Borer Beetles (Xyleborus dispar and X. saxeseni), though less common, cause a more serious form of injury.

\section{Bark Befties (Scolytus rugulosus, Ratz.).}

Trees Attacked and Nature of Damage.-The fruit tree most often damaged is the plum, but the beetles are also found on apple, pear, cherry, apricot, peach and quince, and among wild plants on hawthorn, bird cherry and mountain ash. In 
the case of an infested plum tree it will usually be noticed that some of the twigs or smaller branches are dead and that numerous holes-about the size of a No. 8 shot-have been bored through the bark which peels off disclosing little tunnels that have been made between the bark and the wood (Fig. 6). Further search will probably reveal twigs not yet dead and with a few holes only. On peeling the bark off such a twig fresh borings containing beetles or grubs according to the season will be found. Twigs damaged in this way usually die and the infestation, if it becomes serious, no longer remains confined to the twigs but extends to the larger branches and even to the trunk itself, channels being driven between the wood and the bark, or in the latter only if very thick. The entire tree may thus be killed. The nature of the attack on apple and the other trees is substantially the same as that on plum, though it more seldom assumes serious proportions.

Description and Life-History.-The adult beetles are brownish-black insects of the form shown in the illustration (Fig. 5b). In size they vary considerably but are usually about one-sixteenth of an inch in length. During warm weather in spring the beetles leave their burrows, flying away in search of fresh trees to attack. On discovering a suitable tree the female selects a twig or branch and bores a hole vertically through the bark. It then turns and bites out a tunnel or brood chamber $\frac{1}{4}-\frac{1}{2}$ in. in length along the branch between the bark and wood, laying eggs on each side as it goes. From the egg a small white legless grub is hatched (Fig. 5a, much enlarged), which at once begins to burrow a channel of its own, passing first at right-angles to the brood chamber and then, when clear of the latter, turning to right or left up or down the branch. The grub feeds on the inner bark just next to the sap wood and goes burrowing on until full-grown when it bites a small chamber, usually just in the sap wood, and changes to a pupa. After spending a period as a pupa, it turns to an adult beetle and bores its way out through the bark to the outside, each beetle making its own flight hole. The presence of many holes therefore shows that a brood has already hatched out. Fig. 6 shows a piece of a small plum branch of which most of the bark has been peeled away. The very black tunnels are the brood chambers from which smaller channels pass to right and left getting gradually larger and ending at a hole underneath which is the pupal chamber and through which the adult beetles reached the outside of the branch. It is difficult to say how many generations there are in the year, but there are probably two main broods, the first appearing in spring and the second in summer. The descendants (Iarvæ) of the second brood may in hot summers feed up rapidly and give rise to yet a third generation of adult 
beetles, but most of them probably feed more slowly spending the winter in the twigs and producing the first brood of the following year.

Other Species of Bark Beetle.-A slightly larger kind of Bark Beetle (Scolytus pruni, Ratz.), though rare, is occasionally found in old apple and pear plantations, working in much the same manner as the one above ( $S$. rugulosus), though preferring the larger branches and trunk. It seldom seems sufficiently numerous to be injurious. A further kind of Bark Beetle (Scolytus destructor, Oliv.) is found on elms, to which it may be most harmful. It is only mentioned here as the question is sometimes asked as to whether infested elms are a danger to fruit trees. So far as is known this is not the case as the Elm Bark Beetle does not live in any kind of iruit tree.

\section{Shot Borer Beetles.}

\section{(Xyleborus dispar, Fab and X. saxeseni, Ratz.)}

Trees Attacked and Nature of Damage.-Both species of Shot Borer attack a great variety of trees including plum, apple, pear, oak, sycamore, chestnut and (abroad) conifers, but in this country the plum appears to suffer most injury. In contrast to the Bark Beetles, Shot Borers work in the hard wood, leaving the bark untouched except for an occasional small circular hole showing where the beetles first entered. In further contrast to the Bark Beetles is the remarkable fact that both Shot Borers and their grubs feed primarily, not on the wood itself but on a form of fungus which grows on the walls of their tunnels (possibly also on the sap which oozes into them). As the colonies of beetles are large in number they naturally require extensive burrows and the damage is correspondingly great, the wood being so tunnelled as to weaken or even kill the tree.

The two species of Shot Borer may be known by the shape of their borings. The common Shot Borer ( $X$. dispur) always makes circular burrows such as might have been drilled with a tool. The first hole is bored in through the bark and from $\frac{1}{1}$ to $\frac{1}{2}$ in. into the wood. It then turns to right or left round the branch following a growth ring and from this burrow still more are made rassing up or down the branch parallel with its length. The holes throughout are circular and of approximately the diameter of the beetles themselves. Fig 4 shows a section of a branch cutting through both vertical and horizontal channels. In the other species-sometimes called the Flat-Celled Shot Borer $(X$. saxesen $i)$ - the first tunnel passing in through the bark into the wood is also round. but once into the hard wood the burrows are extended up and down so as to make large flat cavities or slits ahout one-sixteenth of an inch in depth and $\frac{1}{2}-1$ in. in length and breadth. Fig. 2 
shows a section of a branch cut to show these cavities both from the side and from the top. Possibly on account of the size of these burrows, this species seems to prefer larger. branches (or trunks) than the ordinary Shot Borer.

In both species the walls of the burrows are stained by the fungus-black in the case of the ordinary Shot Borer, brown or partly brown in the Flat-Celled Borer. In each case the stains extend in the wood for some distance from the burrows so that a branch cut off even at a point where it appears to be sound may show a characteristic brown stain.

Description and Life-History.-(a) Shot Borer Beetle (Xyleborus dispar). The adult beetles are small black-brown insects, the female (Fig. 3a) about $\frac{1}{4}$ in. in length and the male (Fig. 3b) much shorter. In spring the female bores into the tree and lays eggs in the burrows. White legless grubs are hatched from the eggs and feed on the fungus on the walls of the borings, and also perhaps on the exuding sap. On becoming full-fed these grubs turn to pupæ and then ta adult beetles, which may be found packed so tight in the galleries (just like shot) that it is incredible how each beetle finds enough to feed upon. These beetles again carry on the work of lengthening the burrows in which the winter is spent. It seems uncertain whether there is more than one generation in the year. On the Continent two have been recorded, but in England there is possibly only one main brood. Males are very rare in the burrows except in winter when they may outnumber the females. Unless therefore the females can lay eggs without pairing, most of them would be forced to wait until late autumn or winter before breeding.

(b) The life-history and appearance of the Flat-Celled Borer (Xyleborus saxeseni) is substantially the same as that of the Shot Borer but the beetles themselves (Fig. 1) ard much smaller and there is not the marked difference in size and shape between the sexes. Again there is some doubt as to the number of generations in the year, but as a rule beetles of both sexes and grubs of different ages may all be found together in the large flat brood chambers, and there may well be two broods each year.

\section{III: Methods of Control.}

II the case of both Bark and Shot Borer Beetles, control measures are preventive rather than remedial, and the same remarks apply more or less to all.

1. There is no doubt that trees in an unhealthy state, either because of the attacks of other pests or because of unsuitable conditions, are preferred by the beetles, probably because they are not hindered in their burrow-making by too free a flow of sap. Thus a bad attack by Aphides or Brown Rot on plums, with the resulting weakening or death of twigs, is very likely to cause an increased infestation by Bark Beetles. In 
the same way trees planted under conditions which cause them to suffer during a spring drought may fall victims to the Shot Borers, which can obtain a foothold during the time when the trees are in a temporarily unhealthy state. It is obvious, therefore, that the first line of defence is to keep up a high standard of health by generally recognised measures.

2. Although the dying tree is in an ideal condition for the beetles, it becomes unsuitable when it has died and the wood has dried up, with the result that first the Borer Beetles and then the Bark Beetles are compelled to desert it. The insects must then seek other quarters, and if very numerous they may be compelled to attack not only sickly but also healthy trees which fall victims solely because their enemies are in such overwhelming numbers. It is therefore most important to cut down and clear away all dying and badly damaged trees or branches, burning them even if it is necessary to use other dry wood to avoid delay in destruction. If they cannot possibly be burned they should be carted far away from the orchard. The beetles will come out freely for some time from trunks and branches left lying about, for such wood does not dry sufficiently rapidly to kill the brood inside. The best time to fell is during the first half of autumn for the insects will not leave during the winter and there is thus time to get the wood burned. All infested wood should have been disposed of by March at latest.

3. In certain cases trapping may be useful against Shot Borer Beetles. For instance after all badly affected trees or branches have been burned, there may be left a number slightly attacked which it is desirable to save. In order to give such trees as good a chance as possible beetles which come out in the spring and are in search of fresh quarters may be trapped. This should be done by providing them with wood in an attractive condition-as for instance, freshly cut oak posts or plum trunks (unaffected by beetles) which may be available owing to thinning or replanting with better varieties. The use of the stumps from which affected trees have been cut has also been advised for trapping purposes. Whatever may be used the traps should be in position by March, and should be removed and burned about midsummer.

4. Various preparations have been advised for brushing on to the trunks and branches of trees attacked by Shot Borers. They may either be of such a nature as to deter beetles from beginning an attack or they may be intended to kill the fungus in the burrows (upon which they feed). As the application of these preparations is a difficult business in commercial orchards and as the preparations themselves are more or less experimental, no formulæ are given here but they can be supplied if desired. It is suggested, however, that lime-wash properly applied would have a considerable deterrent effect on beetles in search of trees in which to start a burrow, and as such 
(reatment is valuable against several other pests, a trial will uot in any case be wasted.
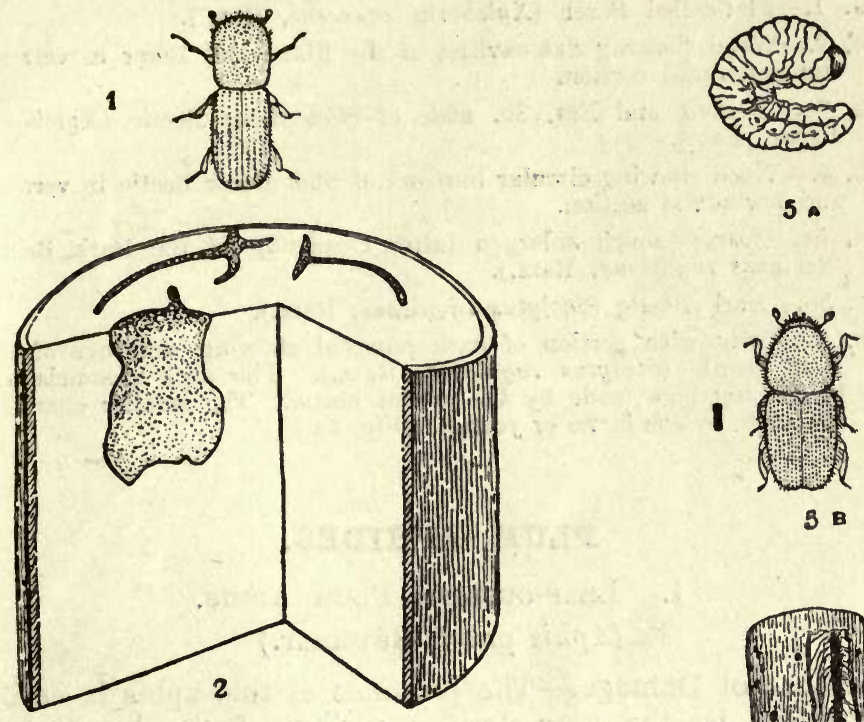

5 .
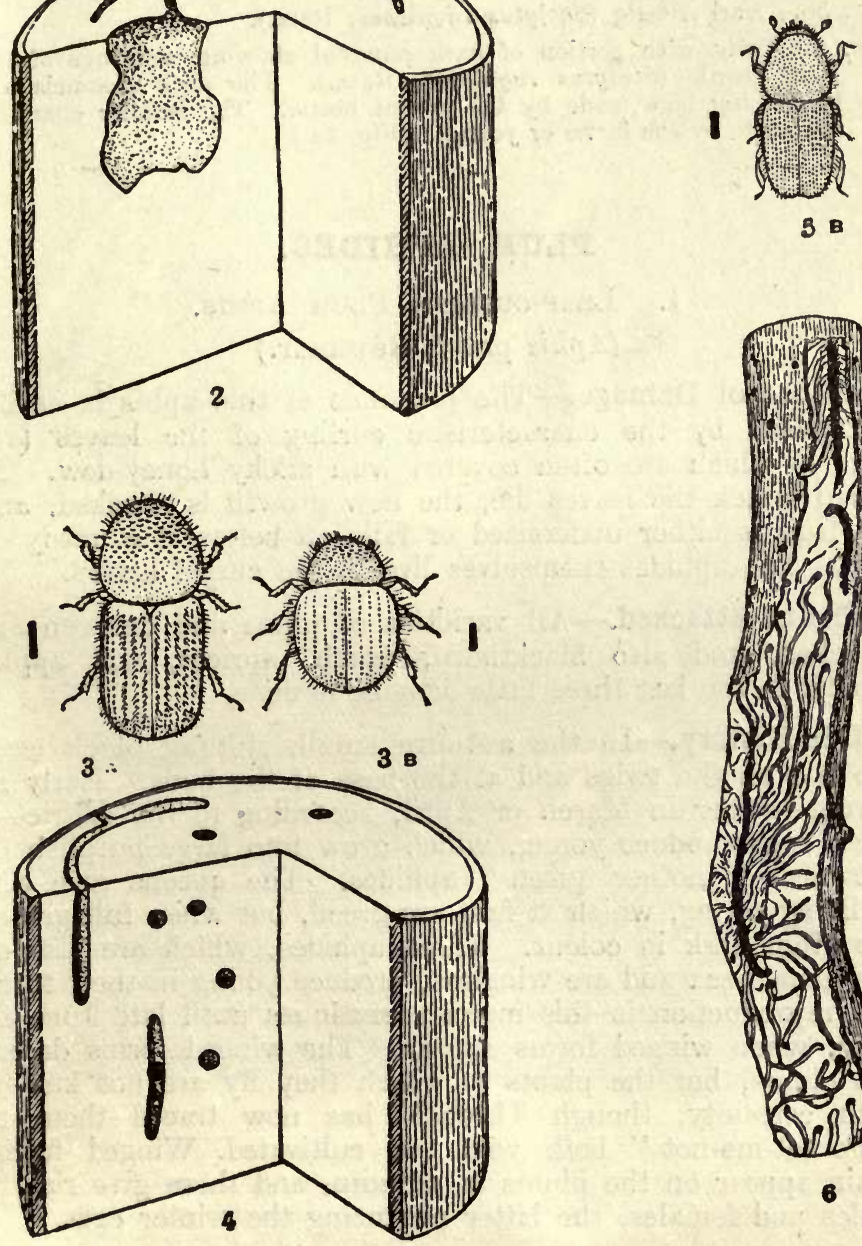

BARK Beftles \& Shot Borers.

[For Description of Plate, see next page.] 


\section{Description of Plate.}

Frg. 1.-Flat-celled Borer (Xyleborus saxeseni, Ratz.).

FIG. 2.-Wood showing flat cavities of the Flat-celled Borer in vertical and horizontal section.

Fic. 3a.-Female and Fic. 3b. male of Shot Borer Beetle (Xyleborus dispar, Fab.).

FIG. 4.-Wood showing circular burrows of Shot Borer Beetle in vertical and horizontal section.

Fig. 5a.-Larva-much enlarged (after Ormerod)-of the Bark Beetle (Scolytus rugulosus, Ratz.).

Fig. 5b.-Bark Beetle (Scolytus rugulosus, Ratz.).

FIG. 6.-Twig with portion of bark removed showing workings of the Bark Beetle (Scolytus rugulosus, Ratz.). The dark channels are brood chambers made by the parent beetle. The smaller chanriels are made by the larvæ or young. (Fig. 5a.)

\section{PLUM APHIDES.}

\section{Leaf-curling Plum Aphis. (Aphis pruni, Réaumur.)}

Nature of Damage.-The presence of this aphis is easily recognised by the characteristic curling of the leaves (see Fig. 1) which are often covered with sticky honey-dew. In a bad attack the leaves die, the new growth is checked, and the fruit is either undersized or falls off before it is ready to pull. The aphides themselves live in the curled leaves.

Plants Attacked.-All varieties of plum and damson are attacked, and also blackthorn, peach, apricot, and apple, though to the last three little damage is done.

Life-History.-In the autumn small, shining black eggs are laid on the twigs and at the base of the buds. Early in spring - either in March or April, according to the districtthese eggs produce young, which grow into large purplish or brownish "mother queen" aphides. The queens give rise to living young, which at first are green, but when full grown are often dark in colour. These aphides, which are also of the female sex and are wingless, produce young in their turn, and reproduction in this manner continues until late June or July, when winged forms appear. The winged forms desert the plums, but the plants to which they fly are not known, with certainty, though Theobald has now traced them to "Forget-me-not" both wild and cultivated. Winged forms again appear on the plums in autumn, and these give rise to males and females, the latter producing the winter eggs.

Natural Fnemies. - The plum aphis is attacked by ladrbirds, lacewing and syrphid flies, as well as by minute 


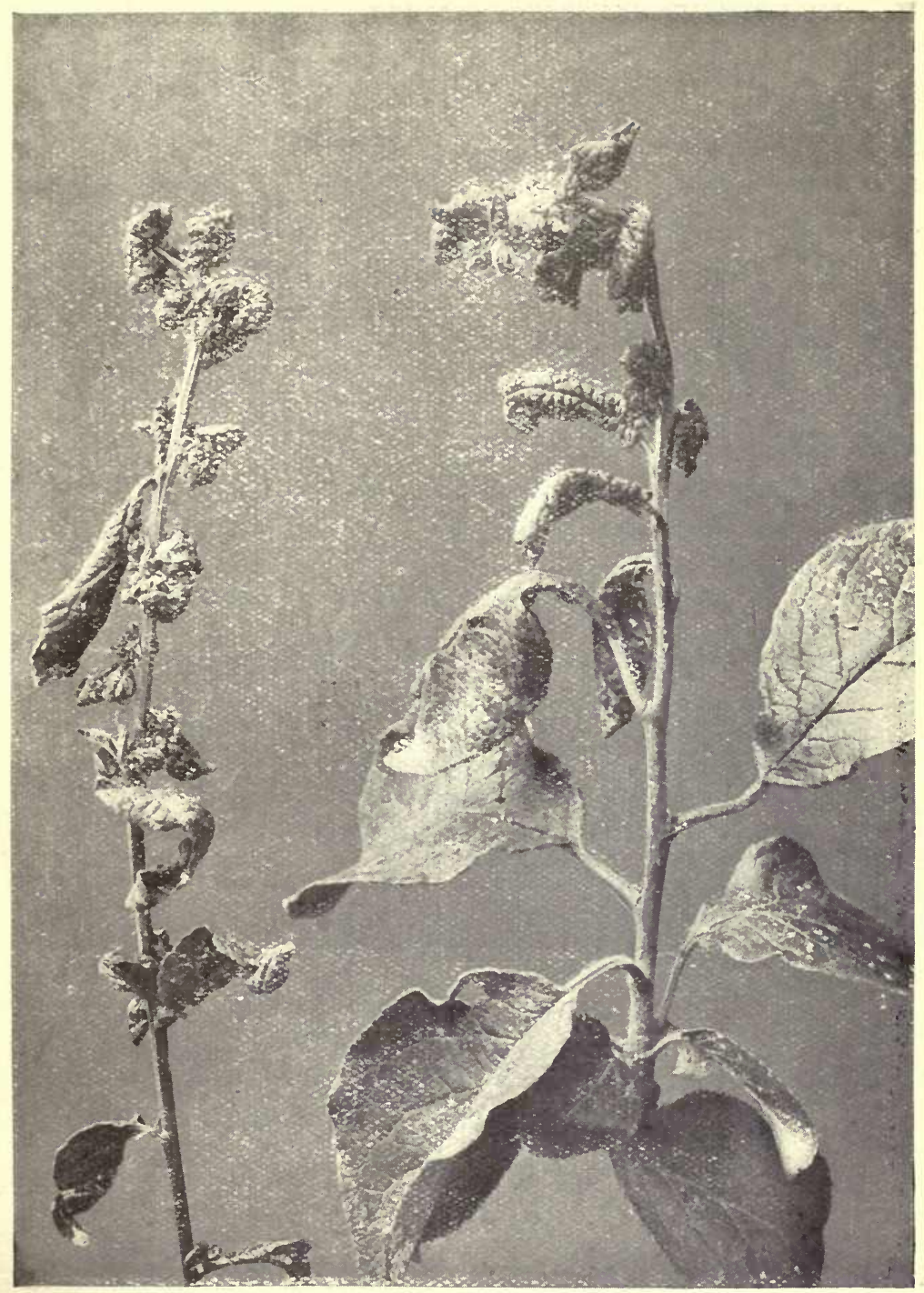

Photo]

Leaf Curlung Plum Aphis.

[R. A. Mailby.

FIG. 1.-Plum twigs attacked by aphides. The upper leaves have been curled by the Leaf-curling Plum Aphis; the lower leaves show the presence of a few Mealy Plum Aphides. 


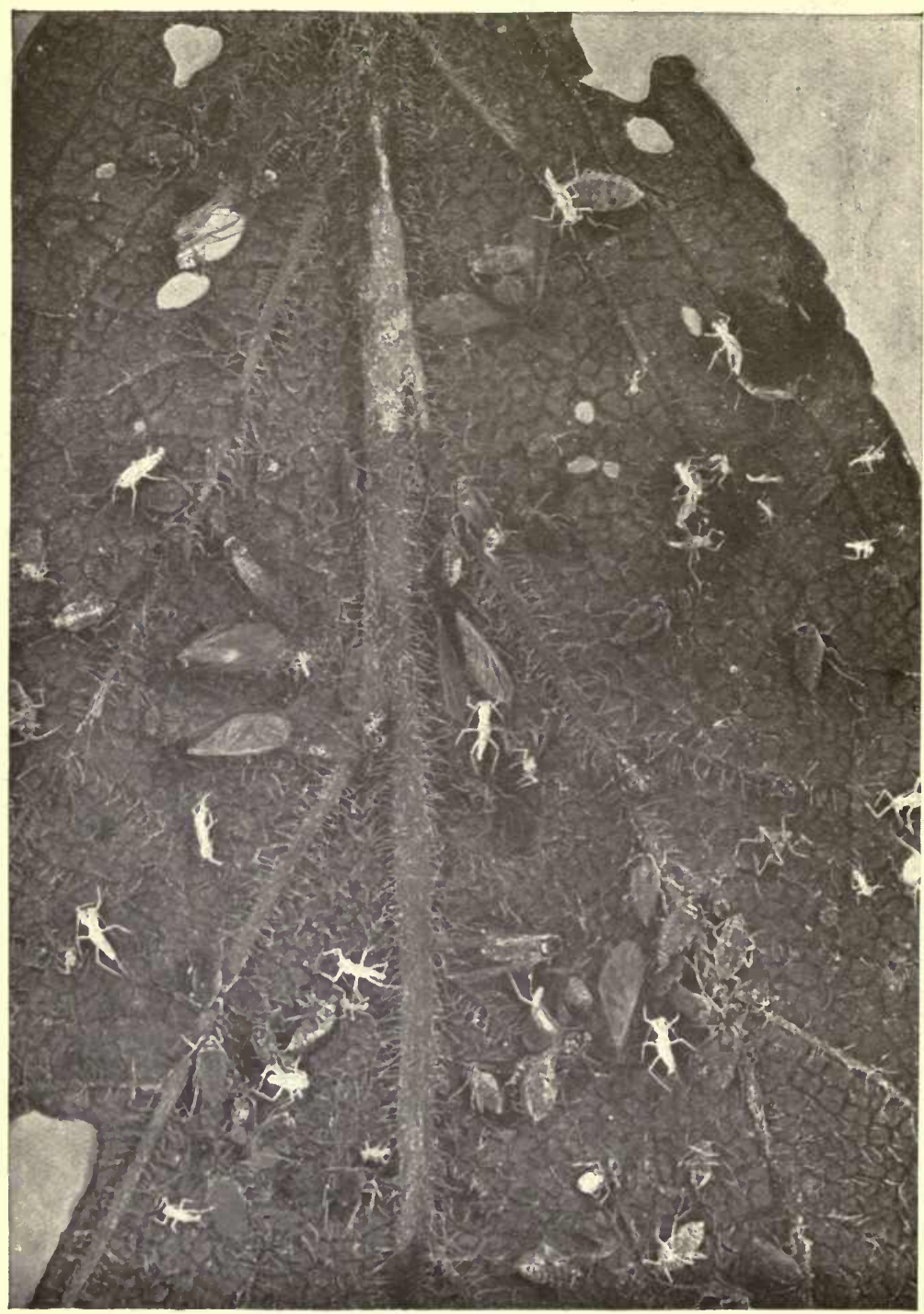

Photo]

[R. A. Malby.

Me.Ai.y Pi.um Aphis.

Fig. 2.-Plum leaf (greatly magnified) attacked by the Mealy Plum Aphis, showing winged and wingless forms and also cast skins. It will be noticed that the leaf has not been curled. 
hymenopterous parasites, but these natural enemies do not as a rule become very numerous until the aphis attack is at its height. It must not be thought, however, that they do no good, since by killing off vast numbers of the aphides they tend to prevent a severe attack the following year.

Measures of Control.-This aphis can be controlled by spraying, but it is of the utmost importance to spray early in the season. When the leaves have once been curled little can be done. Lime-washes applied in late Februảry or March have been found effective, the later applications giving the best results. The aphides may also be controlled by means of contact insecticides, such as nicotine and soft soap, quassia and soft soap, or paraffin emulsion, the spray being applied just before the blossom opens or after the petals have fallen, but, in the latter case, before the leaves have been curled. A close watch is required in order to discover the attack in its early stages.

\section{Mealy Plum Aphis. (Hyalopteruis pruni, Fab.)}

Nature of Damage.-Although serious damage is sometimes reported as being due to this aphis, it is, as a rule, far less harmful than the Leaf-curling Plum Aphis. It is seldom abundant on the plums before midsummer, and is found on the underside of the leaves, on the leaf stalks and young growth, but it produces no curling of the leaves (see Fig. 2). It secretes abundant honey-dew, however, which, falling on the leaves and fruit, may do corisiderable damage.

The insect may be recognised by its light green colour, by the waxy or mealy secretion with which it is covered, and by the fact that it occurs late in the season and does not curl the leaves.

Plants Attacked.-This aphis attacks plums of various kinds, greengages, damsons, peach, nectarine, apricot, and other species of Prunus. It is very probable that it also lives on reeds and grasses.

Life-History. - The eggs of the Mealy Plum Aphis are laid on the plum twigs in the autumn and do not hatch until the end of April or the beginning of May in the following year. "Mother queen " aphides hatch out from these eggs and commence to give birth to wingless females which in their turn give rise to additional wingless females. It is not until the middle or end of June that winged forms are produced, and while some of these probably migrate to grasses or reeds, others only fly from one tree to another, or from one twig to 
another. Those remaining on the plum are presumably reinforced in the early autumn by a return migration of the descendants of those from grasses or reeds and these produce egg-laying females which lay their eggs at the base of the leaf buds and complete the life cycle. From the above it will be seen that this species appears at a much later date than the Leaf-curling Aphis, not usually being present in abundance until after midsummer.

Natural Enemies. - The remarks under this heading on the Leaf-curling Plum Aphis apply also to the present species.

Measures of Control.* -The best wash for use against the aphis is said to be a paraffin emulsion containing liver of sulphur.

Some washes fail owing to the fact that they cannot penetrate the mealy secretion by which the insects are covered.

\section{Hop Damson ApHIs. \\ (Phorodon humuli, Schrank.)}

This aphis is treated fully in Leaflet No. $88 t$, and need only be dealt with briefly here. It is found in injurious numbers chiefly on the damson, but it occasionally occurs on other plums. The life-history is briefly as follows: Eggs are land on the damsons in autumn, and, on hatching in early spring, produce aphides which live for 3 to 5 generations on the damsons. Towards the end of May winged forms appear which desert the damsons and fly to hops. There is a return migration to the damsons in autumn. By sucking the juices of the damson trees these aphides may do considerable damage, while they are also the cause of the notorious hop blight. In hop-growing districts, therefore, it is very necessary that the aphis should not be allowed to multiply when on the damson. The same measures of control may be employed as were suggested in the case of the Leaf-curling Plum Aphis.

\section{Spray Formulæ.}

I.-Lime Wash.+

$$
\begin{aligned}
& \text { Quick-lime } \quad \ldots \quad \ldots \quad \ldots \quad \ldots \quad 10-15 \mathrm{lb} \text {. }
\end{aligned}
$$

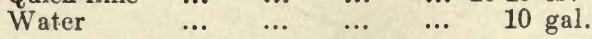

The best stone quick-lime is to be preferred, and the proportion of lime to water should be as high as possible, having regard to the nature of the spraying apparatus available. In making up the wash sufficient water should be poured on to the lime to keep it covered until it is slaked. After slaking, the remainder of the water should be added, the whole well

* Theobald, Insect Pests of Fruit, p. 385.

+ Obtainable from the Ministry.

Lees, Annals of Applied Biology, I, p. 351. Petherbridge, Jour. Bd. Agric., Vol. XXI, p. 915. 
mixed, and strained into the spraying machine. Lees advises that the lime should be allowed to slake for from 6 to 12 hours, before it is used.

If a lime-sulphur wash is required instead of plain lime wash it is suggested that the concentrated solution should be obtained from the manufacturers, unless it is to be used on a large scale, when it may prove economical to make it locally.

\section{I1.-Nicotine Wash.}

Nicotine, 98 per cent. $\quad \ldots \quad \ldots \quad \quad \frac{3}{4}-1$ oz:

$\begin{array}{llllllll}\text { Soft soap } & \ldots & \ldots & \ldots & \ldots & \frac{1}{2}-1 & \mathrm{lb} .\end{array}$

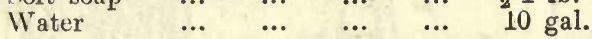

The nicotine and soap are dissolved in the water. The soap may be first mixed with a little hot water in order to dissolve it more quickly. If the water used is at all " hard " $1 \mathrm{lb}$. of soap will probably be needed to every 10 gallons of the wash; with rain water $\frac{1}{2} \mathrm{lb}$. will be sufficient.

$$
\begin{aligned}
& \text { III.-Paraffin Emulsion.* } \\
& \begin{array}{llllll}
\text { Paraftin } & \ldots & \ldots & \ldots & \ldots & 1 \text { pint. }
\end{array} \\
& \begin{array}{lllllll}
\text { Soft Soap. } & \ldots & \ldots & \ldots & \ldots & \ldots & 1 \mathrm{lb} \text {. }
\end{array} \\
& \text { Liver of suiphur, (if needed) } \quad \text {... } 2 \text { oz. } \\
& \begin{array}{llllll}
\text { Water } & \ldots & \ldots & \ldots & \ldots & 10 \\
\end{array}
\end{aligned}
$$

The soap should be dissolved in about 1 gallon of boiling water and the paraffin added while the liquid is still hot. The mixture should be thoroughly churned, preferably by spraying it back into itself with a hand syringe. The remainder of the water, in which, if necessary, the liver of sulphur is dissolved, should then be added, and after it has once more been thoroughly churned the fluid is ready for use. Unless the mixture is completely emulsified the paraffin is liable to burn delicate foliage, and it should, therefore, be prepared and used with care. It has, however, the very marked advantage that the necessary ingredients are always easily obtainable.

Formulie for making other " contact insecticides," such as resin wash or quassia, may be obtained on application to the Ministry. In certain circumstances it is convenient to use a proprietary contact insecticide to avoid the trouble of preparing the home-made washes.

* Lices (Annual Report of the Long Ashton Research Station, 1913, p. 71) suggests this formula, but without the liver of sulphur. 


\section{THE OYSTER-SHELL SCALE.}

(Aspidiotus ostreaformis, Curtis.)

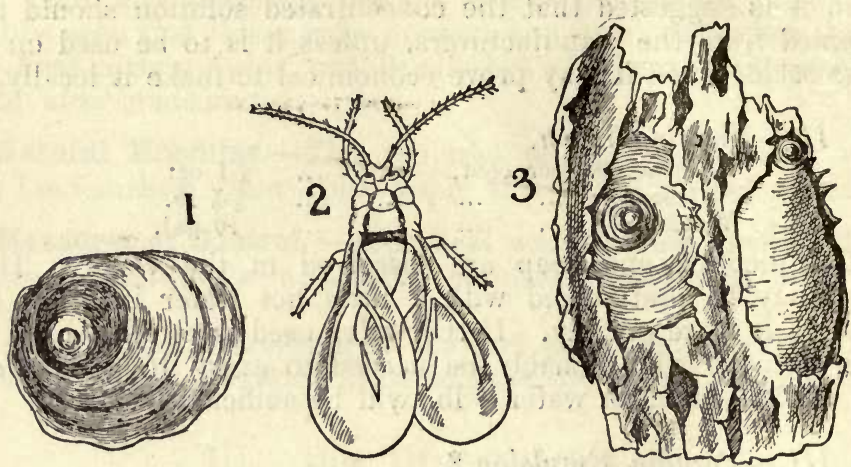

FIG. 1.-Oyster-Shell Scale (female), $12 \frac{1}{2}$ times natural size. FIG. 2.Oyster-Shell Scale insect (male), 25 times natural size. Fig. 3.Oyster-Shell Scales in position on bark, $12 \frac{2}{2}$ times natural size. (All after Newstead, Monograph of the British Coccidæ, Ray Society, 1900.)

This scale insect, which lives under a shield or covering somewhat like a minute oyster-shell (Fig. 1), is widely distributed in Britain and is a pest which should be known to all fruit growers.

Plants Attacked and Nature of Damage.-The OysterShell Scale attacks pIum, cherry, apple, pear, peach, apricot, and nectarine. It has also been found on currant and many other plants, among which heather may be mentioned. The scale insects live on the trunk, branches and twigs of the tree, sucking up the sap, in consequence the tree is weakened and in exceptional cases where the pests are very numerous, twigs, branches, and even whole trees may be killed. This, however, is unusual in commercial plantations, and as a rule the Oyster-Shell Scale is one of the many pests which do not cause obvious injury and in consequence are overlooked. Nevertheless, such insects are worthy of attention, for they never cease their attacks, and by draining away the sap impair the vitality and fruitfulness of the tree.

Description and Life-History.-The most obvious feature to he observed in the case of trees attacked by the Oyster Scale is that the bark appears to be dotted here and there with small white spots or scars slightly larger than a pin's head. Each of these spots shows the position formerly occupied by a scale insect which has died and from which the scale or covering has fallen off. Close observation will then show that on the 
surface of the bark-trunk, branches, or twigs-are numerous minute greenish-grey scales like oyster shells about the same size as the scars just mentioned (Fig. 3). The life-history of the insect which makes these scales is as follows:- In its youngest stage when just hatched from the egg, the pest is a minute and active louse-like creature which runs about on the bark seeking for a place to settle down. In this stage it may also be carried from tree to tree by clinging to other insects or to the feathers of birds. On finding a suitable spot it drives in its trunk and begins to suck the sap, at the same time losing its power of moving about, and forming on its " back" a little scale as a protection. It is in this stage that the winter is passed. Once fixed, scales of the female sex, though growing in size, never move away again. In the case of the male, the full-grown or adult form is a winged insect (Fig. 2) which comes out from under its scale in early summer and flies away. The adult female scale, after pairing with a winged male, lays eggs from which hatch the young "lice " mentioned above, the life-history being thus completed. There appears to be but one generation in the year.

Natural Enemies.-The Oyster-Shell Scale is much reduced in numbers by the attacks of its natural enemies. One specially valuable enemy is a jet-black " ladybird " with two red spots on its wing-cases (Chilocorus). This ladybird beetle which feeds on the scale may usually be seen crawling about on the trunks of affected trees and it is often very conspicuous on warm days in March and April.

Methods of Control.-(1) When buying young stock all trees bearing scales or showing the characteristic little white scars should be rejected unless the seller can guarantee that the stock has been fumigated with hydrocyanic acid gas or otherwise cleared of scales.

(2) The scale insects can be killed by thoroughly washing the trees in winter with lime-sulphur at winter strength made according to the following formula:-

$$
\begin{array}{lll}
\text { Lime-sulphur (1.3 Sp. Gr.) } 3 \text { quarts. } \\
\text { Water } \quad . .
\end{array}
$$

The concentrated lime-sulphur (1.3 Sp. Gr.) solution may be bought ready-made. A strong paraffin emulsion or miscible oil is also effective.

(3) In orchards which are well sprayed against other pests Oyster-Shell Scale seldom develops sufficiently to become troublesome. Any of the washes used for clearing the trees in winter at the same time check the scale, while summer washes tend to destroy the young scales when settling down. The freedom from injury by the Oyster-Shell Scale is one of the benefits which the progressive grower can credit against his spraying account. 


\section{THE PEAR LEAF BLISTER MITE.}

(Eriophyes pyri, Nalepä.)

The Pear Leaf Blister Mite is a troublesome pest of the pear tree and may do much damage, though the injury it calises often seems to pass unrecognised. This is regrettable since, as in the case of most pests, an attack in its early stage is far easier to deal with than later when the infestation is bad.

The Pear Leaf Blister Mite occurs everywhere, but judging by the records would seem to be more troublesome in the southern half of the country than in the northern. The mite is also a pest on the Continent of Europe and in America.

Plants Attacked and Nature of Damage.-The chief damage is done to pear, but the apple is also occasionally attacked, while among wild and garden plants, Mountain Ash or Rowan, White Beam, Wild Service Tree and Cotoneaster all suffer at times from the Mite.

The nature of the damage is much the same in each case, but the following description refers to pear. When the leaves (Fig. 2) of an infested tree have expanded in spring it wlil ke noticed that the upper surface of an attacked leaf is dotted with small yellowish-green pimples, the underside showing corresponding impressions. These pimples or blisters are usually more numerous on the half of the leaf on each side of the midrib than towards the margins. In some cases the blisters, while starting green in colour, soon turn pink or red. Later the blisters become brownish, and the whole leaf often turns black and dies in the latter half of summer. In the case of trees badly infested the young fruitlets and their stalks are also attacked, causing either malformation of the fruit or-more usually-its death, and fall from the tree when quite young.

Description of Pest and Life-History.-The damage is caused by a very minute mite-so small (less than $1 / 100$ inch) as to be invisible without the aid of a microscope. The general appearance of the mite is shown by Fig. 1, and further description is unnecessary as the pest will be identified by the damage it causes and not by its structural characteristics.

The mites spend the winter under the outer bud-scales of the buds. In spring they pass on to the leaves and burrow into the under-surface, setting up the irritation which results in the blister-like pimples on the leaves. In these blisters the female mites lay eggs and the young feed within for a period and then pass out through a minute hole on the underside of the blister and burrow in at another spot, so forming fresh blisters. Reproduction goes on throughout the summer season, but before the leaf falls the mites move again to the shelter of the young buds in which to spend the winter. 


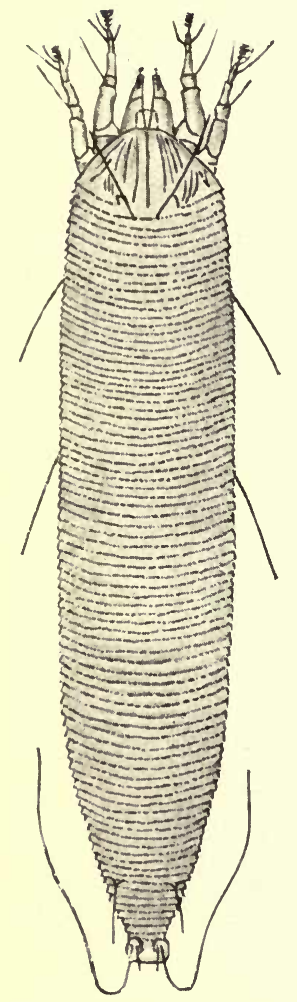

1

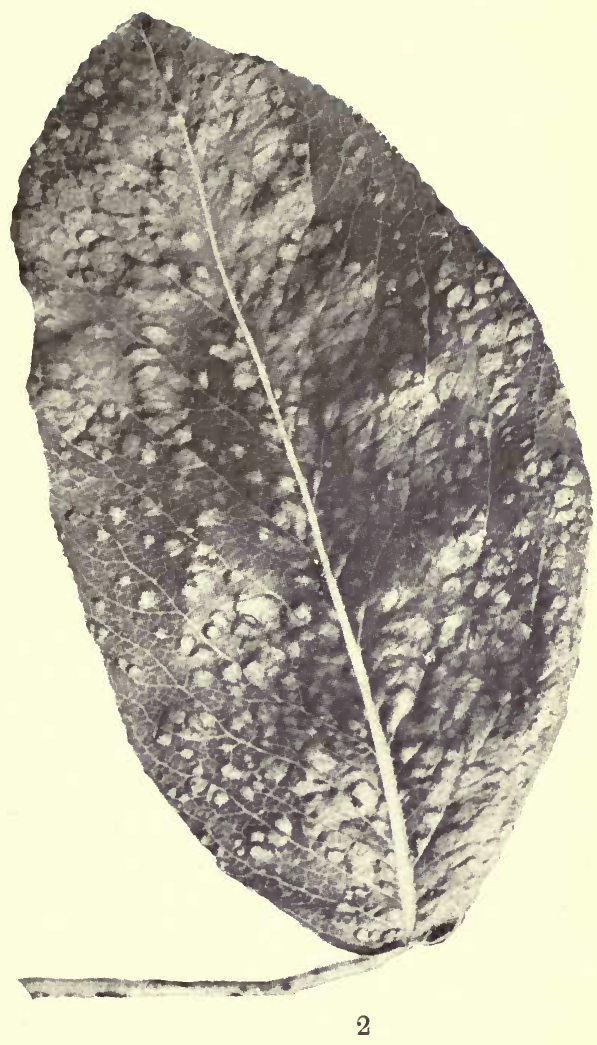

Prar tufaf Blister Mite.

1.-The Mite (Eriophyes pyri, Nalepa) (greatly magnified).

2.-An infested pear leaf, showing blisters caused by the Mites. 

Methods of Control.-(a) A look-out should be kept for the first signs of the pest in an orchard or garren, and treatment given at once before serious damage is done. Buyers of young stock will find it worth their while to inspect prospective purchases before the leaves have fallen, and if mite is discovered to go to another nurseryman. If this precaution has not been taken, special care should be taken to destroy Blister Mite at once in a young plantation as, if left for two or three years, the chance of obtaining successful growth is greatly prejudiced.

(b) Spraying during the dormant season is satisfactory in destroying the mites which are then under the bud-scales and not so well protected as when in the leaves. The spraying should be carried out either directly after the leaves have fallen (about November) or just before the buds begin ta open in spring (about February). Either lime-sulphur or oil emulsions may be used. Lime-sulphur should be obtained from the makers and be mixed with water according to the makers' directions for winter use. In experiments at Wye, Theobald found that a lime-sulphur-caustic-soda wash applied in November and February was more effective than either limesulphur alone or paraffin emulsion. His formula for such a wash, in addition to lime-sulphur, contains $1 \mathrm{lb}$. of caustic soda and $1 \mathrm{lb}$. of soft soap to each 10 gallons. Oil emulsions may be bought in the form of a miscible oil* which merely requires dilution with water according to the maker's instructions. A home-made emulsion may be obtained as follows :-

$$
\begin{array}{lllllr}
\text { Paraffin oil } & \ldots & \ldots & \ldots & \ldots & 1 \text { gall. } \\
\text { Soft soap } & \ldots & \ldots & \ldots & \ldots & 1 \frac{1}{2}-2 \\
\text { Water } & \ldots & \ldots & \ldots & \ldots & 10 \text { gall. }
\end{array}
$$

The soap is first dissolved in about a gallon of boiling water. The soap solution is then removed from the fire and the paraffin at once added, the whole being well mixed by squirting the liquid back into itself with a hand syringe. The strong emulsion may be kept until required for use, when the remaining nine gallons of water should be added and the whole thoroughly stirred-or better, mixed as before with a hand syringe.

(c) It is said that attacks may be checked by spraying in summer with a weak oil emulsion, but in view of the success obtainable by winter spraying a partial remedy is hardly worth troubling about.

* Miscible oils may be taken as comparable to paraffin emulsions in their action. They are so prepared as to emulsify at once in water without the addition of soap. but are not usually designed for summer washes-only for winter use. The makers' instructions for mixing should be taken. 
(d) In the case of single trees in gardens, an attack may be kept under control by picking off and burning attacked leaves as soon as they can be recognised. This remedy is, of course, only applicable where an infestation is noticed at once, and not after two or three years, when the mites have become well established throughout the tree.

\section{THE PEAR MIDGE.}

(Diplosis (Contarinia) pyrivora, Riley.)

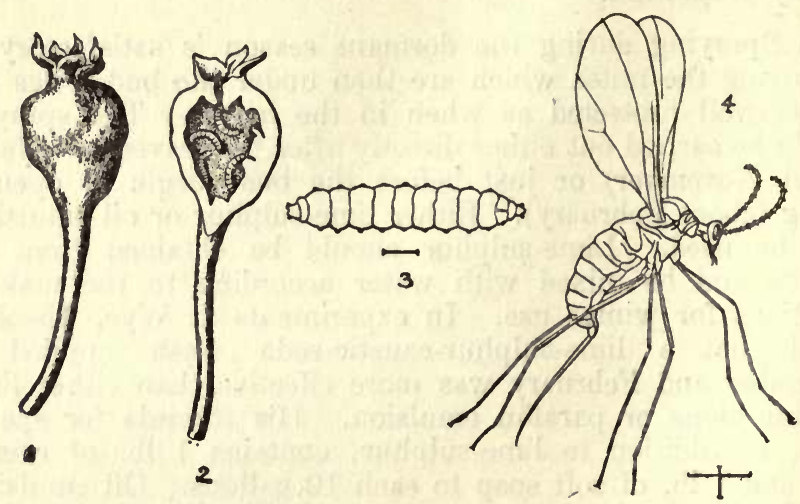

1. Pear stunted and malformed by the larvæ within it. 2. Section of pear with larvæ. 3. Larva, much magnified. 4. Female fly, much magnified. Lines show natural length of fly and larva.

The Pear Midge is a most serious pest, for by attacking the fruit itself, it directly reduces the profit, whereas many other pests may be present in some numbers without seriously or immediately affecting the yield of the crop. Fortunately it does not attack all varieties of pears equally, and the later flowering varieties may escape while early flowering varieties of the William's " Bon Chrétien " type are completely cleared of fruit.

The insect was recorded as a pest in Continental orchards by Kollar as long ago as 1837; and it is supposed to have been introduced into America about 1877 though there is reason to believe that it was known in that country many years before. Attention was first called to its occurrence in England by Miss Ormerod in 1883, but the absence of earlier records may well be accounted for by the lack of trained observers, and the fact that the damage is very similar in its effects to that due to weather and other natural causes. Of late years it appears to have been steadily on the increase.

Nature of Damage.-The presence of this pest usually first becomes evident from the rapid falling of the young fruit, when about the size of marbles. In bad cases the whole of 
the crop of a tree will quickly drop in this way. Upon examination the freshly fallen fruit will usually be found to be deformed and much distorted, and often will be disfigured with black patches of decayed tissue which may or may not have broken into cracks. Upon cutting oren such an attacked fruitlet, a blackened mass of pulp and excreta with a number of the small whitish-yellow maggots (see Figs. 1 and 2) will be found. Later the dead fruitlets become quite black, shrivelled, and more or less hollow inside: even if the maggots are absent these signs will show at once the presence of the pest. It has been noted that an attacked fruitlet always grows much more rapidly than a sound one and becomes deformed, sometimes rounded, at other times bulged out at the side or otherwise distorted. Consequently an attack may be noted soon after the fruit has set. An internal examination should always be made, as pears may become deformed from other causes.

Description and Life-History.-The adult midge appears in April, about the time the blossoms on early pears commence to show signs of the white petals-usually about the middle of April. It is, however, seldom noticed, being barely onetenth of an inch long and lives but a short time. Its general appearance may be gathered from Fig. 4. The male is blackish-grey to black in colour, clothed with pale yellowish or white hairs and has long antennæ. The female is duskygrey always paler in colour than the male, and its antennæ are shorter. It has a long ovipositor (when fully extended, as long as or longer than the body) for the purpose of depositing eggs inside the pear blossom.

The eggs are laid by the female in batches of from ten to thirty within the flowers, the unopened buds being pierced by the ovipositor for this purpose. They are white, rather long, pointed at one end and semi-transparent, and they hatch in from four to six days.

The larvæ maggots are footless, yellowish-white in colour (Fig. 3). They make their way into the developing fruit and in about five to six weeks are full grown and ready to leave. By this time the decay in the interior of the fruitlet caused by the presence of the maggots has usually reached the outside at one or more spots, and on these spots the skin soon cracks, allowing the maggots within to escape. Upon reaching the soil the maggots burrow therein to a depth of $1 \frac{1}{2}-2 \frac{1}{2}$ inches and spin a delicate silken cocoon about one-tenth of an inch long, in which they remain for some considerable time (in some cases apparently until the following spring) before pupation. Should a young fruitlet remain intact externally, the maggots are imprisoned, but sooner or later it falls to the ground and subsequently decays, when the maggots are able to escape and burrow into the ground. When mature 
the larfæ measure from one-seventh to one-sixth of an inch in length. They are able, in common with other maggots of the genus, to make a jumping movement which assists them in escaping from the fruit,

Methods of Control.-1. In small gardens, where only bush fruit are grown, the best remedy is the hand-picking and destruction of all infested fruit, with repeated shallow cultivation of the ground beneath the trees in June and July.

2. In larger orchards great benefit has been derived from stocking heavily with poultry in April, May and June, i.e., when the flies are appearing from the ground, and while the maggots are leaving the fruit.

\section{THE PEAR AND CHERRY SAWFLY.}

(Eriocampa limacina, Cameron.)

Pear Slugworms are neither slugs nor worms but are the young (or larvæ) of a species of sawfly which is found throughout most of the country, though complaints are more frequent from the South than from the North, and relate more often to gardens than to commercial plantations.

Plants Attacked and Nature of Damage.-Pears and cherries are the fruits most often injured, but there are records of the pests being found on apples, while hawthorns and similar shrubs suffer from the attacks of the Pear Slugworm or allied species. The damage is done to the foliage and its nature is characteristic, the leaf being eaten in such a way that only the veins and the lower epidermis (or skin) are left. In bad cases every leaf is treated in this way, and in place of green foliage the tree is left only with shrivelled brown skeleton leaves. Naturally under such circumstances the crop is unable to develop, or if the attack does not occur till late in the summer, the maturing of the fruit-buds for next season is prevented.

Description and Life-History.-If leaves attacked as described above are examined while there are still green areas left, small, slimy, slug-like grubs, black or dark olive-green in colour, will be found on the surface of the leaves. In shape these slugworms are broad at the head-end and pointed towards the tail, rather like young tadpoles, but underneath are the legs and sucker feet of the typical sawfly caterpillar. The origin of the slugworms is as follows:-At the end of May or in June the adult, sawflies, blackish, four-winged insects of the usual sawfly appearance, come out of their cocoons in the soil 

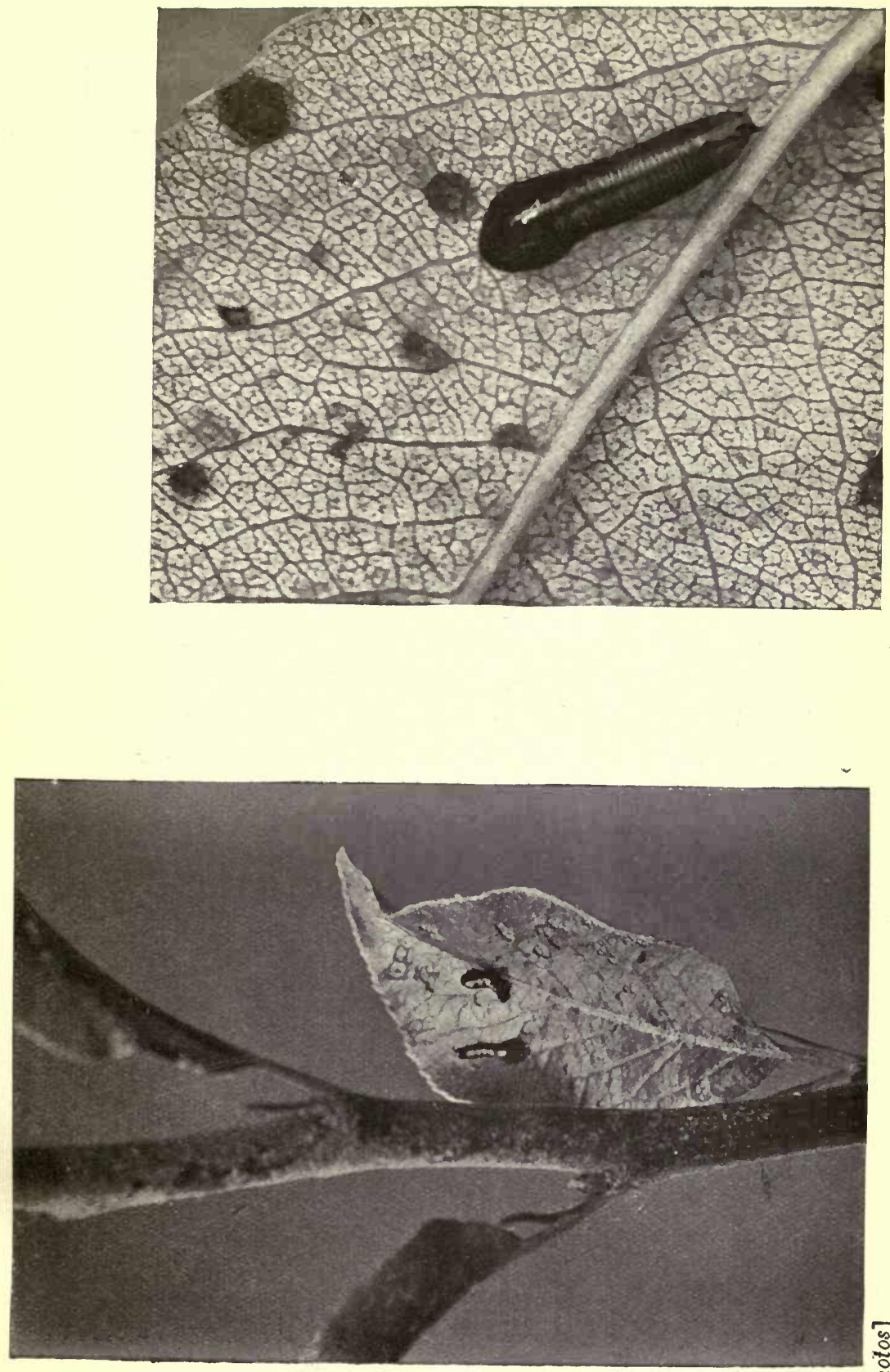

r 


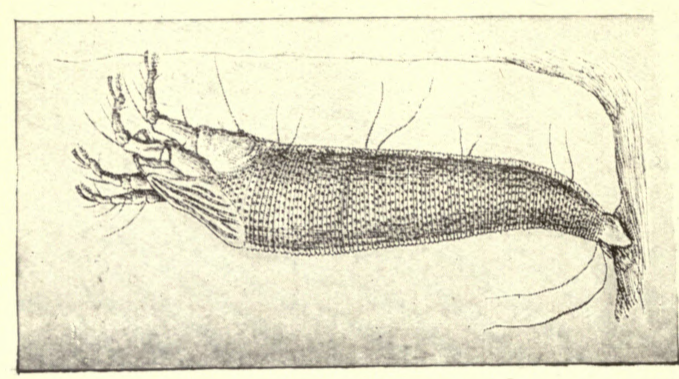

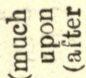

造虫点

4 200

त.

웡

บิ 글. 队․ำ

ง

ن 壬

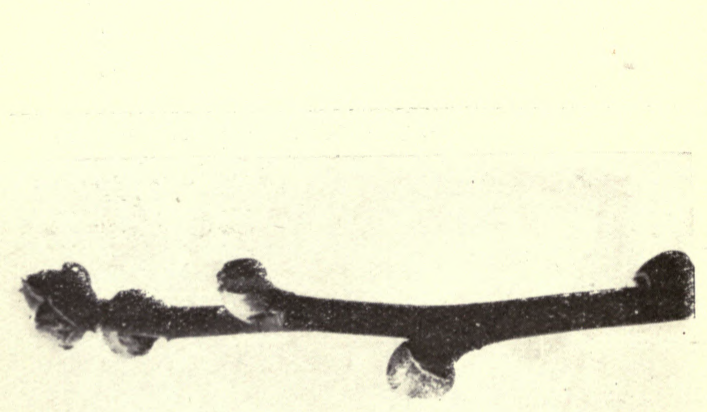

뭉 맹ㅎㅇ

गै t?.0

$+{ }^{\circ}$

당뭉

क्ष

ö

요의

भु-

1 .

볍등ㅇㅇ

때

स

安喑

战客.

武地

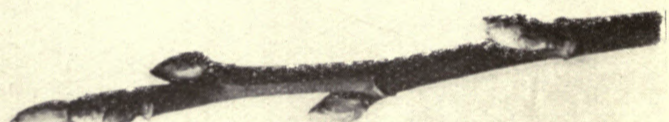

$0 \unlhd+$

벙등 d

그면

A

舅

它 
and the females lay their eggs in slits in the undersides of the leaves of pears or cherries (like other sawflies, the Pear Slug Sawfly has a saw-like apparatus at the end of the abdomen for cutting slits in which to lay eggs). In rather less than a fortnight the eggs give rise to young larvæ, at first whitish in colour, which force their way out from the upper surface of the leaf and begin feeding, soon assuming the typical slugworm appearance. When full-fed the slugworms change to orange-yellow caterpillars, in shape not unlike those of the gooseberry sawfly. In this stage they do not feed but crawl down to the soil and spin a cocoon within it, the outside of the cocoon being stuck all over with particles of soil. In summer the insect turns to a pupa within the cocoon and a fresh brood of sawflies comes out in about a fortnight. There may be two and possibly three broods during the summer; and the larvæ of the last brood, which feed in early autumn, remain for the winter as larvæ within their cocoons in the soil, turning to pupæ the following spring. From these pupæ the first brood of adults appears in May or June.

Methods of Control.-(1) Slugworms are easily destroyed by spraying. In the case of the earlier broods of larvæ lead arsenate is effective and can safely be used so long as the fruit is not to be picked for six weeks after spraying. Later, hellebore or nicotine wash can be applied up to fourteen days before picking. The slugworms are not difficult to kill and even soap and water applied with force is fairly effective.

Formula:-

(a) Lead Arsenate.

$\begin{array}{llllll}\text { Lead arsenate paste } & \ldots & \ldots & \ldots & \frac{1}{2} & \mathrm{lb}\end{array}$

$\begin{array}{llllllll}\text { Water } & \ldots & \ldots & \ldots & \ldots & \ldots & \ldots & 10 \\ & & \end{array}$

(b) Hellebore.

$\begin{array}{llllll}\text { Hellebore powder } & \ldots & \ldots & \ldots & 4 \mathrm{oz} \text {. up to } 1 \mathrm{lb} \text {. }\end{array}$

$\begin{array}{llllllll}\text { Water } & \ldots & \ldots & \ldots & \ldots & \ldots & \ldots & 10 \\ \text { gallons. }\end{array}$

The powder is thoroughly mixed with the water and the liquid used without straining.

(c) Nicotine.

Nicotine, 98 per cent. $\quad \ldots \quad \ldots \quad$... $\quad \frac{8}{4}$ oz. (fluid measure). $\begin{array}{lllllll}\text { Soft soap } & \ldots & \ldots & \ldots & \ldots & 1 \frac{1}{2} & \text { lb. }\end{array}$

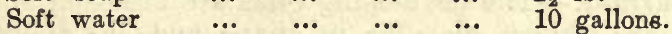

(2) Freshly slaked lime dusted on to the larvæ is efficient in gardens where only a few trees have to be dealt with and the application can be made thoroughly. Some recommend a mixture of soot and lime, but the latter alone is sufficient.

(3) Various measures, such as the removal of the surface soil in winter from around trees which have been attacked, have been suggested, also hoeing, digging, \&c., but apart from the questionable success of these measures, they do not seem worth considering in opposition to such proved treatments as spraying and dusting. 


\section{THE BLACK CURRANT MITE.}

(Eriophyes ribis, Nalepa.)

The disease known as " big bud " in Black Currants caused by the Black Currant Mite, was first recorded in these islands in the year 1869, but according to Miss Ormerod it had been responsible for losses in the district of Blantyre, N.B., for 20 years previously. Similarly Theobald* states that abcut the same period it was known to the Maidstone growers. = The original home of the mite, however, is uncertain. It has now spread throughout Great Britain and Ireland, and occurs in most of the countries of Western Europe. It has also been introduced into Canada.

It has been scheduled as a destructive pest by the Department of Agriculture for Ireland, where attempts are being made to stamp it out, but this end does not yet appear to have been attained.

The Black Currant Mite is undoubtedly the most serious animal pest of the Black Currant, and its attacks have caused a marked reduction in the area devoted to this fruit. In spite of much careful research by numerous investigators, no really satisfactory methods of control have yet been discovered, and there is need for still further investigation. It is only necessary here to describe the nature of the attack and to indicate the lines of the treatment which have given the more hopeful results.

Plants Attacked-Nature of Injury.-The plant which suffers most seriously from the mite is the Black Currant, but Red and White Currants and the Gooseberry are also attacked. Owing to the difficulty in carrying out the necessary experiments, it does not appear to have been proved that the mites can pass from one species of host plant to another, but it is highly probable that they can do so. The point is obviously one of great practical importance.

The nature of the injury in the case of the chief host plants is briefly as follows:-

Black Currant.-The developing buds are attacked and swell until they are almost globular in shape and are about twice the size of the normal buds - thus giving rise to the term " big bud." Buds, if slightly attacked, may produce small stunted and crumpled leaves, but as a rule they dry up and die in early summer.

The natural result of this loss of buds is a progressive decrease in the crop which may ultimately fail altogether. In the case of certain old bushes, however, it has been noticed that the number of "big buds" produced each year has

* Theobald, "Insect Pests of Fruit," p. 232. 
increased up to a certain point, but subsequently has remained stationary, and in spite of the attack a small crop is always obtained. Notes on the resistance to the disease shown by some varieties or individual bushes of black currants will be found in the section on Methods of Control. Owing to the fact that the extent of this resistance is so variable, no list of resistant varieties is given. Young bushes frequently appear to resist attack for 4 or 5 years but subsequently break down, and a variety should not be judged until it has been tried for a considerable period.

Red Currant.-Theobald* states that " the mites produced a dense growth of buds, every here and there, which were found to be teeming with them. At the same time the shoots bearing the attacked buds were abnormally swollen, many twice the thickness of normal ones."

Gooseberry. - In the case of the Gooseberry the noticeable features of the attack concern the young shoot, soft tender leaves, and to some extent the fruit blossom. The mites cause a marked blistering and, according to Miss Taylor, $\uparrow$ " after a bad attack the whole leaf surface, the veins and the petiole become covered with succulent outgrowths." "Leaves so attacked are considerably under the normal size and the main stem itself is reduced in length. The leaf colour is yellow green and the tree has a generally unhealthy colour." Obvious injury only occurs early in the season-later, when the leaves and shoots harden, no further damage is done and the later-formed leaves are normal in size.

The reason for the difference in the form of attack on the three plants would seem to lie in the nature of the buds. The black currant bud is somewhat loosely made, and hence the mites can penetrate to the centre. In the red currant and gooseberry the buds are tightly compressed and the mites cannot work their way in. +

Description and Life-History.-The general appearance of the mite when highly magnified is shown by Fig. 2, but the animal is only about $\frac{1}{100}$ inch in length, and if a big bud is cut open, the mites are hardly discernible to the naked eye; even through a pocket lens they appear only as minute white specks.

From July throughout autumn and winter and until March the mites live mainly inside the buds, where eggs are laid and fresh generations are produced. During a period covering roughly the months of March, April, May and June the diseased buds either dry up and die, or produce distorted foliage, and the mites are forced to migrate to fresh quarters. When weather conditions are favourable- that is to say,

* Theobald, “Insect Pests of Fruit,” p. 241.

+ Taylor, Journal of Agricultural Science, VI, p. 131.

+ Taylor, loc. cit., p. 133. 
on sunny days with some wind*-the mites crawl out of the buds and stand erect on the outside of the bud. They then either " jump" or are blown off by the wind, which is capable of carrying them, probably, for a considerable distance. The mites may also migrate by clinging on to insects which settle on the affected bushes, and may travel for short distances on the twigs by crawling. Naturally in this process of migration, in which chance plays so large a part, very many of the mites can never reach an appropriate food plant, but so enormous is the number of mites produced-Miss Taylor calculates that under favourable conditions 1,000 mites may leave one bud in an hour-that sufficient reach fresh currants to carry on the attack in spite of all losses. After migration, but before the new buds are large enough to enter, the mites live at the bases of the leaf stalks, between the developing buds and the stem and among the young leaves at the growing points of the shoots. When the buds are sufficiently large, that is to say about July, the mites enter into them and reproduce, causing the well-known " big buds."

Natural Enemies.-Black Currant Mites are attacked by the larva of a minute parasitic insect ('Tetrastichus eriophyes) and by a parasitic fungus (Botrytis eriophyes). They are also preyed on by other mites and insects. The reproductive powers of the mite. however. appear more than sufficient to counterbalance all losses in this manner.

Methods of Control.-1. As has already been stated there are no entirely successful measures for combating the Black Currant Mite, and badly affected bushes should be grubbed up and burnt. In replanting it should be remembered that adjacent red currants and gooseberries may be attacked; and it is, therefore, better to choose a fresh site for the young bushes. It should hardly be necessary to point out that stock showing big buds should never, in any circumstances, be purchased or planted, but experience shows that this error is still sometimes committed. Similarly, cuttings should never be taken from diseased bushes, unless they are required for some special purpose, in which case they should be dipped for ten minutes in water heated to a temperature of $115^{\circ} \mathrm{F}$., a treatment which appears to kill the mite in all its stages. $f$

In order to obtain cuttings entirely free from mite, Goude + recommends that soft cuttings should be taken in April-May, and after being dipped for one hour in a nicotine insecticide (nicotine 98 per cent. $\frac{1}{2} \mathrm{oz}$., soft soap $4 \mathrm{oz}$., water 5 gallons) and then rinsed in clear water, they should be stuck in a cold frame.

* Taylor, loc. cit., p. 121, et seq.

+ Spencer Pickering and F. V. Theobald. "Fruit Trees and their Enemies, with a Snraying Calendar," p. 81.

† Goude, Jour. Min. Agric., p. 460, August, 1921. 
With reference to the different varieties of Black Currant, certain forms have been claimed to be immune, but further evidence is required as to this supposed immunity, which too often breaks down. It is often observed, however, that in a plantation where several varieties are grown some are more subject to attack than others, while occasionally almost free bushes are found in close proximity to plants badly diseased. There is, undoubtedly, much variation in the powers of resistance shown both by different varieties and by different individuals in each variety, and the establishment of a highly resistant race does not seem impossible.

2. In gardens, attacked buds should be destroyed as soon as they can be detected so as to kill the mites before the period of migration. In commercial orchards, if many of the bushes are affected, it may prove impracticable to collect " big buds," but when the mite first appears in a previously clean plantation the twigs carrying diseased buds should be removed and burnt. If only one or two bushes show signs of attack it is better to remove and burn the whole bush. It might be thought that in the case of a bad attack cutting the bushes to the ground would prove a complete cure, but this has not proved to be the case, though it is not known how the fresh shoots become infested. Success has been claimed, however, for certain systems which are based on drastic pruning of this nature. The bushes are planted much more closely than usual, and then either (1) every alternate bush is annually cut to the ground or (2) the whole of the old wood is removed immediately after the fruit has been gathered.

3. Some growers appear to have obtained considerable success by applying dry or wet " sprays," while others have reported a complete failure. Treatments of this nature are open to the objection that the mites are only affected by them when on migration, and, as the migratory period extends over three months, it is necessary to spray or dust several times.

The dry spray treatment, originally suggested by Collinge,* is, perhaps, in more general use than the wet spray. It consists in dusting the bushes four times with ground quick lime and sulphur, at intervals of a fortnight, beginning at the end of March. The first dressing should contain only 1 part of quick lime and 4 parts of sulphur, the second, 1 part of quick lime and 8 parts of sulphur, and the last two dressings, sulphur alone. Risk of burning is lessened by using slaked lime instead of quick lime, about equal quantities of lime and sulphur being allowed. The powder should be applied when the bushes are damp, and it is best distributed by means of one of the machines made for the purpose.

* Collinge, "A Manual of Injurious Insects, pp. 240, 241. 
4. No suggestions are made for the control of the Black Currant Mite on other host plants. The attacks either appear to be rare or, more probably, are overlooked.

\section{RED SPIDERS.}

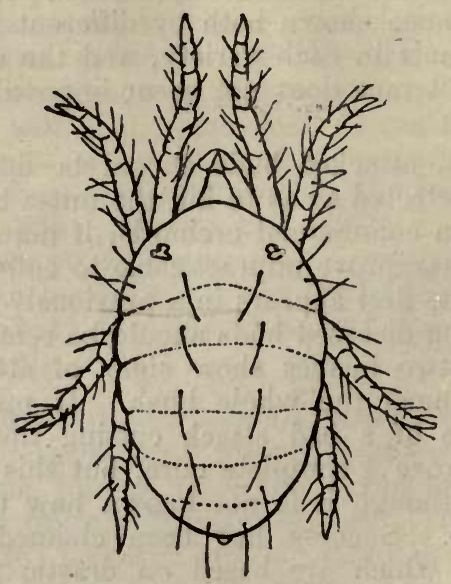

RED SPIDER (greatly magnified).

The pests so well known to horticulturists as "Red Spiders" are in reality mites and belong to the group which includes the Cheese Mites, Gall Mites, and similar pests. They comprise a number of different kinds, all very much alike but fortunately the precise differences between them are not of vital importance from the practical point of view. It will therefore be sufficient to note that there are two sections of which one, characterised by the Gooseberry Rèd Spider (Bryohia), spins little or no web, while the other, of which the Greenhouse Red Spider (Tetranychus) is typical, usually spins a fairly thick silken web. Naturally the kinds which make a thick web are more difficult to kill by spraying than those not so protected and the difference is therefore worth observing.

Plants Attacked and Nature of Damage.-The injury to gooseberries and hops and to plants under glass such as vines $\mathrm{cr}^{\circ}$ cucumbers, is perhaps of most importance, but Red Spiders are also found on most fruit trees, many flowering plants (e.g., violets), and a number of trees and shrubs such as the lime, gorse and ivy.

The injury in all cases is done by the feeding of the Red Spiders, both young and old, which bite into the leaf, usually 
on the underside, and suck the sap. The leaves in consequence become sickly and show a more or less marked change of colour, turning first yellow and then-in a bad attackgreyish white. In the latter case the leaves die and the fruit is unable to mature. Gooseberries suffer chiefly in the spring and early summer, but attacks on plums and apples occur later, often towards the end of the growing season, when premature leaf-fall may be caused. In these cases the leaves sometimes take on a rusty colour instead of yellow. Greenhouse plants may suffer at any time when in leaf. Dry conditions are likely to cause attack both under glass and outside.

Description and Life-History.-Red Spiders themselves are little red creatures, considerably smaller than the head of the average pin. When adult they have four pairs of legs, a short rounded body and a mouth formed for biting and sucking. The Red Spiders of apples and other "top " fruit spend the winter in the egg stage, the eggs-brilliant crimson in colour-being often crowded together on the twigs. These eggs hatch in early spring and the mites feed and breed throughout the summer in the leaves, eggs again being laid on the twigs in or before autumn.

The Gooseberry Red Spider seems to be less definite in its mode of spending the winter. Doubtless a number fass through in the egg stage but others hatch earlier, and both eggs and mites may be found on the bushes in winter. In any case the mites have left the eggs by the time the buds unfold and they feed and breed in the foliage. As a rule their activity does not extend beyond midsummer.

The Greenhouse Red Spiders and the Hop Red Spiders, differ from those mentioned above in that they spin-chiefly on the undersides of the leaves-fairly thick silken webs among which they live and lay their eggs. They spend the winter partly in the egg stage but also largely as young mites which shelter in crevices of the bark of vines and other fruit trees, in cracks in woodwork, or in the case of hops on the poles, on trees, or under stones and clods.

Methods of Control.-(I) Spraying.-Red Spiders on fruit trees are controllable by spraying, but as in the case of almost every pest the work must not be put off too long or the damage will already be past repair. Never should the foliage be allowed to turn to the silvery-grey colour before the work is put in hand. In the case of gooseberries a tendency in spring to lose a healthy green colour should be regarded with suspicion and leaves should be examined with a magnifying glass in order to see if Red Spiders are present. An inexpensive glass is quite good enough for the purpose and will have many other uses in the control of pests. Spraying when necessary must be thorough so that the leaves are thoroughly wetted. 
Of spray fluids for the destruction of Red Spiders, sulphur compounds or paraffin emulsion are those usually recommended. From the former class, potassium sulphide is the standard insecticide but in the case of gooseberries limesulphur would seem to answer the same purpose, and can be used simultaneously against Red Spider and American Gooseberry Mildew. Paraffin emulsion compounds have fallen to some extent out of favour, probably owing to occasional foliage injury. Paraffin jelly has, however, been found very effective by Theobald* (Wye Agricultural College).

In the case of the Greenhouse Red Spiders which make thick webs, special precautions have to he taken to ensure proper wetting and Lloyd $t$ (Waltham Cross Experiment Station) states that he finds flour paste very effective for the purpose, having the advantage of causing no hardening of the foliage in cucumbers, a marked defect in the case of solutions containing soap. Flour paste has also been used for the control of Red Spider in the U.S.A. even without the addition of a sulphur compound, and it is probable that the addition of it to all sulphur washes would be beneficial, even when they are required for outdoor use. Formulæ for preparing the various washes are given below with the exception of lime-sulphur which is fully described in Leaflet No. $195_{+}^{+}$on American Gooseberry Mildew.

FORMULA.

(a) Potassium Sulphide (Iiver of Sulphur) Wash. (Original Formula.)

$$
\begin{array}{lllllll}
\text { Potassium } & \text { sulphide } & \ldots & \ldots & 5 & \text { oz. } \\
\text { Soft soap } & & \ldots & \ldots & \ldots & \frac{1}{2} & \text { lb. } \\
\text { Water } & \ldots & \ldots & \ldots & \ldots & 10^{2} & \text { gall. }
\end{array}
$$

In preparation the soap and potassium sulphide are dissolved in the water.

(b) Potassium Sulphide (Liver of Sulphur) Wash. (Lloyd's Formula.)

$$
\begin{array}{llllll}
\text { Potassium } & \text { sulphide } & \ldots & \ldots & 1 \mathrm{oz} . \\
\text { Flour } & \ldots & \ldots & \ldots & \ldots & 1^{\frac{1}{2}} \mathrm{oz} . \\
\text { Water } & \ldots & \ldots & \ldots & \ldots & 2 \text { gall. }
\end{array}
$$

"Place 14 pints of water in a bucket and add $1 \mathrm{oz}$. liver of sulphur which will completely dissolve while the flour paste is being prepared. Make $1 \frac{1}{2} \mathrm{Oz}$. ordinary wheat flour into a smooth paste with a very little water. Add water to 2 pints

* Insect Pests of Fruit. F. V. Theobald.

t Circular (Vol. 1. No. 5) Lea Valley and Dist. Nurserymen's Assocn., Ltd.

* Obtainable from the Ministry and also included in Sectional Volume No. 1 , price $8 d$. 
till the mixture is as thin as milk and as free from lumps. Boil this until it froths up, stirring it all the time. Add it to the solution of liver of sulphur and mix thoroughly. Apply with a hand or knapsack sprayer and wet the plants all over. The flour paste must be used the day it is prepared, and any mixed spray remaining at night must be thrown away.'

(c) Flour spray (U.S.A. formula).

One pound of flour is made into a "batter" with a little water, and is then mixed with 1 gallon of water. The mixture, is heated until a clear paste is formed. For spraying, 8 gallons of flour paste are used in 100 gallons of water.

(d) Paraffin Jelly (Theobald's formula).

$$
\begin{array}{lllllll}
\text { Paraffin } & \ldots & \ldots & \ldots & \ldots & 5 \text { gall. } \\
\text { Soft soap } & \ldots & \ldots & \ldots & \ldots & 8 & \mathrm{lb} .
\end{array}
$$

Boil the soft soap and paraffin together and, when boiling, add 1 pint of water and stir well. This becomes a jelly on cooling; add $10 \mathrm{lb}$. of this jelly to every 40 gallons of water.

Caution.-Owing to possible danger from fire the boiling should take place out of doors and away from buildings.

(II) Moisture.-Apart from spraying, which will dieal with all fruit crops, the chief means of controlling Red Spider is by keeping the plants sufficiently moist. Red Spider attacks are specially likely when plants have even temporarily become too dry. Cold water sprayed on alone has been found of great assistance.

\section{CURRANT AND GOOSEBERRY APHIDES.}

Currant and gooseberry bushes are ofter considerably damaged by Aphides or Plant Lice. In some districts bushes may be quite ruined; the leaves turn brown and shrivel up and the fruit falls off. Long spells of dry, warm weather are very favourable to the development of the insects. As Aphides are usually more or less prevalent on the bushes, and as favouring natural conditions may result in their increase to overwhelming numbers, attempts should be made, especially in autumn and in spring, to destroy them.

An interesting feature in the life-history of these Aphides is that only part of their life is passed on the currant and gooseberry bushes. At certain times of the year they migrate to other kinds of plants, returning as winged individuals in autumn or the next spring. All the species affecting the currant and gooseberry feed above ground except one found on the currant which feeds on the roots.

The bushes are affected in various ways. The leaves may show marked blisters, green, yellow, and red in colour, under cover of which the insects feed. The leaves curl up and hang down and form rosettes and the attacked shoots remain short 
and become bent and hidden by rolled up curled leaves. The fruit fails or falls away owing to the destruction of the leaves.

Theobald writes of nine species found on the genus Ribes; of these four may be mentioned here.

Aphis grossulariae, Kalt.- Is found on the currant and gooseberry from May onwards. Later it leaves these plants to fly to other species, but the complete year's round of life is still in doubt. On the currant and gooseberry this Aphis attacks the leaves and the young wood. The leaves get crowded together and overlap and the Aphides are thus sheltered from any spray applied too late.

Winter is passed on the currant and gooseberry in the egg stage. The eggs hatch and from April onwards the wingless females are found on the under surface of the leaves which show green, yellow, and red blisters. The winged individuals appear in summer and fly to the lettuce; they have also been found on nipplewort, sow-thistle, and guelder-rose. The return to the currant and gooseberry takes place in autumn.

Myzus ribis, Linn.-This species is found on the currant and gooseberry from May to July. It gives rise to blisters on the leaf, as with the previous species, and it often causes the leaves at the apex of the shoots to curl. Winged females migrate in late summer but details are lacking.

Macrosiphum lactuce, Schrank.-This species found on red and black currants migrates to the lettuce and other composites at midsummer and returns to the currant in the autumn.

Methods of Control.-Aphid attacks on gooseberry or currant are not easy to deal with, for until the injury becomes apparent the presence of the pest is seldom realised. Early spraying, before leaves have become curled or shoots distorted, is effective and any good contact insecticide, such as nicotine and soap or paraffin emulsion, may be used (for formulø see Leaflet No. 308, Plum Aphides). - When (in small gardens) young growth is attacked at the tip, it is often better to bend over the shoot and dip the tip into a vessel of insecticide instead of spraying, as by the latter means it is difficult to wet aphides in a "rosette." Prunings should always be burned.

\section{The Currant Root and Elm Leaf Apuis.}

Schizoneura ulmi, Linn.-This species, in summer, is found on the elm where it causes a very marked curling of the leaves. Winged individuals in late summer and autumn leave the elm and distribute themselves over a number of different species of plants, amongst which are the currant and gooseberry. The insects infest the roots and are then covered by a woolly material like that of the Woolly Aphis of the apple. A 
migration back to the elm takes place sometimes in the same autumn, but more commonly in the next spring. It is probable that this insect is more prevalent than is generally supposed and that its presence is associated with a reduction in the growth of the bushes. In the present state of our knowledge it is impossible to speak definitely on the subject, to which, however, attention should be given as it may prove of considerable importance to currant growers.

In the present unsatisfactory position as regards soil fumigants, little can be said as to methods of control. When a consignment of young stock for planting is found to be infected, dipping the roots in an insecticide should be tried.

\section{THE BROWN SCALE.}

(Lecanium persicae, Geoffroy.)

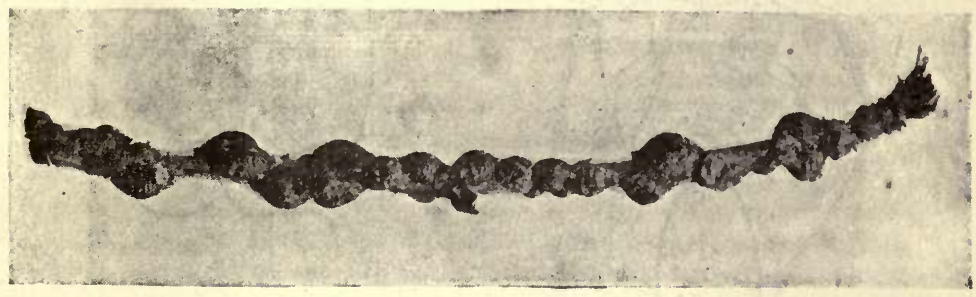

Photo]

[R. A. Malby.

Fra. 1.-Brown Scale on Peach Twig (slightly magnified).

This insect or its variety $L$. ribis Fitch is found in great abundance on the gooseberry, currant, peach and nectarine, and also on a number of other cultivated and wild plants. It has a decided preference for the older branches, the young shoots being attacked only when the insects become overcrowded. As a rule it is much more prolific on plants grown in sheltered spots, especially on wall-trained trees in a fairly sunny aspect, and peaches and nectarines in houses often suffer severely.

The Brown Scale is very generally distributed throughout England, but is less known in Wales, Scotland and Ireland.

Description and Nature of Damage. - The mature female and old dead females are easily recognised as brown " scales," a little longer than broad, flat beneath and highly convex above (Fig. 1). At first these "scales" are dusky yellow with darker transverse bands, but become darker with age until they may be light reddish-brown to dark chestnut- 
coloured. There is usually a clearly defined central ridge with many grooves running therefrom to the sides. (The var. ribis is rather more circular in form, has the transverse bands more distinct in the early stage, and is of a rather brighter reddish-brown when mature.) The insects leave a distinct pale scar when removed from a twig. Bushes or trees infested with these pests seldom bear much fruit, and the leaves ripen and fall much earlier than on clean bushes, both results being due to the drain on the vitality of the plant by the persistent sucking up of the sap.

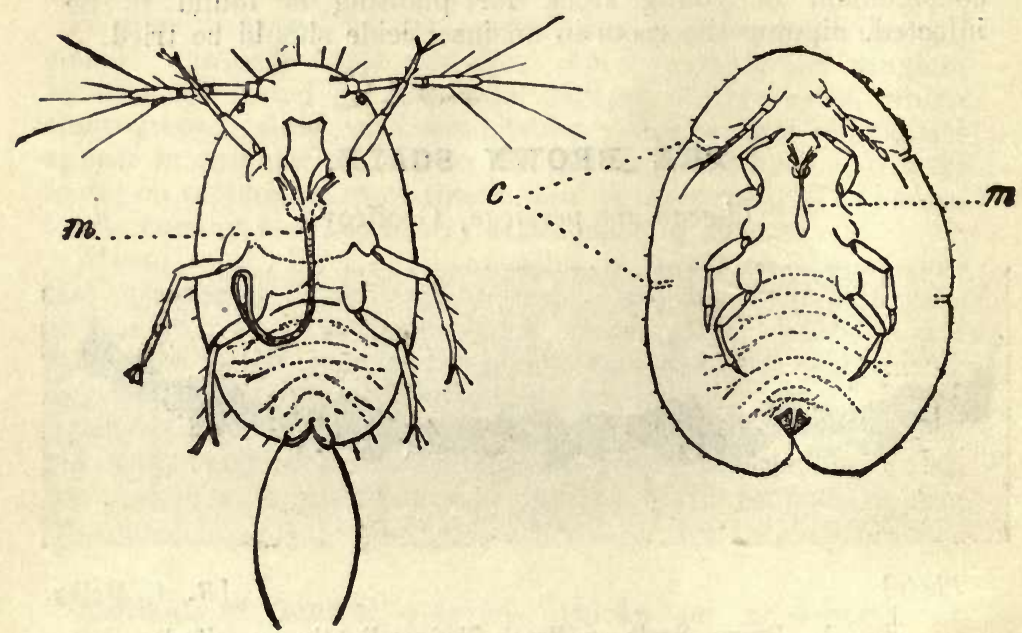

Frg. 2.-Larva magnified about

50 diameters. $(m)$, mouthparts.

FIG. 3.-Underside of young female magnified about 15 diameters. (c), channels leading to respiratory tubes (stigmata). $(m)$, mouthparts.

Iarva.-The young larvæ (Fig. 2) are quite minute, about the size of a large cheese mite, which they somewhat resemble, except that they possess but three pairs of legs, have rather long antennæ, and two bristles at the end of the abdomen. The mouthparts (Fig. $2 \mathrm{~m}$ ) form a sucking tube with which the insect pierces the bark, and through which it sucks up the juices of the plant.

Male.-The male of this insect has not yet been discovered, and there can be no doubt that the females are able to reproduce their species without the intervention of the opposite sex.

Life-History. - The female begins to lay her eggs (usually during the latter half of summer), while the body is yet soft and distended; and as the process develops the under surface 
of the insect shrinks, so that a relatively large carity is formed beneath the insect which is filled with hundreds of whitish translucent eggs. At this stage the insect dies and her dead body, the so-called "scale," forms a protection for) the eggs, and for a short period also for the young larvæ or " lice." In autumn the young escape from beneath the dead parent chiefly through the little slit or cleft at the posterior extremity, leaving behind them the white egg shells and a little white mealy secretion.

The larvæ usually fix themselves under the partly detached or curled-up portions of the bark, so that they are often completely hidden, and in this way pass the winter without any material change. They are then of a reddish-brown colour, and so small that they are not easily seen. In spring they cast their skins, and may become active for a short period; in June they become adults and the cycle commences again. The old "scales" or dead females may, if undisturbed, remain attached to the host plant for a very long period-two or three years in some instances; it often happens, therefore, that the representatives of two or three generations may occur on the plant at the same time.

In the open in this country the Brown Scale is usually single-brooded, but under exceptional circumstances two or even three broods have been noted within a year.

Remedies and Methods of Control.-This scale can be best controlled by winter and by spring washing. It should be borne in mind that it is the larvæ or young insects which are found living during the winter months; and as they are very minute and often protected by the semi-detached bark, the spraying must be thorough or the result will not be satisfactory. Care must also be taken to ensure that the under sides of the branches are well sprayed, as the insects are usually more abundant in such situations than on the exposed and more accessible portions of the bushes.

It is advisable to complete pruning before spraying opera tions are commenced; and in the case of old and badly infested plants it is desirable to remove as much of the old wood as is practicable.

The spraying apparatus should have the nozzle fitted at an angle of about 45 degrees so that the spray may be conveniently directed to the under sides of the branches.

In the case of the gooseberry, "brushing " is practically inpossible owing to the thorns, but peaches can be cleaned by scrubbing in the winter.

(1) The best winter wash is lime-sulphur. The concen. trated lime-sulphur solution can be bought ready made and should be diluted to winter strength -3 quarts of lime-sulphur (1.3 specific gravity) to 10 gallons water, or according to the maker's directions. 
(2) If preferred, instead of lime-sulphur a caustic wash or a strong paraffin emulsion may be used. Directions for making these washes are given in Leaflet No. 70 .

(3) Summer washing is less effective than spraying n winter, which should be considered the standard treatment, but some good may be done by a thorough application of lime-sulphur diluted to summer strength (3 pints of limesulphur, 1.3 specific gravity, to 10 gallons of water), or paraffin emulsion. For gooseberries of the varieties Berry's Early, Freedom; Lancashire Lad, and Crown Bob, the concentrated lime-sulphur (1.3 specific gravity) should be used at the rate of $1 \frac{1}{2}$ pints to 10 gallons of water. The advantage of using lime-sulphur on gooseberries lies specially in the fact that it will also control American Gooseberry Mildew, but it should not be used on peaches or nectarines, or gooseberries of the variety Yellow Rough and Valentine's Seedling when in leaf.

\section{THE MAGPIE MOTH.}

(Abraxas grossulariata, Linn.)

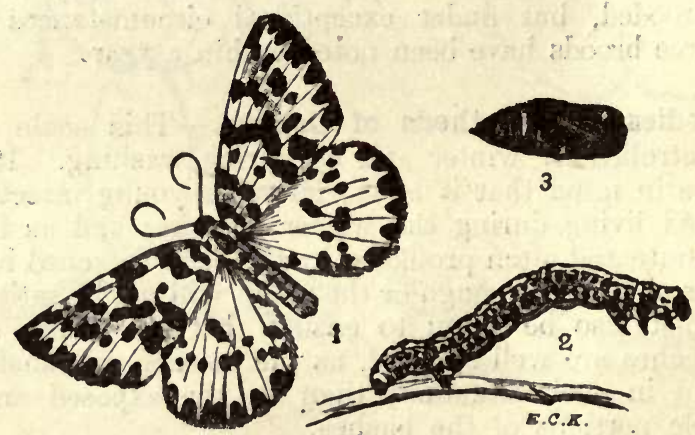

1. Moth; 2. Caterpillar; 3. Chrysalis. All natural size.

The Magpie Moth, also known as the Currant Moth, is a well-known enemy of gooseberries and currants to which it may do considerable damage if allowed to breed unchecked. Fortunately, it is not really difficult to control and, therefore, with reasonable care, it need never cause a serious loss of crop. As in the case of another abundant gooseberry pest-the Gooseberry Sawfly-the great thing is to deal with the attack in its early stages, before, and not after, the damage has been done. The Magpie Moth occurs-and attacks may therefore be expected-throughout the British Isles, in town and industrial areas as well as in the open country. Abroad, the moth is recorded as a pest in Central and Northern Europe, and its range extends across Asia to Japan. 
Piants Attacked and Nature of Damage. - The caterpillars of the Magpie Moth feed on currant and gooseberry, plum, sloe, apricot, nut, laurel (Prunus laurocerasus), spindle (Euonymus), and probably other plants, but damage of importance is usually confined to currants, gooseberries, and occasionally apricots. The pest is perhaps more often harmful in confined gardens than in large orchards. The injury, which consists in the destruction of foliage by the caterpillars, begins as soon as the leaves appear and continues until June, the bushes in a bad attack being completely stripped. This naturally weakens the trees, and may cause a loss of crop for one or two years.

Description and Life-History.-The Magpie Moth is the well-known black, white and yellow insect shown in Fig. 1. It appears in July and August and lays eggs, singly or in small groups, on the leaves of gooseberries, currants, \&c. . In about a fortnight minute blackish caterpillars are hatched from the eggs and feed on the foliage, growing slowly, until the autumn, when, while still small, they go into winter quarters sheltered among the dead leaves of their food-plant, in moss and lichen growing on the bushes, or in any cranny where they may get some protection during winter. As soon as foliage appears in spring the caterpillars leave their winter quarters and again begin to feed, growing in size until the end of May or early June, when the bushes may have been almost stripped of foliage, with the natural result that the fruit cannot develop. The caterpillar, shown in Fig. 2, is then black and white in colour, with a yellow stripe down each side. When full-fed it turns into a shining black chrysalis, with narrow vellow bands round the "tail" (abdominal) segments, and is suspended in a slight cocoon among the leaves or twigs of the foodplant, on fences, walls, or other places. The moth emerges in about a month and the life-cycle begins again. Rarely there is a fartial second brood, a few caterpillars feeding up rapidly and producing moths in autumn, but this second brood is never sufficiently numerous to do any damage.

It is important to distinguish between true Magpie Moth caterpillars and those of the Gooseberry Sawfly, since after an attack of the former no damage will again occur until the following season, while in the case of the latter damage must be expected at intervals throughout the summer unless preventive measures are taken. Gooseberry Sawfly caterpillars (Leaflet No. 12) may be recognised by the fact that they are green, more or less speckled with black, and so are very different from the black, white and, yellow Magpie caterpillars.

Methods of Control.-(1) In gardens with only a comparatively few bushes, the caterpillars can best be dealt with 
by hand-picking in spring as soon as signs of damage are apparent.

(2) In Commercial Plantations: Spraying.-Magpie caterpillars are easily killed by means of lead arsenate, but a difficulty arises from the fact that this insecticide is very poisonous and cannot be used when the gooseberries are fruiting. Lead arsenate spray should, therefore, be applied either (1) just before the flowering period, or (2) at the end of August to kill the young caterpillars. The time available for the work during the first period is very short, as it is necessary to wait until as much foliage as possible has been produced, while, on the other hand, spraying must cease before bees have begun to visit the flowers. It is possible that a second application of lead arsenate might be given directly after the flowers have set, but the berries swell so rapidly that there would be a risk of poisoning the fruit unless the work was carried out rapidly and with discrimination.

If spraying be deferred until the end of summer, the nozzle should be directed as much as possible on to the undersides of the leaves.

When an attack has not become apparent until it is too late to use lead arsenate, then hellebore (which loses its poisonous properties rapidly) may be used within three weeks of the time when the fruit is to be gathered. Pyrethrum, which must be fresh, is non-poisonous, and may be applied at any time. There are also various non-poisonous proprietary compounds to be bought from most horticultural firms.

(3) Formulce.
A. Lead arsenate paste* ... ..
$\frac{1}{2} \mathrm{lb}$.
$\begin{array}{lllll}\text { Water } & \ldots & \ldots & \ldots & \\ \end{array}$
10 gallons.
B. Hellebore powder* ${ }^{*} \quad \ldots \quad \ldots .2 \mathrm{lb}$.
$\begin{array}{lllllll}\text { Water } & \ldots & \ldots & \ldots & \ldots & 10 \text { gallons. }\end{array}$
C. Pyrethrum powder $\quad \ldots \quad \ldots$... $2 \mathrm{lb}$.

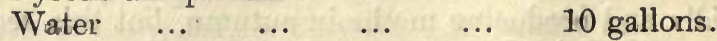

In mixing lead arsenate it is best to work up the paste into a thin cream with a little water, subsequently adding the remainder.

Sprays B and C are improved by the addition of $\frac{1}{2} \mathrm{lb} .-1 \mathrm{lb}$. of soft soap to each 10 gallons, and when being used, they should be kept well shaken up. Half-a-pound of soap will be enough unless the water is hard, when the full quantity may be allowed.

* Lead arsenate and Hellebore are poisonous to man and animals and should be kept under lock and key. Special tubs should be reserved for mixing the spray fluid. 


\title{
THE GOOSEBERRY SAWFLY.
}

\author{
(Nematus ribesii, Curtis.)
}

The Gooseberry Sawfly is a common and destructive pest in most parts of the British Isles. It also occurs in many European countries, in the United States and in Canada, being thought to have reached the two latter countries in soil adhering to the roots of imported gooseberry or currant bushes.

Plants Attacked and Nature of Damage.-The Gooseberry Sawfly occurs most frequently on the gooseberry, but it also attacks red currants, and (more rarely) black currants. The injury is due to the sawfly caterpillars, which devour the leaves (Fig. 1), and in a bad attack strip the bushes completely, with the result that the season's crop may be lost, and the bushes so weakened that they can produce little fruit during the following year. A characteristic feature of the pest is the rapidity with which it increases whenever it is neglected. Too frequently no notice is taken of an attack on one or two bushes when the rest could easily be controlled, and the following year, or even later in the same season, it is found that the whole plantation is attacked, with the consequence that much trouble must be taken and expense incurred in destroying the caterpillars.

Description and Life-History.-The adult sawflies (Fig. 3) first appear in April or May. The female is about one-third of an inch in length, with clear transparent wings, and a body black and yellow in front and yellowish-orange behind. The male is similar but somewhat smaller in size and the upper part of the body behind the wings is black and the size somewhat smaller. Eggs (Fig. 2) are laid by the female on the gooseberry leaves, usually a large number being laid on one leaf (see Fig. 5); they are fixed into shallow slits in the surface of the leaf, but are fairly conspicuous. In about a week the caterpillars, which at first are pale green, slightly speckled with black, are hatched from the eggs, and for some days feed together in a colony, first eating the surface of the leaf and then nibbling holes. As they grow older they spread all over the bush, eating the whole of the leaf. They are then sage-green in colour, with a black head and numerous black spots (Fig. 4). When full-grown about four weeks after they have hatched, the caterpillars lose the black spots and are pale green, almost orange behind the head (which is now green) and near the "tail." At this stage they leave the bushes and make oval brown cocoons (Fig. 5) in the soil, from which, in the summer, the adults emerge in from 10-21 days. There are usually three broods of sawflies in the course of the season, and if the weather is very favourable (dry and warm) there may even be four. In consequence the pest may increase in numbers enormously 


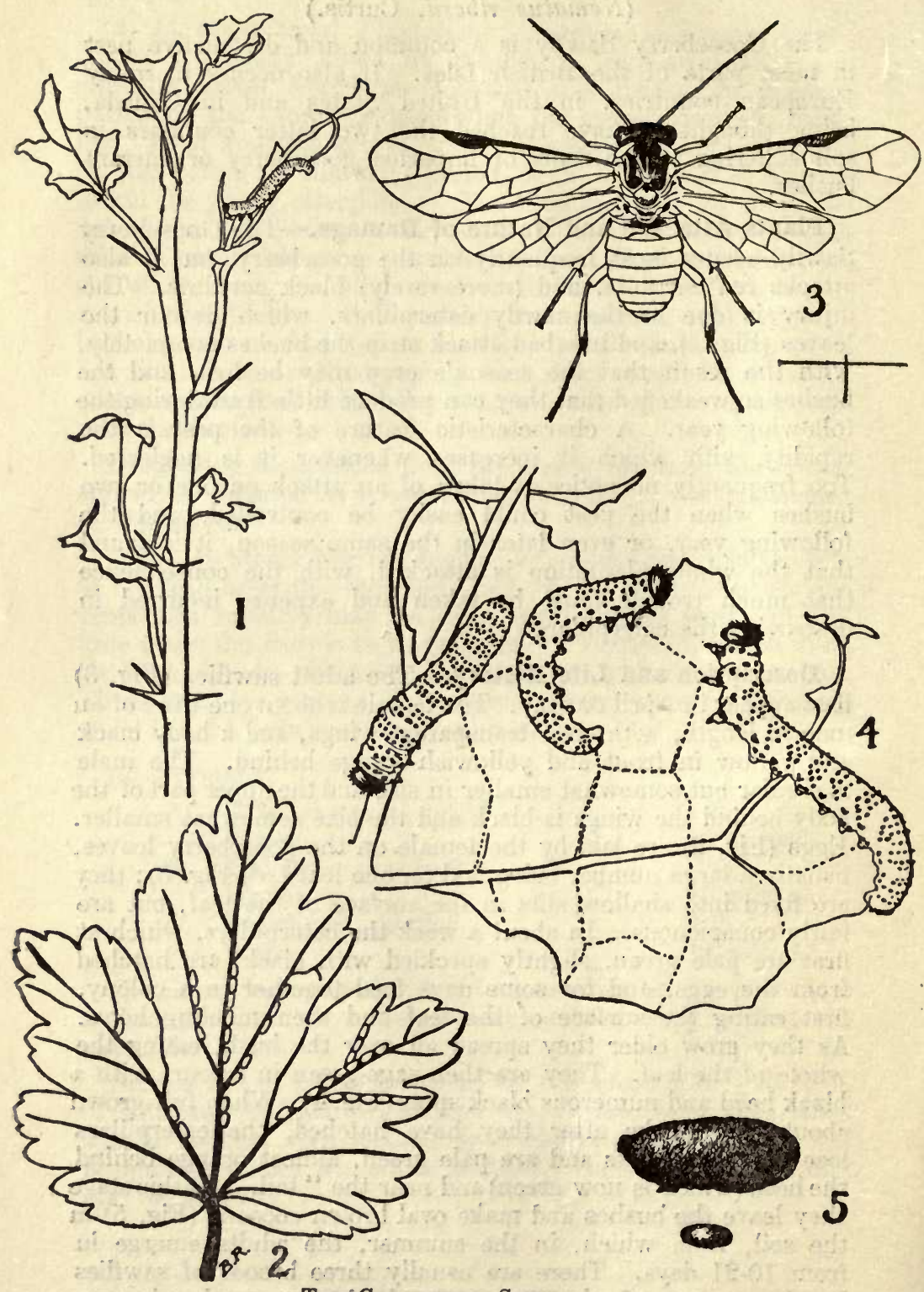

THE GooseberRy SA wFLY.

(1.) Gooseberry shoot injured by Sawfly caterpillars. (2.) Leaf showing Sawfly eggs. (3.) Gooseberry Sawfly. (4.) Gooseberry Sawfly caterpillars. (5.) Cocoon. 
by the close of the summer. There is considerable overlapping in the various broods, so that flies, eggs and larvæ of all sizes may be found on the bushes at the same time. The cocoons of the last brood of larvæ remain in the soil during the winter, and produce flies the following spring.

Gooseberry Sawfly caterpillars are sometimes confused with those of the Magpie Moth, but it is easy to separate them, since Magpie larvæ are black and white with some yellow at the sides, and are, therefore, very different from the speckled green sawfly caterpillars.

In addition to the species here described, other species of sawfly larvæ are also found on gooseberries; but from the growers' point of view it is unnecessary to distinguish them.

Natural Enemies.-Several species of ichneumon fly have been recorded as parasites on the caterpillars of the Gooseberry Sawfly, but the latter do not appear to suffer from them to an appreciable extent. As a whole, natural enemies do not exercise a sufficient check on the sawfly, and artificial measures of control are often necessary.

Methods of Control.-Attention is again drawn to the advisability of dealing with small attacks. Otherwise it is almost certain that serious trouble will follow.

(1) Hand-picking is the simplest method in the case of a few bushes, but it must be done before the colonies of young larvæ have scattered over the bush. Some prefer to pick the leaves on which eggs have been laid.

(2) Spraying is thoroughly effective against this pest; the chief difficulty lies in the fact that the best washes are poisonous. Lead arsenate may be used in the case of an early attack where it can be applied before the gooseberries have flowered, and also after the fruit has been gathered. Hellebore, when fresh, and nicotine are also effective, and though poisonous do not retain their poisonous qualities for long. They may therefore be used with safety if an interval of three weeks be allowed between the dates of spraying and picking. Pyrethrum, which must be fresh, may be tried where a non-poisonous insecticide is needed, and there are also certain proprietary insecticides now on the market which are quite satisfactory and can be recommended for small gardens.

(3) Formula:-
A. Lead arsenate paste Water
$\frac{1}{2} \mathrm{lb}$.
B. Hellebore powder $\quad \ldots \quad \ldots \quad 2 \mathrm{lb}$

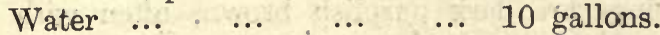
$\begin{array}{llllll}\text { C. Pyrethrum powder } & \ldots & \ldots & 2 \mathrm{lb} \text {. } \\ \text { Water } & \ldots & \ldots & \ldots & \ldots & 10 \text { gallons. }\end{array}$

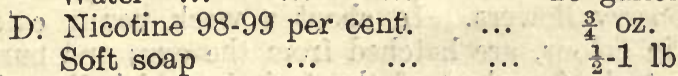

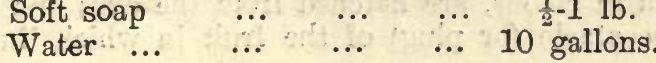


In mixing lead arsenate it is best to work up the paste into a thin cream with a little water, subsequently adding the remainder.

Sprays B and C are improved by the addition of $\frac{1}{2}-1 \mathrm{lb}$. of soft soap to each 10 gallons, and when being used they should be kept well shaken up. Half a pound of soap will be enough in the case of $B, C$ and $D$ unless the water is hard, when the full quantity may be allowed.

\section{THE RASPBERRY MOTH.}

\section{(Lampronia rubiella, Bjerk.)}

The Raspberry Moth, also known in the caterpillar stage as the Red Raspberry Grub, occurs throughout England and Scotland, sometimes causing considerable losses both in commercial plantations and private gardens. Next to the Raspberry Beetle (Byturus tomentosus) it is perhaps the most serious insect enemy of raspberries in Great Iritain. Abroad it is widely distributed on the Continent and appears to be specially harmful in Holland.

Nature of Injury.-If an infested plantation be examined towards the end of April or early in May it will be found that many of the young shoots, particularly those towards the tops of the canes, have withered or died owing to the fact that the inside of each attacked shoot has been eaten away. Inside the tunnel in the shoot is usually found a small red caterpillar or, later, a brown chrysalis. The damage is, therefore, very characteristic and when a large proportion of the shoots are attacked, great loss of crop may occur, since each injured shoot dies without producing flowers. The only pest with which the larva of the Raspberry Moth is sometimes confused is that of another small moth (Aspis udmanniana I.) which may be known as the Blackberry Leaf Spinner. This pest sometimes feeds on raspberries, the leaves of which it ties up into a large bundle. The caterpillar is brown or chocolate coloured and feeds within the bundle of leaves; it never burrows into the shoots and may be recognised both by its habits and colour.

Description and Iife-History.-The Raspberry Moth is a small insect with a wing expanse of from $\frac{1}{4}-\frac{3}{8}$ inch. In colour the wings are dark purplish brown, often with a satin-like sheen and with several conspicuous yellow spots. The moths appear at the end of May and in June and lay their eggs in the raspberry flowers. In about a week young caterpillars, whitish in colour, are hatched from the egg 3 and burrow into the receptacle (or plug) of the fruit in which they feed, but 
during this period they do practically no damage, and in fact it is difficult to tell which fruits have been attacked. When the fruits begin to ripen the caterpillars leave them and crawl about searching for places in which to make cocoons. These cocoons are about one-tenth of an inch in diameter and are placed sometimes in cracks or erevices in the canes or supporting stakes, sometimes among the soil or rubbish round the stools. The young caterpillars spend the winter in the cocoons and then, early in April, leave them and crawl up the canes to the shoots into which they burrow. Each caterpillar then feeds within a shoot for four to six weeks, and during this time it becomes bright pink in colour, with a blackish head and plate on the first segment. When mature it changes to a brown chrysalis, usually within the burrow in the shoot, and three or four weeks later the moth appears.

(1) Methods of Control.-After an attack every effort should be made to clean all rubbish from the stools, carting it, and also old canes, a short distance from the plantation, where the whole should be burnt if possible. Old cracked stakes should be renewed and the soil forked or hoed right up to the stools.

(2) There appear to have been few experiments in spraying in this country but the following trials should certainly be made.

(a) Spray the canes, the soil round the stools and all stakes during the winter with paraffin emulsion (or miscible oil*) at winter strength, the object being to soak the cocoons and kill the larvæ inside.

(b) At the end of March spray the canes, soil round the stools and stakes heavily with lime-wash as used for apple and plum trees. At this period the larvæ will be preparing to leave their cocoons and the object in spraying is to cover the canes, stakes and soil round the stools with a coating of lime which will prevent the larvæ reaching the buds.

(c) At the beginning of April spray the young shoots with lead arsenate using a strong mixture. In Russia, Paris green and lime used in this manner have been found quite effective and might also be tested here. The object in this case is to cover the shoots with a poisonous coating so that the larvæ must eat the poison and be killed while entering the shoots.

(3) In plantations which are so badly affected that little crop is obtained, a radical cure may be attempted by cutting

* Miscible cils may be taken as comparable to paraffin emulsions in their action. They are so prepared as to emulsify at once in water without the addition of soap, but are not usually designed for summer washes-only for winter use. The makers' instructions for mixing should be taken. 
back all young canes in the spring to within six or eight inches of the ground exactly as if a new plantation had been made. No flowers will then be produced and in consequence the moths will have nowhere to lay their eggs and there will be no fruit in which the young larvæ could feed. The following year the plantation should be almost free of the pest.

(4) In small gardens it is quite possible to keep the pest well in check by picking off the shoots as soon as they begin to wither in the spring, destroying the pink grub inside.

\section{(5) Spray Formulæ.-}

(a) Paraffin Emulsion, winter strength.

$$
\begin{aligned}
& \begin{array}{lllll}
\text { Paraffin Oil } & \ldots & \ldots & \ldots & 1 \text { gallon. }
\end{array}
\end{aligned}
$$

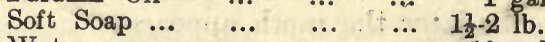

$$
\begin{aligned}
& \begin{array}{llllll}
\text { Water } & \ldots & \ldots & \ldots & \ldots & 10 \\
& \text { gallons. }
\end{array}
\end{aligned}
$$

Dissolve the soft soap in about a gallon of boiling water, remove the solution from near the fire and, while still hot, add the paraffin. Churn the mixture very thoroughly by syringing it back into itself. When required for use add soft water to make 10 gallons and mix again thoroughly so as to make sure that there is no free paraffin floating on the surface.

(b) Lime Wash.

Best Quicklime ... $\quad \ldots \quad \ldots \quad$ 10-15 lb.

Water $\quad \ldots \quad \ldots \ldots . . . . \quad \ldots \quad 10$ gallons.

Obtain only best stone quicklime and store carefully to prevent it from air-slaking. Builder's lime, which is often partially air-slaked, should not be used.

Slake the lime with a little water, and when slaked into a fine powder, add the remainder of the water, stirring vigorously the whole time. Strain carefully before filling the spraying machine and keep the lime-wash well agitated throughout the application.

(c) Lead Arsenate.

Lead Arsenate paste ... $\quad . .6 \quad 1 \mathrm{lb}$.

$\begin{array}{lllllll}\text { Water } & \ldots & \ldots & \ldots & \ldots & 15 & \text { gallons. }\end{array}$

In mixing lead arsenate it is best to work up the paste first into a thin cream with a little water, subsequently adding the remainder.

(d) Paris Green.

Paris Green paste ... ... 1 oz.

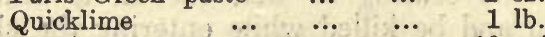

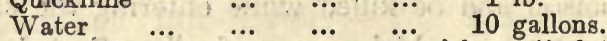

Slake the lime to a cream with a little water and make it up to nearly 10 gallons with water. Then work up the Paris green with a little, water and add it to the mixture of lime and water, stirring well hefore use. The quantity of lime used has been increased considerably above the normal in order that a better coating over the shoots may be obtained. 


\section{WINGLESS WEEVILS.}

The Clay-Coloured Weevil (Otiorrhynchus picipes, Fab.), the Black Weevil (O. sulcatus, Fab.), and the Plum Weevil (O. tenebricosus, Herbst.), are three species of beetle varying slightly in size but not unlike in general appearance. In the grub or larval stages they not only possess more or less similar habits, but also resemble one another so closely that no simple distinguishing characters can be given. The adult beetles are wingless and therefore unable to fly. They make their appearance in late spring and early summer, feeding upon a large variety of plants and trees, attacking leaves, shoots or bark, and causing much damage. During the summer eggs are deposited, probably in the soil near suitable plants, and the resulting white, footless grubs find their way to the roots, where they continue feeding until full-grown early in the following spring. They then turn to white pupæ in the soil, a stage which is of comparatively short duration, the rerfect weevils soon emerging. This life-history is more or less typical of each of the three species, but it is naturally subject to variation when the insects are living under greenhouse sonditions.

\section{Description and Nature of Damage.}

(1) The Clay-Coloured Weevil (Otiorrhynchus picipes, Fab.).

This weevil is the most harmful of the three species just mentioned and the smallest in size, varying from $\frac{1}{4}-\frac{1}{3}$ inch in length. In colour it is chocolate-brown, speckled with light brown, but from living in the soil it becomes dirty, and then sppears practically the same colour as the soil in the neighbourhood which it inhabits.
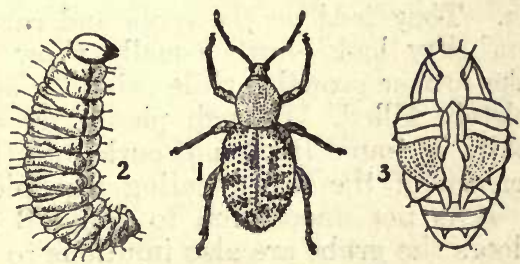

The Clay-Colouted Wegvir.

1. Adult Beetle. 2. Larva. 3. Pupa.

In habits the weevils are mainly nocturnal, spending the day hidden among clods of earth and to some extent among dense foliage on trees and bushes. At night they crawl out to feed and much havoc is wrought to fruit blossoms, fruit buds, and tender shoots of raspberries, the outer skin of the latter being gnawed and not infrequently the bark of the canes lower down being also devoured; the leaves are eaten into 
holes, and in a severe attack quite stripped. Though sometimes known as the Raspberry Weevil, the insect does not confine its attention to raspberries: it is also very harmful to young grafted stock and to young trees in orchards. In the former case it eats the graft or the bark at the junction of scion with stock, and in the latter case the leaves and shoots, and it may even bite the bark from off the main stem and larger branches. In addition to fruit the weevils attack hops and sometimes such annual crops as peas and beans. Woodland is usually overrun with these insects, and may easily serve as a centre of infestation for neighbouring fruit plantations. The larvæ or grubs feed at the roots of many plants, but owing to their resemblance to those of other similar kinds of weevil, it is not possible to say precisely how much damage they do.

(2) The Black Weevil (Otiorrhynchus sulcatus, Fab.).

The Black (or Vine) Weevil is a beetle which is more troublesome under glass than in the open. It is about onethird of an inch long, in colour black, minutely speckled with yellow, and the elytra (wing cases) are rough with raised lines like a file or rasp.

The adult weevils appear under glass in spring (early or late according to the temperature of the house), and may be found more or less throughout the summer, but it is not known whether there is more than one generation in the year. In the beetle stage they are chiefly injurious to vineshoots and to the shoots and foliage of fruit trees or shrubs grown under glass, but they have also been recorded as attacking raspberries in the open in much the same way as the Clay-Coloured Weevil.

The larva, which is a white, legless grub with a brown head, is very injurious to plants in pots-notably to ferns, primulas and cyclamens. They feed on the roots and cause the plants to have an unthrifty look-ferns usually show a bad colour and fail to make proper growth, while primulas and cyclamens may be completely killed. If such plants are examined the grubs will usually be found lying half curled up (like the letter C) near the crown of the plant, eating the thicker or more fleshy parts. It is not uncommon to find 6-8 grubs in one pot. Out of doors the grubs are also injurious to many garden plants and also to strawberries.

(3) The Red-Legaed or Plum Weevil (Otiorrhynchus tenebricosus, Herbst.)

This black, shining weevil, half an inch long with dull reddish legs, is very injurious to plum trees in years when it appears in large numbers. Peaches, nectarines and apricots are also attacked, and it has been known to damage raspberries severely, chewing the young shoot and destroying tender 
foliage. Little appears to be known as to the damage done by the larva of this species.

Methods of Control.-(1) Prevention.-The weevils dealt with in this leaflet are exceedingly difficult to eradicate once they have become established in the nursery or greenhouse, and it is therefore of great importance to prevent them from obtaining a foothold. This is less difficult than in the case of many pests owing to the fact that the weevils cannot fly, and can therefore only reach fresh ground by crawling or by being carried in soil when in the grub stage.

(a) In the case of land to be used for nursery stock or for such semi-permanent crops as raspberries or strawberries, it is well worth devoting a year to making sure that no weevils are present. There will be little likelihood of this if the land in question has been well farmed arable, but if it has carried fruit, nursery stock, or has been at all weedy and foul, a season should be devoted to getting it thoroughly clean, either by fallowing, followed by mustard ploughed-in in the autumn, or by growing potatoes or roots, the choice to be made according to the state of the land and local circum. stances. If a dry spring permits of thorough working in February, March and April, when the grubs are full-fed and pupating, this will do much to reduce the number of adult weevils which would emerge in May and June.

Where the land is adjacent to a wood or uncultivated landa common source of infection-the intervening ditch should be kept cleaned out (or dug out if necessary) the hedgerow trimmed, and if possible overhanging boughs lopped from the trees at the edge of the wood.

(b) In the case of greenhouses devoted to growing ferns, primulas, \&c., the fresh stock should be watched carefully and if the plants do not thrive the roots of the least healthy should be searched for the white grubs. Ferns, for instance, though full of leaf tend to remain rather yellow when attacked by weevil. Potting soil should also be examined carefully for grubs, and if grub-infested soil has to be used then it should first be sterilised by heat. Before restocking an old greenhouse the clearing out should be very thorough, particularly, as regards soil under the stages and ornamental " rock work" in ferneries which are both often infested by weevil grubs.

(2) Treatment.-(a) In the case of infested nurseries and orchard land already planted, young trees and grafted stock can be protected from the adult weevils by banding as for Winter Moth since the weevils spend the day in the soil and only crawl up at night. Apart from this the only treatment is to catch the weevils at night by shaking them on to tarred trays or boards or on to special trays made for such purposes. Vast numbers of weevils can be caught in this way hy a careful 
worker, but care is necessary as the insects readily fall off when alarmed either by too strong a light or by jarring the bushes or canes. No insecticide has proved of any use against the weevils when in the soil but spraying the plants with a poison has not been properly tested. Suggestions to this end will be sent on request.

(b) In the case of greenhouses, the only complete treatment is to clean out the house and repot the stock, shaking out the soil from the roots and killing the grubs. The pest can be kept in check by searching plants and stages carefully at night (especially in spring and early summer) for the adult weevils. Watering the plants with insecticides and mixing insecticides with the soil in the pots have given variable results but no treatment of this nature has yet been sufficiently standardised to justify a recommendation in a leaflet. Where a grower has the time and inclination to experiment, an insecticidal treatment is well worth consideration.

\section{THE VAPOURER MOTH.}

(Orgyia antiqua).
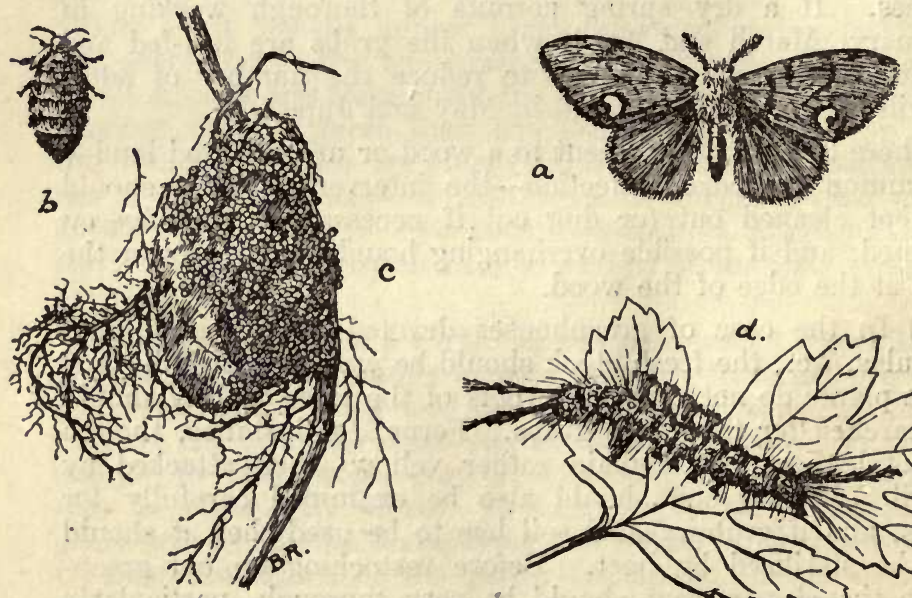

c

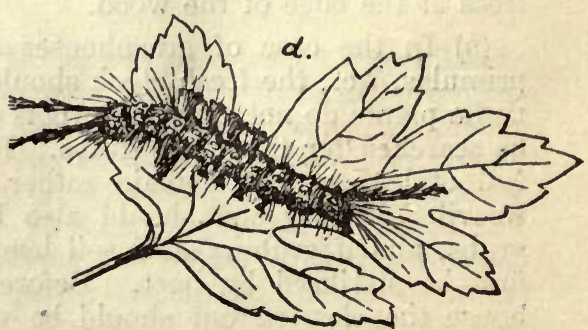

Vapolrer Moth : $a$. Male; $b$. Female; $c$. Cocoon, surrounded by eggs; d. Caterpillar.

The caterpillars of this moth attack the foliage of a great variety of plants, including most of the fruit trees and a large variety of forest trees both hardwoods and conifers. They also devour herbaceous plants in gardens and greenhouses, and may in fact be described as general feeders.

From May to September the caterpillars may be found; from Tuly up to, and including October the adult moths appear. 
The insect is common throughout Great Britain and Ireland, especially in urban districts, and abroad its range extends throingh Europe, N. Africa and Western Asia.

\section{Description.-Moth.-The two sexes are extremely} different in appearance. The male (Fig. a.) measures from 1 inch to $1 \frac{1}{2}$ inch in expanse of wings. The body is brown: the wings are ochreous or chestnut brown, the fore-wings having dark markings. Near the hind angle of each fore-wing is a somewhat crescent-shaped clear white spot. The female (Fig. b.) is yellow-grey in colour, hairy, and unable to fly, the wings being reduced to mere stumps.

Eggs.-The eggs (Fig. c.) are whitish-grey in colour and are laid in great numbers on or about the empiy cocoon of the female moth.

Caterpillar.-The caterpillar (Fig. d.) is very hairy and of gay colouration, a mixture of red, yellow and brown, with four brushes of hairs on the back, and a pencil of long black hairs protruding from each side of the head, one on the sides and one similar at the tail. There are two red warts on each ring of the body. When full grown the caterpillar measures about an inch.

Pupa.-The chrysalis is dark brown and lies under cover of a samewhat oval-shaped yellow-grey web or cocoon (Fig. c.). Mixed in the web are hairs from the caterpillar.

Life-History. - The male moth being in possession of normal wings flies actively during the day, and usually rather high above the ground. The female, wingless and sluggish, does not go far from the cocoon, but pairs and remains on the outside of it for the remainder of her life, laying on and all around it up to 300 eggs or more. Some of these eggs hatch in a fortnight to three weeks, while others laid at the same time may not produce caterpillars until the following spring. From this it follows that all stages of the insect may be met with at the same time. Soon after hatching the young caterpillars scatter over the tree. When they are full-fed they spin cocoons, which are attached to leaves, twigs, bark, or to a neighbouring post or fence. The moths emerge from the pupæ in about three weeks. Two broods or even three in the year are possible, for if the eggs that have passed through the winter hatch in the early part of May, the resulting caterpillars may become adult in time to allow for a second and perhaps even a third brood of moths by October. On the other hand (and probably this is more usual) there may be only one generation in the year, in which case the eggs laid by the first brood pass through the autumn and winter and hatch in the following spring. Weather conditions have great influence on the production of second broods, which are usually most numerous in a hot summer. Owing to the irregularity 
in the hatching of the eggs and the varying extent to which a second brood is produced, there is considerable overlapping between the successive generations. and larve may be found throughout the whole summer and early autumn.

Methods of Control.-1. The cocoons with eggs may be destroved during the winter.

2. The caterpillars which are conspicuous may be dealt with by hand-picking if spraying is not desirable, or shaken off their food plant and destroyed from May to September.

3. Attacked plants may be sprayed with lead arsenate to poison the foliage on which the caterpillars are feeding.

Formula-Lead Arsenate Paste ... $1 \mathrm{lb}$.

$$
\text { Water } \quad \ldots \quad \ldots . \quad \ldots \quad 20-25 \text { gallons. }
$$

4. Owing to the females being wingless and moving ver'y little, the species can only spread in the caterpillar stage, and so if care is taken in dealing with the first attack, the insect is not thereafter difficult to control.

GOAT MOTH (Cossus ligniperda) and WOOD IEOPARD MOTH (Zeuzera asculi).

1. The Goat Мотн.
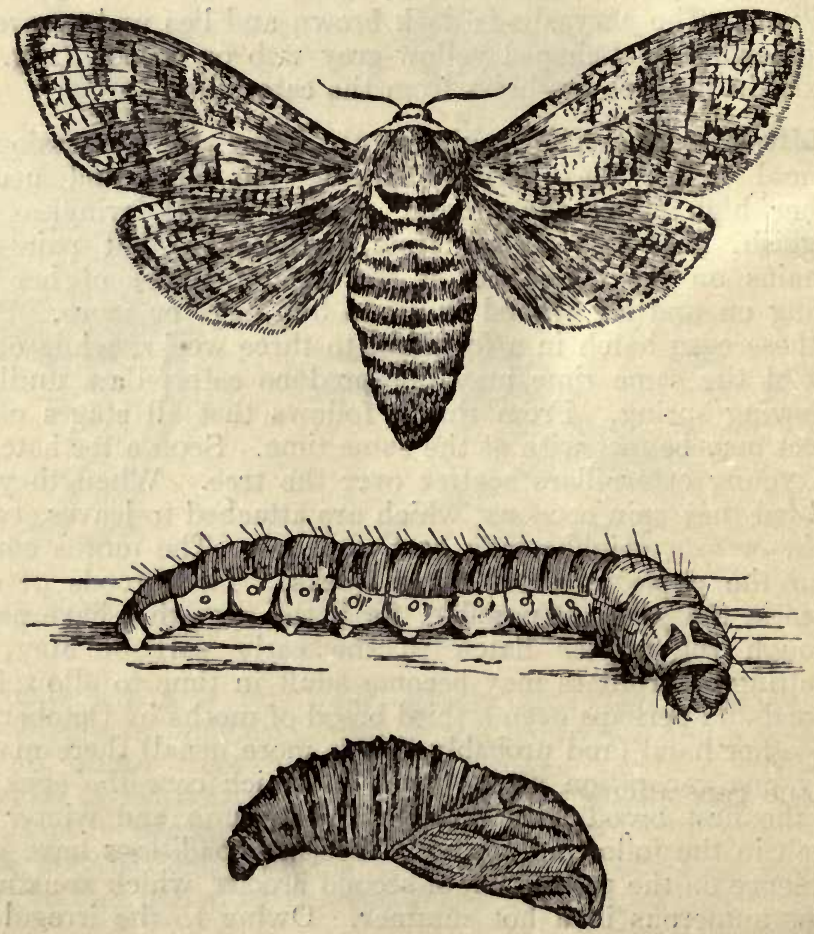
Trees Attacked.-The caterpillars of this moth bore galleries in the stems of many species of broad-leaved trees, e.g., willow, Foplar, walnut, birch, elm, beech, lime, sycamore, ash, and various fruit trees. The softer woods are more commonly infested.

The caterpillars are large and a great number may be found at work in the same tree; the wood, on this account, is so tunuelled and honeycombed as to be rendered useless for technical purposes.

Indications of Infestation.-(a) The little heaps of excrement and frass thrown by the feeding caterpillars from their galleries to the outside.

(b) The odour of the caterpillars, which by some has been compared to that of the goat. The burrows also have the same characteristic smell.

Isolated trees, or those in an avenue or at the edge of a wood, are chosen by the females for their egg laying in preference to trees in close forest, though the latter are sometimes attacked.

Descripticn.-Moth.-The goat moth, which flies at night, is large and plump. The female measures $1 \frac{1}{2}$ inches or more in length, and over 3 inches in spread of wing; the male is somewhat smaller. The head is small and the eyes large; the proboscis and antennæ are short. The antennæ of the male are distinctly comb-like, whilst those of the female are saw-like. The fore wings are pale-brown mottled with ashy-grey, and have numerous irregular black streaks and marks; the hind wings are darker greyish-brown. The thorax is densely hairy, brown and grey in front, and with a blackish band across it behind. The large heavy abdomen is grey with whitish rings.

Caterpillar.-The caterpillar is somewhat flattened, and hence the galleries are oval in shape. When young the caterpillar is dull pink, but as it grows the upper surface becomes dark red or purple, the sides and under-surface being yellowish flesh-coloured. The head is black; the segment behind the head bears a dark shield, and the segments have fine bristle-like hairs. The full grown caterpillar may measure about 4 inches in length.

Pupa.-Pupation takes place in the burrow in the stem, near to the outside, the chrysalis being surrounded by a cocoon covered by wood chips and sawdust. Sometimes the caterpillar leaves the tree and pupates in the soil, in which case the cocoon consists chiefly of particles of soil. 
Life-History. - The moths fly in June and July; the eggs are laid in little heaps in cracks and crevices in the bark generally very low down, but sometimes up to the height of a man. The caterpillars on hatching feed at first below the bark, but later they gnaw irregular ascending galleries in the wood. In cases of overcrowding (and more than 100 caterpillars have been taken from one stem) some of the caterpillars may leave the tree and bore into another. When full grown the caterpillar pupates, and the pupation stage lasts about $a$ month or on occasion somewhat longer. Before the emergence of the moth the pupa pushes its way partly out of the burrow in the tree and the empty pupal skin may be seen projecting after the emergence of the moth. The cocoon has been found projecting from the soil of a garden near an infested balsam poplar.

The life cycle appears to vary in length. A period of two years is given by some authorities but the majority consider that it extends to three years, and that under exceptional conditions it may last for four or even five years.

Methods of Control.-(1) Trees which are badly attacked and are of no great value should be cut down and the larvie destroyed.

(2) When a tree is only slightly attacked or when it is of special value for shade or ornamental purposes, one of the following methods may be employed:-( $($ ) Small quantities of carbon bisulphide may be injected into the holes in the trunk. (b) Small pieces of potassium or sodium cyanide may be pushed into these holes. Whichever poison is used the holes must be thoroughly blocked with clay immediately after the operation.

Injections of carbolic acid, paraffin, or a solution of nicotine are also said to have succeeded in certain cases. but either carbon bisulphide or one of the cyanides will be found most effective. The latter substances must however be treated with care, as carbon bisulnhide is exceedingly inflammable while the cyanides are virulent poisons.

(3) As a preventive against the egg-laying of the moth the trunk of the tree, un to a height of eight feet, may be painted with a mixture of clav. lime and soft soan or clay and cow dung. The mixture should also cover any exposed roots at the hase of the trunk and should be applied during the month of Mav. 'This measure is mainly of service in narks and $g^{\wedge} r^{\text {tens }}$ where a few trees are affected and it is desired to take crery precaution to prevent the insect from spreading. 
2. The Wood Leopard Moth.

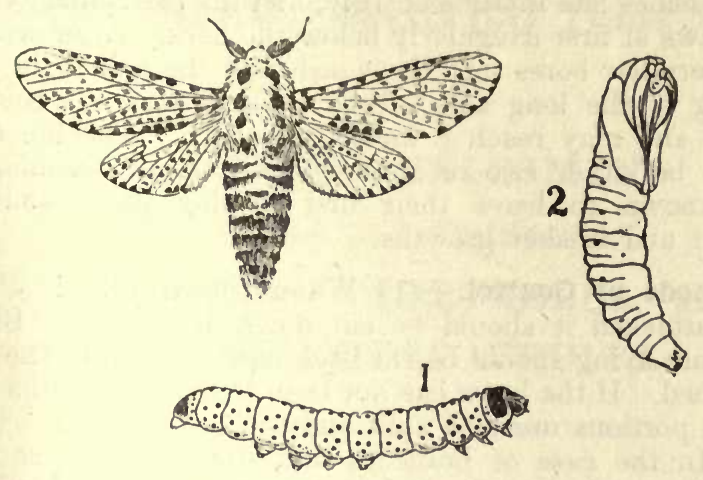

Trees Attacked.-Like the Goat Moth, this pest has importance both for the forester and the fruit-grower. The caterpillars of Zeuzera asculi feed in the stem and branches of a number of broad-leaved trees, e.g, lilac, lime, sycamore, birch, beech, oak, sweet chestnut, ash, willow, poplar, and such fruit trees as apple, pear, and cherry, where they may cause considerable harm. The horse chestnut, from which the scientific name of the moth is derived, is not so frequently attacked as other trees. In the case of this insect, the caterpillars are not found many together in an attacked stem, but generally singly. The presence of the caterpillar may be betrayed by its copious out-throw of frass and wood-coloured excrement. The moth is frequently found in the Metropolitan districts, and sometimes causes considerable destruction to trees and shrubs in the public parks and private gardens of the Metropolis.

Description. - Moth. - The moth, which is named "Leopard " on account of its spotted wings, measures" between 2 and 3 inches in expanse of wings in the case of the female, the males being smaller. The fore wings are white, with a number of black or blue-black spots. The hind wings are similarly marked, but the spots are fainter. "The thorax is white, with 6 large dark spots arranged in pairs, and a smaller spot between the hindmost pair.

Caterpillar (1).-The full-grown caterpillar may measure 2 inches in length. It is white or yellow-white in colour with black spots; the head is dark, the joint behind the head bearing a black shield or plate, whilst a black plate is also present on the last segment.

Pupa (2).--The pupa is brown and may be found at first just below the place of exit, and later, after the emergence of the moth, it may be seen projecting from the tunnel in the infested tree. 
Life-History. - The moths lay their eggs singly on stems and branches late in June or July, and the caterpillar on hatching gnaws at first irregularly below the bark. After wintering, the caterpillar bores into the wood, and the gallery or tunnel, running in the long axis of the infested stem, is round and regular and may reach 8 inches in length. The life cycle is said to be either two or three years. The caterpillars have been known to leave their first feeding place and attack younger and fresher growths.

Methods of Control.-(1) When the trunk of a tree is badly attacked it should be cut down and burnt. Branches which are dying should be cut back until the end of the burrow is reached. If the larva has not been found during this process the cut portions must be split and the larva killed.

(2) In the case of branches and stems which are slightly attacked or which it is desired to save, a pointed wire may be pushed down the burrows to kill the larva, or the methods suggested against the goat moth, Section (2), may be employed. The fumes of burning sulphur or tobacco forced into the holes by means of a pair of bee bellows have also been found effective. 


\section{GEO. MONRO, LTD.,}

Registered GEO. MONRO Trade Mark.

COMMISSION SALESMEN

for Indoor and Outdoor

FRUIT, FLOWERS, VEGETABLES, and all kinds of IMPORTED FRUITS.

\section{Eirctors:}
Major Ejpwin G. Monro,
A. J. Monro,
Gro. Moxro,
Chas. Cole,
B. J. Moxro,
Capt. J. Stuart Monro.

\section{Covent Garden, London}

Telephone No.-Gerrard 546r.

and at

Smithfield Market, Manchester.

Telephone No.-1453 City.

\section{SUNDRIES DEPARTMENT}

For the supply of all Horticultural Sundries required by the Trade.

4, Tavistock Street,

Covent Garden,

Telephone No.-Regent 3042. W.C.2. 


\section{"BUNYARDS" MAIDSTONE.}

(Established 1796.)

\section{THE Secret of Success in Fruit} Growing is to keep two points in mind:-

(I) Start properly-with healthy, well-grown and vigorous trees, true to name and on the right stock.

The Best is the Cheapest in the end, so plant Our 'Trees and avoid disappointment.

(2) Having started with the Best Trees, keep them in first-class condition by using:-

\section{BUNYARD'S Lime Sulphur.}

BUNYARD'S American Blight Cure. BUNYARD'S Fruit Tree Manures, Spraying Machinery, Pruning Knives, Saw, \&c., \&c.

Lists FREE on Application.

GEO. BUNYARD \& CO., LTD.

The Royal Nurseries, Maidstone. 


\section{DAY USE}

\section{RETURN TO DESK FROM WHICH BORROWED}

\section{ENTOMOLOGY LIBRARY}

This book is due on the last date stamped below, or on the date to which renewed.

Renewed books are subject to immediate recall.

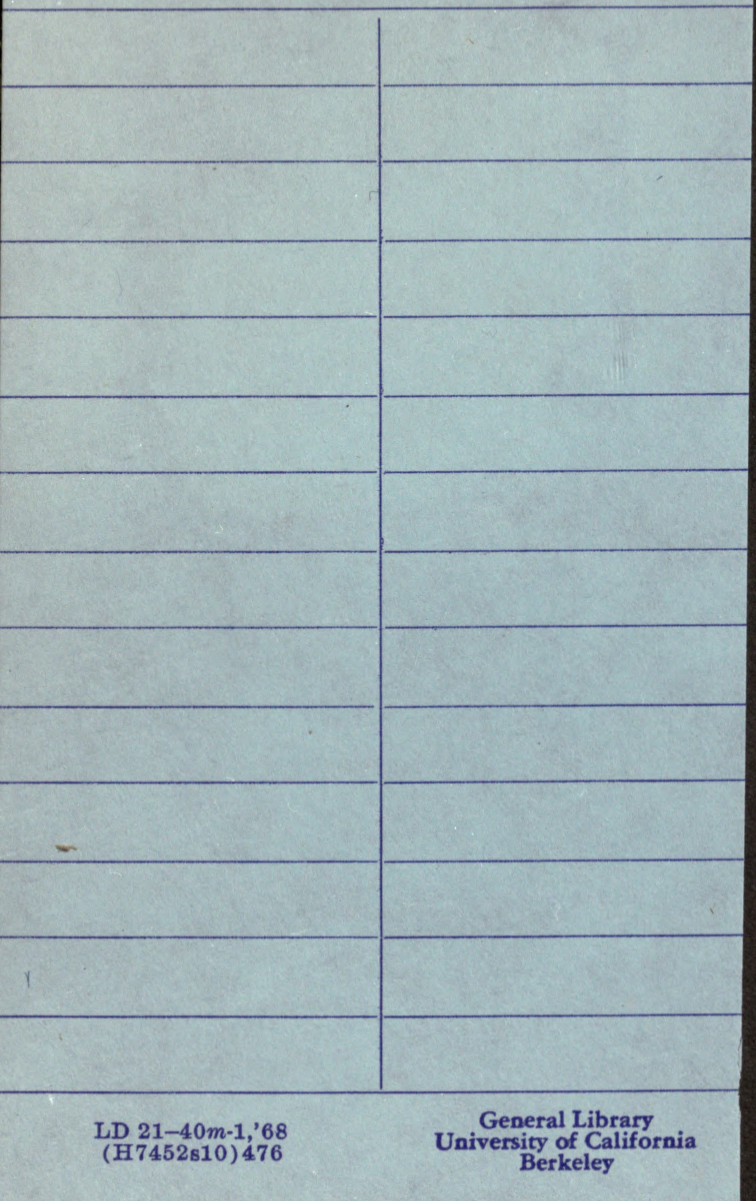


